\title{
Paracetamol (acetaminophen) or non-steroidal anti-inflammatory drugs, alone or combined, for pain relief in acute otitis media in children (Review)
}

Sjoukes A, Venekamp RP, van de Pol AC, Hay AD, Little P, Schilder AGM, Damoiseaux RAMJ

Sjoukes A, Venekamp RP, van de Pol AC, Hay AD, Little P, Schilder AGM, Damoiseaux RAMJ.

Paracetamol (acetaminophen) or non-steroidal anti-inflammatory drugs, alone or combined, for pain relief in acute otitis media in children.

Cochrane Database of Systematic Reviews 2016, Issue 12. Art. No.: CD011534.

DOI: 10.1002/14651858.CD011534.pub2. 
TABLE OF CONTENTS

HEADER

ABSTRACT

PLAIN LANGUAGE SUMMARY

SUMMARY OF FINDINGS

BACKGROUND

OBJECTIVES

METHODS

Figure 1.

Figure 2.

Figure 3.

RESULTS

Figure 4.

Figure 5.

Figure 6.

DISCUSSION

AUTHORS' CONCLUSIONS

ACKNOWLEDGEMENTS

REFERENCES

CHARACTERISTICS OF STUDIES

DATA AND ANALYSES

Analysis 1.1. Comparison 1 Paracetamol versus placebo, Outcome 1 Pain at 48 hours.

Analysis 1.2. Comparison 1 Paracetamol versus placebo, Outcome 2 Adverse events.

Analysis 1.3. Comparison 1 Paracetamol versus placebo, Outcome 3 Fever at 48 hours.

Analysis 2.1. Comparison 2 NSAIDs versus placebo, Outcome 1 Pain at 48 hours.

Analysis 2.2. Comparison 2 NSAIDs versus placebo, Outcome 2 Adverse events.

Analysis 2.3. Comparison 2 NSAIDs versus placebo, Outcome 3 Fever at 48 hours.

Analysis 3.1. Comparison 3 NSAIDs versus paracetamol, Outcome 1 Pain at 24 hours.

Analysis 3.2. Comparison 3 NSAIDs versus paracetamol, Outcome 2 Pain at 48 to 72 hours.

Analysis 3.3. Comparison 3 NSAIDs versus paracetamol, Outcome 3 Pain at 4 to 7 days.

Analysis 3.4. Comparison 3 NSAIDs versus paracetamol, Outcome 4 Adverse events.

Analysis 3.5. Comparison 3 NSAIDs versus paracetamol, Outcome 5 Mild pain at 24 hours.

Analysis 3.6. Comparison 3 NSAIDs versus paracetamol, Outcome 6 Mild pain at 48 to 72 hours.

Analysis 3.7. Comparison 3 NSAIDs versus paracetamol, Outcome 7 Mild pain at 4 to 7 days.

Analysis 3.8. Comparison 3 NSAIDs versus paracetamol, Outcome 8 Mean pain score at 24 hours.

Analysis 3.9. Comparison 3 NSAIDs versus paracetamol, Outcome 9 Mean pain score at 48 to 72 hours.

Analysis 3.10. Comparison 3 NSAIDs versus paracetamol, Outcome 10 Mean pain score at 4 to 7 days.

Analysis 3.11. Comparison 3 NSAIDs versus paracetamol, Outcome 11 Fever at 24 hours.

Analysis 3.12. Comparison 3 NSAIDs versus paracetamol, Outcome 12 Fever at 48 to 72 hours.

Analysis 3.13. Comparison 3 NSAIDs versus paracetamol, Outcome 13 Fever at 4 to 7 days.

Analysis 3.14. Comparison 3 NSAIDs versus paracetamol, Outcome 14 Re-consultations.

Analysis 3.15. Comparison 3 NSAIDs versus paracetamol, Outcome 15 Delayed antibiotic prescriptions.

Analysis 4.1. Comparison 4 NSAIDs + paracetamol versus paracetamol, Outcome 1 Pain at 24 hours.

Analysis 4.2. Comparison 4 NSAIDs + paracetamol versus paracetamol, Outcome 2 Pain at 48 to 72 hours.

Analysis 4.3. Comparison 4 NSAIDs + paracetamol versus paracetamol, Outcome 3 Pain at 4 to 7 days.

Analysis 4.4. Comparison 4 NSAIDs + paracetamol versus paracetamol, Outcome 4 Adverse events.

Analysis 4.5. Comparison 4 NSAIDs + paracetamol versus paracetamol, Outcome 5 Mild pain at 24 hours.

Analysis 4.6. Comparison 4 NSAIDs + paracetamol versus paracetamol, Outcome 6 Mild pain at 48 to 72 hours.

Analysis 4.7. Comparison 4 NSAIDs + paracetamol versus paracetamol, Outcome 7 Mild pain at 4 to 7 days.

Analysis 4.8. Comparison 4 NSAIDs + paracetamol versus paracetamol, Outcome 8 Mean pain at 24 hours.

Analysis 4.9. Comparison 4 NSAIDs + paracetamol versus paracetamol, Outcome 9 Mean pain at 48 to 72 hours. 
Analysis 4.11. Comparison 4 NSAIDs + paracetamol versus paracetamol, Outcome 11 Fever at 24 hours.

Analysis 4.12. Comparison 4 NSAIDs + paracetamol versus paracetamol, Outcome 12 Fever at 48 to 72 hours.

Analysis 4.13. Comparison 4 NSAIDs + paracetamol versus paracetamol, Outcome 13 Fever at 4 to 7 days.

Analysis 4.14. Comparison 4 NSAIDs + paracetamol versus paracetamol, Outcome 14 Re-consultations.

Analysis 4.16. Comparison 4 NSAIDs + paracetamol versus paracetamol, Outcome 16 Serious complications.

DECLARATIONS OF INTEREST

SOURCES OF SUPPORT 
[Intervention Review]

\section{Paracetamol (acetaminophen) or non-steroidal anti-inflammatory drugs, alone or combined, for pain relief in acute otitis media in children}

Alies Sjoukes ${ }^{1}$, Roderick P Venekamp², Alma C van de Pol${ }^{1}$, Alastair D Hay ${ }^{3}$, Paul Little ${ }^{4}$, Anne GM Schilder ${ }^{5}$, Roger AMJ Damoiseaux ${ }^{1}$

1Julius Center for Health Sciences and Primary Care, University Medical Center Utrecht, Utrecht, Netherlands. 2Julius Center for Health Sciences and Primary Care \& Department of Otorhinolaryngology, University Medical Center Utrecht, Utrecht, Netherlands. ${ }^{3}$ Centre for Academic Primary Care, NIHR School for Primary Care Research, School of Social and Community Medicine, Unversity of Bristol, Bristol, UK. ${ }^{4}$ Primary Care and Population Sciences, Faculty of Medicine, Aldermoor Health Centre, University of Southampton, Southampton, UK. ${ }^{5}$ evidENT, Ear Institute, Faculty of Brain Sciences, University College London, London, UK

Contact address: Roger AMJ Damoiseaux, Julius Center for Health Sciences and Primary Care, University Medical Center Utrecht, Heidelberglaan 100, Utrecht, Utrecht, 3508 GA, Netherlands. rdamoiseaux@hotmail.com, R.A.M.J.Damoiseaux@umcutrecht.nl.

Editorial group: Cochrane Acute Respiratory Infections Group.

Publication status and date: New, published in Issue 12, 2016.

Citation: Sjoukes A, Venekamp RP, van de Pol AC, Hay AD, Little P, Schilder AGM, Damoiseaux RAMJ. Paracetamol (acetaminophen) or non-steroidal anti-inflammatory drugs, alone or combined, for pain relief in acute otitis media in children. Cochrane Database of Systematic Reviews 2016, Issue 12. Art. No.: CD011534. DOI: 10.1002/14651858.CD011534.pub2.

Copyright @ 2016 The Cochrane Collaboration. Published by John Wiley \& Sons, Ltd.

\section{A B S T R A C T}

\section{Background}

Acute otitis media (AOM) is one of the most common childhood infectious diseases and a significant reason for antibiotic prescriptions in children worldwide. Pain from middle ear infection and pressure behind the eardrum is the key symptom of AOM. Ear pain is central to children's and parents' experience of the illness. Because antibiotics provide only marginal benefits, analgesic treatment including paracetamol (acetaminophen) and non-steroidal anti-inflammatory drugs (NSAIDs) is regarded as the cornerstone of AOM management in children.

\section{Objectives}

Our primary objective was to assess the effectiveness of paracetamol (acetaminophen) or NSAIDs, alone or combined, compared with placebo or no treatment in relieving pain in children with AOM. Our secondary objective was to assess the effectiveness of NSAIDs compared with paracetamol in children with AOM.

\section{Search methods}

We searched the Cochrane Central Register of Controlled Trials (CENTRAL), Issue 7, July 2016; MEDLINE (Ovid, from 1946 to August 2016), Embase (from 1947 to August 2016), CINAHL (from 1981 to August 2016), LILACS (from 1982 to August 2016) and Web of Science (from 1955 to August 2016) for published trials. We screened reference lists of included studies and relevant systematic reviews for additional trials. We searched WHO ICTRP, ClinicalTrials.gov, and the Netherlands Trial Registry (NTR) for completed and ongoing trials (search date 19 August 2016).

\section{Selection criteria}

We included randomised controlled trials (RCTs) comparing the effectiveness of paracetamol or NSAIDs, alone or combined, for pain relief in children with AOM. We also included trials of paracetamol or NSAIDs, alone or combined, for children with fever or upper respiratory tract infections (URTIS) if we were able to extract subgroup data on pain relief in children with AOM either directly or after obtaining additional data from study authors. 


\section{Data collection and analysis}

Two review authors independently assessed methodological quality of the included trials and extracted data. We used the GRADE approach to rate the overall quality of evidence for each outcome of interest.

\section{Main results}

We included three RCTs (327 children) which were assessed at low to moderate risk of bias.

One RCT included 219 children with AOM, and used a three-arm, parallel group, double-blind design to compare paracetamol versus ibuprofen versus placebo. All children also received antibiotics and those with fever $>39^{\circ} \mathrm{C}$ could have received paracetamol (30 mg to 60 $\mathrm{mg}$ ) additionally to the studied treatments.

Another RCT involved 156 febrile children (26 of whom had AOM). The study design was a three-arm, parallel group, double-blind design and compared paracetamol versus ibuprofen versus ibuprofen plus paracetamol.

The third RCT included 889 children with respiratory tract infections ( 82 of whom had AOM). This study applied a $3 \times 2 \times 2$ factorial, openlabel design and compared paracetamol versus ibuprofen versus ibuprofen plus paracetamol. Study participants were randomised to one of the three treatment groups as well as two dosing groups (regular versus as required) and two steam inhalation groups (steam versus no steam).

Authors of two RCTs provided crude subgroup data on children with AOM. We used data from the remaining trial to inform comparison of paracetamol versus placebo ( 148 children) and ibuprofen versus placebo ( 146 children) assessments. Data from all included RCTs informed comparison of ibuprofen versus paracetamol (183 children); data from the two RCTs informed comparison of ibuprofen plus paracetamol versus paracetamol alone ( 71 children).

We found evidence, albeit of low quality, that both paracetamol and ibuprofen as monotherapies were more effective than placebo in relieving pain at 48 hours (paracetamol versus placebo: proportion of children with pain $10 \%$ versus $25 \%, \mathrm{RR} 0.38,95 \% \mathrm{Cl} 0.17$ to 0.85 ; number needed to treat to benefit (NNTB) 7; ibuprofen versus placebo: proportion of children with pain $7 \%$ versus $25 \%, \mathrm{RR} 0.28,95 \% \mathrm{Cl}$ 0.11 to 0.70 ; NNTB 6 ). Very low quality evidence suggested that adverse events did not significantly differ between children treated with either paracetamol, ibuprofen or placebo.

We found insufficient evidence of a difference between ibuprofen and paracetamol in relieving ear pain at 24 hours ( 2 RCTs, 39 children; RR $0.83,95 \% \mathrm{Cl} 0.59$ to 1.18 ; very low quality evidence), 48 to 72 hours ( $3 \mathrm{RCTs}, 183$ children; RR $0.91,95 \% \mathrm{Cl} 0.54$ to 1.54 ; low quality evidence) and four to seven days ( 2 RCTs, 38 children; RR $0.74,95 \% \mathrm{Cl} 0.17$ to 3.23 ; very low quality evidence).

Data on the effectiveness of ibuprofen plus paracetamol versus paracetamol alone came from two RCTs that provided crude subgroup data for 71 children with AOM. The small sample provided imprecise effect estimates and we were consequently unable to draw any firm conclusions (very low quality evidence).

\section{Authors' conclusions}

Despite explicit guideline recommendations on its use, current evidence on the effectiveness of paracetamol or NSAIDs, alone or combined, in relieving pain in children with AOM is limited. Low quality evidence indicates that both paracetamol and ibuprofen as monotherapies are more effective than placebo in relieving short-term ear pain in children with AOM. There is insufficient evidence of a difference between ibuprofen and paracetamol in relieving short-term ear pain in children with AOM, whereas data on the effectiveness of ibuprofen plus paracetamol versus paracetamol alone were insufficient to draw any firm conclusions. Further research is needed to provide insights into the role of ibuprofen as adjunct to paracetamol, and other analgesics such as anaesthetic eardrops, for children with AOM.

\section{PLAIN LANGUAGE SUMMARY}

\section{Pain relievers for children with acute middle ear infection}

\section{Review question}

We wanted to find out if pain relievers are effective for relieving pain in children with acute middle ear infection (acute otitis media (AOM)) and which medications, alone or together, provide the most effective pain relief.

\section{Background}

Acute middle ear infection or AOM is one of the most common childhood infections. Ear pain due to middle ear infection and pressure building up behind the eardrum is the key symptom of AOM and central to children's and parents' experience of the illness. Because antibiotics provide only marginal benefits, pain relievers such as paracetamol (acetaminophen) and non-steroidal anti-inflammatory drugs (NSAIDs) are considered the cornerstone of AOM management in children.

\section{Search date}

Paracetamol (acetaminophen) or non-steroidal anti-inflammatory drugs, alone or combined, for pain relief in acute otitis media in 
Our evidence is current to 19 August 2016.

\section{Study characteristics}

We included data from three trials of low to moderate risk of bias of 327 children with AOM. One trial (219 children) compared paracetamol versus ibuprofen versus a dummy drug in children with AOM. In this trial, all children also received antibiotic treatment and those with fever $>39^{\circ} \mathrm{C}$ may have received paracetamol in addition to the studied treatments. Two other trials compared the effects of paracetamol versus ibuprofen versus ibuprofen plus paracetamol in children with fever and patients with respiratory tract infections, respectively. The authors of these two trials provided crude subgroup data on children with AOM (26 and 82 children, respectively).

\section{Study funding sources}

In one trial, paracetamol, ibuprofen and a dummy drug were supplied by a pharmaceutical company (Ethypharm). No further details were provided about the role of this company in the design, conduct, analysis, or reporting of the trial. The other two trials were funded by governmental (non-commercial) grants. In one trial the drugs were purchased from and provided by two companies (Pfizer and DHP Investigational Medicinal Products) which had no role in the design, conduct, analysis, or reporting of the trial.

\section{Key results}

Very limited information was available to assess how useful painkillers are for relieving children's pain due to AOM. We found that both paracetamol and ibuprofen when used alone were more effective than a dummy drug in relieving ear pain at 48 hours (25\% of children receiving a dummy drug had residual pain at 48 hours versus $10 \%$ in the paracetamol group and $7 \%$ in the ibuprofen group). The adverse events reported in the trials did not significantly differ between children treated with either paracetamol, ibuprofen or dummy drug, but this finding should be interpreted cautiously, given there were few participants, and infrequent occurrence of adverse events. We found insufficient evidence of a difference between paracetamol and ibuprofen in relieving short-term (at 24 hours, 48 to 72 hours and 4 to 7 days) ear pain in children with AOM. We could not draw any firm conclusions on the effects of ibuprofen plus paracetamol versus paracetamol alone in relieving ear pain in children with AOM mainly because of the very limited number of participants (very small sample size).

\section{Quality of evidence}

Evidence quality for ear pain relief at 48 hours for the comparisons paracetamol versus a dummy drug and ibuprofen versus a dummy drug was judged low (study limitations and questions about the applicability of evidence affected our confidence in the results); the quality of evidence for adverse events was judged very low (study limitations, small sample size and infrequent occurrence of adverse events affected our confidence in the results).

Evidence quality for ear pain relief at 48 to 72 hours for the comparison ibuprofen versus paracetamol was judged low (study limitations and questions about the applicability of evidence affected our confidence in the results); the quality of evidence for ear pain relief at 24 hours and four to seven days was judged very low (study limitations and very small sample size affected our confidence in the results).

Evidence quality for all outcomes in the trials comparing ibuprofen plus paracetamol versus paracetamol alone was very low (study limitations and very small sample size affected our confidence in the results). 


\section{SUMMARY OF FINDINGS}

\section{Summary of findings for the main comparison. Paracetamol versus placebo for acute otitis media in children}

\section{Paracetamol versus placebo for acute otitis media in children}

Patients: children with acute otitis media

Setting: outpatients in four centres

Intervention: paracetamol

Control: placebo

\begin{tabular}{|c|c|c|c|c|c|c|}
\hline \multirow[t]{2}{*}{ Outcomes } & \multicolumn{2}{|c|}{ Anticipated absolute effects ${ }^{*}(95 \% \mathrm{Cl})$} & \multirow{2}{*}{$\begin{array}{l}\text { Relative effect } \\
(95 \% \mathrm{Cl})\end{array}$} & \multirow{2}{*}{$\begin{array}{l}\text { № of partici- } \\
\text { pants } \\
\text { (studies) }\end{array}$} & \multirow{2}{*}{$\begin{array}{l}\text { Quality of the } \\
\text { evidence } \\
\text { (GRADE) }\end{array}$} & \multirow[t]{2}{*}{ Comments } \\
\hline & Risk with placebo & Risk with paracetamol & & & & \\
\hline \multicolumn{7}{|l|}{ Pain at various time points } \\
\hline 24 hours & no data available & & $\mathrm{n} / \mathrm{a}$ & $\mathrm{n} / \mathrm{a}$ & $\mathrm{n} / \mathrm{a}$ & \\
\hline \multirow[t]{2}{*}{48 to 72 hours (48 hours) } & Study population & & \multirow{2}{*}{$\begin{array}{l}\text { RR } 0.38 \\
(0.17 \text { to } 0.85)\end{array}$} & \multirow{2}{*}{$\begin{array}{l}148 \\
(1 \mathrm{RCT})\end{array}$} & \multirow{2}{*}{$\begin{array}{l}\oplus \oplus \odot \odot \\
\text { low }^{1}\end{array}$} & \multirow{2}{*}{$\begin{array}{l}\text { NNTB based } \\
\text { on the study } \\
\text { population risk } \\
\text { was } 1 /(253 \text { to } \\
96)^{\star} 1000=7\end{array}$} \\
\hline & 253 per 1000 & $\begin{array}{l}96 \text { per } 1000 \\
(43 \text { to } 215)\end{array}$ & & & & \\
\hline 4 to 7 days & no data available & & & & & \\
\hline Adverse events & Study population & & $\begin{array}{l}\text { RR } 1.03 \\
\text { (0.21 to } 4.93)\end{array}$ & $\begin{array}{l}148 \\
(1 \mathrm{RCT})\end{array}$ & $\begin{array}{l}\oplus \ominus \ominus \ominus \\
\text { very low }{ }^{2}\end{array}$ & \\
\hline Mean time to resolution of pain & no data available & & $\mathrm{n} / \mathrm{a}$ & $\mathrm{n} / \mathrm{a}$ & $\mathrm{n} / \mathrm{a}$ & \\
\hline Mean pain score at various time points & no data available & & $\mathrm{n} / \mathrm{a}$ & $\mathrm{n} / \mathrm{a}$ & $\mathrm{n} / \mathrm{a}$ & \\
\hline \multicolumn{7}{|l|}{ Fever at various time points } \\
\hline 24 hours & no data available & & $\mathrm{n} / \mathrm{a}$ & $\mathrm{n} / \mathrm{a}$ & $\mathrm{n} / \mathrm{a}$ & \\
\hline \multirow[t]{2}{*}{48 to 72 hours ( 48 hours) } & Study population & & \multirow{2}{*}{$\begin{array}{l}\text { RR } 1.03 \\
\text { (0.07 to } 16.12 \text { ) }\end{array}$} & \multirow{2}{*}{$\begin{array}{l}148 \\
(1 \mathrm{RCT})\end{array}$} & \multirow{2}{*}{$\begin{array}{l}\oplus \ominus \ominus \ominus \\
\text { very low }\end{array}$} & \\
\hline & 13 per 1000 & 14 per 1000 & & & & \\
\hline
\end{tabular}




\begin{tabular}{|c|c|c|c|c|}
\hline 4 to 7 days & no data available & $\mathrm{n} / \mathrm{a}$ & $\mathrm{n} / \mathrm{a}$ & $\mathrm{n} / \mathrm{a}$ \\
\hline Re-consultations & no data available & $\mathrm{n} / \mathrm{a}$ & $\mathrm{n} / \mathrm{a}$ & $\mathrm{n} / \mathrm{a}$ \\
\hline Delayed antibiotic prescriptions & no data available & $\mathrm{n} / \mathrm{a}$ & $\mathrm{n} / \mathrm{a}$ & $\mathrm{n} / \mathrm{a}$ \\
\hline
\end{tabular}

${ }^{\star}$ The risk in the intervention group (and its $95 \% \mathrm{Cl}$ ) is based on the assumed risk in the comparison group and the relative effect of the intervention (and its $95 \% \mathrm{Cl}$ ).

Cl: Confidence interval; NNTB: number needed to treat to benefit; RR: Risk ratio; $\mathbf{R C T}$ : randomised controlled trial;

\section{GRADE Working Group grades of evidence}

High quality: We are very confident that the true effect lies close to that of the estimate of the effect

Moderate quality: We are moderately confident in the effect estimate: The true effect is likely to be close to the estimate of the effect, but there is a possibility that it is substantially different

Low quality: Our confidence in the effect estimate is limited: The true effect may be substantially different from the estimate of the effect

Very low quality: We have very little confidence in the effect estimate: The true effect is likely to be substantially different from the estimate of effect

1 We downgraded the evidence from high to low quality due to study limitations and questions about the applicability of evidence.

${ }^{2}$ We downgraded the evidence from high to very low quality due to study limitations and imprecise effect estimate (small sample size and infrequent occurrence of the outcome).

${ }^{3}$ We downgraded the evidence from high to very low quality due to study limitations, imprecise effect estimate (infrequent occurrence of the outcome) and questions about the applicability of evidence.

\section{Summary of findings 2 . NSAIDs versus placebo for acute otitis media in children}

\section{NSAIDs versus placebo for acute otitis media in children}

Patients: children with acute otitis media

Setting: outpatients in four centres

Intervention: ibuprofen

Control: placebo

\begin{tabular}{|c|c|c|c|c|c|c|}
\hline \multirow[t]{2}{*}{ Outcomes } & \multicolumn{2}{|c|}{ Anticipated absolute effects ${ }^{\star}(95 \% \mathrm{Cl})$} & \multirow{2}{*}{$\begin{array}{l}\text { Relative effect } \\
(95 \% \mathrm{Cl})\end{array}$} & \multirow{2}{*}{$\begin{array}{l}\text { № of partici- } \\
\text { pants } \\
\text { (studies) }\end{array}$} & \multirow{2}{*}{$\begin{array}{l}\text { Quality of the } \\
\text { evidence } \\
\text { (GRADE) }\end{array}$} & \multirow[t]{2}{*}{ Comments } \\
\hline & Risk with placebo & Risk with ibuprofen & & & & \\
\hline 24 hours & no data available & & $\mathrm{n} / \mathrm{a}$ & $\mathrm{n} / \mathrm{a}$ & $\mathrm{n} / \mathrm{a}$ & \\
\hline 48 to 72 hours (48 hours) & Study population & & $\begin{array}{l}\text { RR } 0.28 \\
\text { (0.11 to } 0.70)\end{array}$ & $\begin{array}{l}146 \\
(1 \mathrm{RCT})\end{array}$ & $\begin{array}{l}\oplus \oplus \ominus \ominus \\
\text { low }^{1}\end{array}$ & $\begin{array}{l}\text { NNTB based } \\
\text { on the study }\end{array}$ \\
\hline
\end{tabular}

(0.11 to 0.70

low

on the study 


\begin{tabular}{|c|c|c|c|c|c|c|c|}
\hline \multirow{2}{*}{\multicolumn{2}{|c|}{ 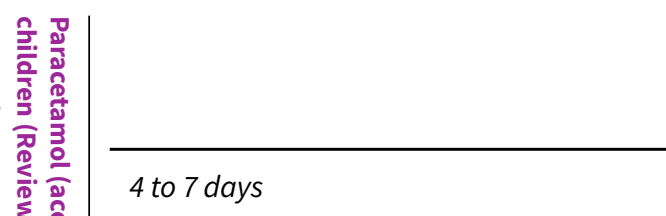 }} & 253 per 1000 & $\begin{array}{l}71 \text { per } 1000 \\
\text { ( } 28 \text { to } 177)\end{array}$ & & & & $\begin{array}{l}\text { population risk } \\
\text { was } 1 /(253 \text { to } \\
71)^{\star} 1000=6\end{array}$ \\
\hline & & \multicolumn{2}{|l|}{ no data available } & $\mathrm{n} / \mathrm{a}$ & $\mathrm{n} / \mathrm{a}$ & \multicolumn{2}{|l|}{$\mathrm{n} / \mathrm{a}$} \\
\hline 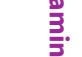 & \multirow[t]{2}{*}{ Adverse events } & \multicolumn{2}{|l|}{ Study population } & \multirow{2}{*}{$\begin{array}{l}\text { RR } 1.76 \\
\text { (0.44 to } 7.10)\end{array}$} & \multirow{2}{*}{$\begin{array}{l}146 \\
(1 \mathrm{RCT})\end{array}$} & \multirow{2}{*}{$\begin{array}{l}\oplus \ominus \ominus \ominus \\
\text { very low }{ }^{2}\end{array}$} & \\
\hline 울 & & 40 per 1000 & $\begin{array}{l}70 \text { per } 1000 \\
(18 \text { to } 284)\end{array}$ & & & & \\
\hline 임 & Mean time to resolution of pain & \multicolumn{2}{|l|}{ no data available } & $\mathrm{n} / \mathrm{a}$ & $\mathrm{n} / \mathrm{a}$ & \multicolumn{2}{|l|}{$\mathrm{n} / \mathrm{a}$} \\
\hline$\frac{\overline{0}}{2}$ & Mean pain score at various time points & \multicolumn{2}{|l|}{ no data available } & $\mathrm{n} / \mathrm{a}$ & $\mathrm{n} / \mathrm{a}$ & \multicolumn{2}{|l|}{$\mathrm{n} / \mathrm{a}$} \\
\hline 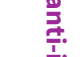 & \multicolumn{7}{|l|}{ Fever at various time points } \\
\hline $\overrightarrow{\underline{2}}$ & 24 hours & \multicolumn{2}{|l|}{ no data available } & $\mathrm{n} / \mathrm{a}$ & $\mathrm{n} / \mathrm{a}$ & \multicolumn{2}{|l|}{$\mathrm{n} / \mathrm{a}$} \\
\hline$\frac{2}{0}$ & \multirow[t]{2}{*}{48 to 72 hours ( 48 hours) } & \multicolumn{2}{|l|}{ Study population } & \multirow{2}{*}{$\begin{array}{l}\text { RR } 1.06 \\
\text { (0.07 to 16.57) }\end{array}$} & \multirow{2}{*}{$\begin{array}{l}146 \\
(1 \mathrm{RCT})\end{array}$} & \multirow{2}{*}{$\begin{array}{l}\oplus \ominus \ominus \ominus \\
\text { very low } \text { lo }^{3}\end{array}$} & \\
\hline 禀 & & 13 per 1000 & $\begin{array}{l}14 \text { per } 1000 \\
(1 \text { to } 221)\end{array}$ & & & & \\
\hline 节 & 4 to 7 days & \multicolumn{2}{|l|}{ no data available } & $\mathrm{n} / \mathrm{a}$ & $\mathrm{n} / \mathrm{a}$ & \multicolumn{2}{|l|}{$\mathrm{n} / \mathrm{a}$} \\
\hline $\begin{array}{l}\stackrel{\circ}{3} \\
\underline{\underline{g}} .\end{array}$ & Re-consultations & \multicolumn{2}{|l|}{ no data available } & $\mathrm{n} / \mathrm{a}$ & $\mathrm{n} / \mathrm{a}$ & \multicolumn{2}{|l|}{$\mathrm{n} / \mathrm{a}$} \\
\hline$\frac{\pi}{02}$ & Delayed antibiotic prescriptions & \multicolumn{2}{|l|}{ no data available } & $\mathrm{n} / \mathrm{a}$ & $\mathrm{n} / \mathrm{a}$ & \multicolumn{2}{|l|}{$\mathrm{n} / \mathrm{a}$} \\
\hline 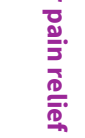 & \multicolumn{7}{|c|}{$\begin{array}{l}\text { *The risk in the intervention group (and its } 95 \% \mathrm{Cl} \text { ) is based on the assumed risk in the comparison group and the relative effect of the intervention (and its } 95 \% \mathrm{CI} \text { ). } \\
\text { Cl: Confidence interval; NNTB: number needed to treat to benefit; RR: Risk ratio; RCT: randomised controlled trial; }\end{array}$} \\
\hline 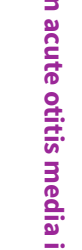 & $\begin{array}{l}\text { GRADE Working Group grades of eviden } \\
\text { High quality: We are very confident that } t \\
\text { Moderate quality: We are moderately cor } \\
\text { stantially different } \\
\text { Low quality: Our confidence in the effect } \\
\text { Very low quality: We have very little conf }\end{array}$ & $\begin{array}{l}\text { he true effect lies clo } \\
\text { fident in the effect } \mathrm{e} \\
\text { estimate is limited: } 1 \\
\text { dence in the effect e }\end{array}$ & $\begin{array}{l}\text { that of the es } \\
\text { late: The true } \\
\text { rue effect may } \\
\text { late: The true } e\end{array}$ & $\begin{array}{l}\text { ect } \\
\text { be close to the e } \\
\text { different from } t \\
\text { be substantially }\end{array}$ & $\begin{array}{l}\text { mate of th } \\
\text { estimate } \\
\text { ferent fro }\end{array}$ & $\begin{array}{l}\text { oct there is a } \\
\text { mate of effec }\end{array}$ & ility that it is sub- \\
\hline
\end{tabular}

${ }^{1}$ We downgraded the evidence from high to low quality due to study limitations and questions about the applicability of evidence.

${ }^{2}$ We downgraded the evidence from high to very low quality due to study limitations and imprecise effect estimate (small sample size and infrequent occurrence of the outcome). 


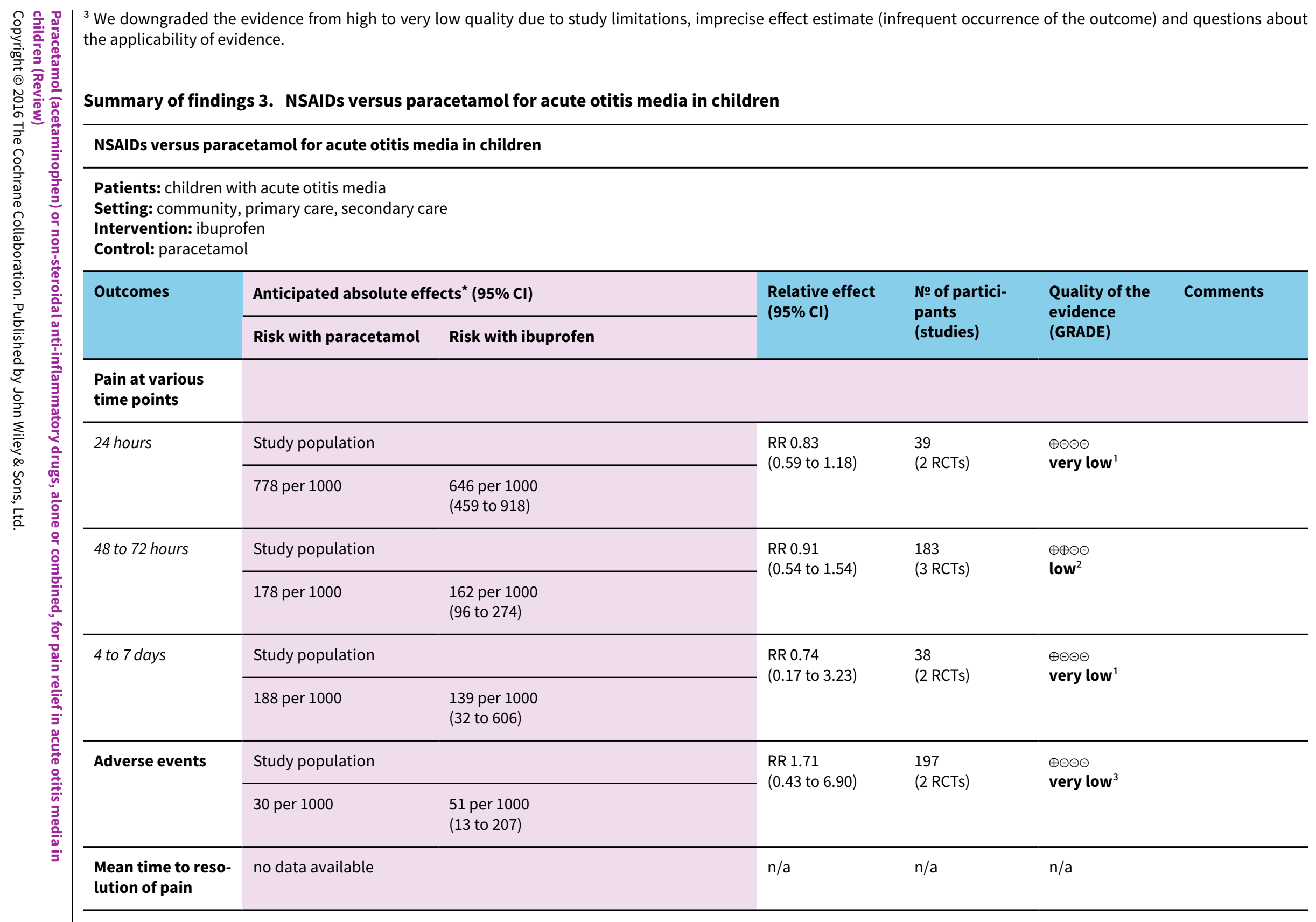

Patients: children with acute otitis media

community, primary care, secondary care 


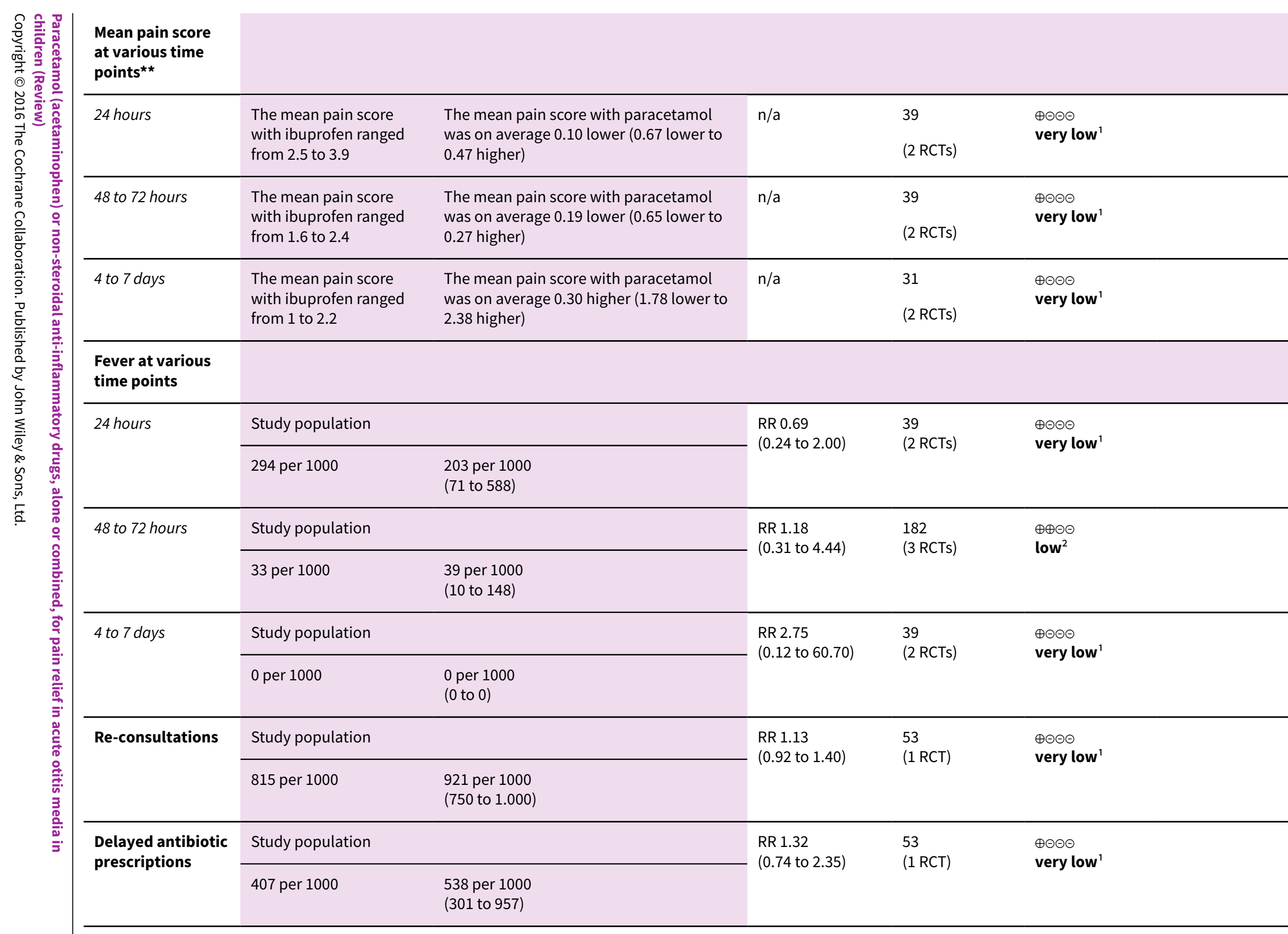




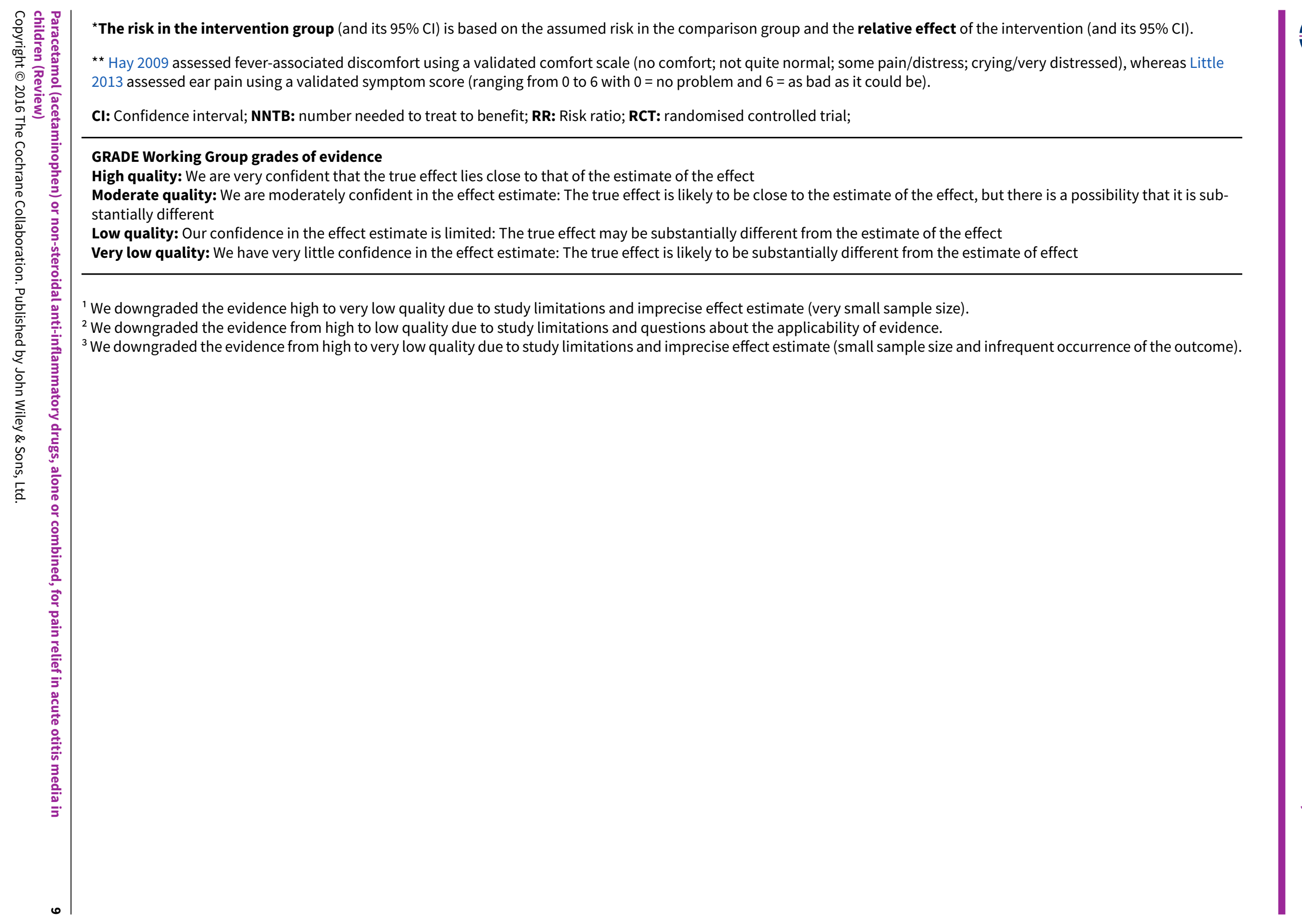




\section{B A C K G R O U N D}

\section{Description of the condition}

AOM is one of the most common childhood infectious diseases, with an estimated incidence of approximately 300 physician-diagnosed AOM episodes per 1000 person-years in children aged up to two years (Liese 2014). By three years of age, over $80 \%$ of all children have experienced at least one AOM episode (Teele 1989). Moreover, AOM is an important cause of antibiotic prescriptions in children (Ashworth 2005; Grijalva 2009). Although severe complications of AOM, such as acute mastoiditis, meningitis and intracranial abscess, are rare in high-income countries, AOM significantly impairs quality of life for children and their parents and carers. AOM is associated with substantial healthcare resource use and lost work days for parents and carers (Greenberg 2003).

AOM is defined by the presence of middle ear effusion together with acute onset of signs and symptoms of middle ear inflammation (Bluestone 2007; Lieberthal 2013). Cardinal signs of AOM are bulging of the eardrum or new onset of ear discharge not due to acute otitis externa; typical AOM symptoms include ear pain and general symptoms of illness such as fever, irritability and problems feeding and sleeping (Lieberthal 2013). Ear pain due to infection of the middle ear and pressure behind the eardrum is a major symptom of AOM (Lieberthal 2013). Pain is central to children's and parents' experience of the illness (Barber 2014; Schechter 2003). Antibiotics provide only marginal benefits (Rovers 2006; Venekamp 2015), and analgesic treatment, including paracetamol (acetaminophen) and NSAIDs, is regarded as the cornerstone of AOM management in children (Lieberthal 2013).

\section{Description of the intervention}

The exact mechanism of paracetamol action is not fully understood, but has been assumed to act as a selective inhibitor of COX-1 and COX-2 in the central nervous system (Bruno 2014). Unlike NSAIDs, paracetamol does not prevent prostaglandin synthesis by competitive binding to the COX enzyme, but modulates the COX pathway through its ability to reduce COX activity (Bruno 2014). Although paracetamol might have some peripheral effects, its main action appears to be located centrally by inhibiting prostaglandin synthesis in the brain (Marzuillo 2014). Due to its minor peripheral effects, paracetamol lacks significant anti-inflammatory activity (van den Anker 2013). When administered as an oral suspension, the peak plasma concentration of paracetamol is reached in around 30 minutes; for oral tablets and suppositories this is approximately 30 to 45 minutes and two to four hours respectively (Marzuillo 2014). The recommended dose of paracetamol for children is 10 to $15 \mathrm{mg}$ / kg per dose, every four to six hours orally (van den Anker 2013).

In contrast to paracetamol, NSAIDs have both central and peripheral effects and can be divided in traditional and selective COX-2 inhibitors (Bruno 2014). COX-2 inhibition leads to reduced release of pyrogenic molecules in the inflamed cells (mainly prostaglandin E2) causing the anti-inflammatory and analgesic effects of NSAIDs (Bruno 2014; Rainsford 2009), while COX-1 inhibition is mainly responsible for gastrointestinal adverse effects (Bruno 2014). Gastrointestinal adverse effects such as peptic ulcers or bleeding are caused by a dual effect of NSAIDs on the gastrointestinal tract; the prostaglandin biosynthesis and maintenance of gastric mucosal integrity (Bruno 2014). Ibuprofen, a non-selective COX inhibitor, is the most commonly used NSAID in children, with a recommended dose of 5 to $10 \mathrm{mg} / \mathrm{kg}$ per dose every six to eight hours orally, to a maximum dose of $500 \mathrm{mg}$ per day (van den Anker 2013). The relatively low incidence of serious gastrointestinal adverse effects associated with ibuprofen, as compared with other NSAIDs, is thought to be the result of its relatively short half-life (Rainsford 2009). However, ibuprofen, like other NSAIDs, is associated with rare but serious adverse drug reactions of the skin (Stevens-Johnson syndrome), renal (papillary necrosis) and cardiovascular systems (Rainsford 2009). Furthermore, ibuprofen has been associated with an increased risk of inducing bronchospasm in children with asthma (Rainsford 2009). However, a recent study found no association between paracetamol or ibuprofen and early childhood asthma when adjusted for potential confounding (Sordillo 2015). Compared with paracetamol, ibuprofen has a longer duration of action, and as such, has the advantage of less frequent dosing (every 6 to 8 hours versus every 4 hours for paracetamol) (van den Anker 2013).

\section{How the intervention might work}

Because pain is a major symptom of AOM in children, current guidance explicitly recommends analgesic treatment, irrespective of antibiotics use (Lieberthal 2013). In daily practice, paracetamol and NSAIDs (ibuprofen) are widely used for relieving pain and fever in children. Paracetamol is generally considered to be well tolerated and safe with only few adverse effects, such as rash and other allergic reactions, when used at therapeutic dosages (Marzuillo 2014; Southey 2009). However, paracetamol has the potential for hepatotoxicity following overdose (Marzuillo 2014). In general, the safety profile of ibuprofen is considered to be comparable with paracetamol when both drugs are used at the recommended doses and in the absence of specific contraindications (children with gastrointestinal bleeding or ulcers, congenital heart disease, severe kidney and liver disease, concurrent use of anticoagulant and steroid drugs, and in children aged less than six months) (Southey 2009; van den Anker 2013).

\section{Why it is important to do this review}

Whilst the effectiveness of analgesic eardrops in children with AOM has been reviewed (Foxlee 2006), this has not been done for paracetamol or NSAIDs, alone or combined. Previous Cochrane reviews on paracetamol or NSAIDs (or both) focused either on children with fever due to infectious diseases (Meremikwu 2005; Wong 2013), or included both children and adults with the common cold (Kim 2013). As such, these reviews did not include RCTs on paracetamol or NSAIDs (or both) for relieving symptoms in childhood AOM. Since AOM is a specific clinical entity with a high incidence and substantial societal impact, a comprehensive literature search and systematic review was warranted to assess 1) the effectiveness of paracetamol or NSAIDs, alone or combined, compared with placebo or no treatment in relieving pain in children with AOM and 2) whether the effects of NSAIDs and paracetamol in terms of relieving pain differ in children with AOM.

\section{O B JECTIVES}

Our primary objective was to assess the effectiveness of paracetamol (acetaminophen) or NSAIDs, alone or combined, compared with placebo or no treatment in relieving pain in children with AOM. Our secondary objective was to assess the effectiveness of NSAIDs as compared with paracetamol in children with AOM. 


\section{METHODS}

\section{Criteria for considering studies for this review}

\section{Types of studies}

RCTs assessing the effectiveness of paracetamol or NSAIDs, alone or combined, in relieving pain in children with AOM.

We also included trials of paracetamol or NSAIDs, alone or combined, for children with fever or URTIs if we could extract subgroup data on pain relief (including discomfort, distress and/or irritability) in children with AOM either directly or upon request by the original trial authors.

We intended to include trials reporting concurrent therapy (e.g. co-treatment with oral or topical antibiotics) if we could make direct comparison between the intervention and control group (e.g. paracetamol with concurrent antibiotic therapy versus placebo with concurrent antibiotic therapy) and if participants in each arm were not treated differently. We defined 'not treated differently' as a maximum of $10 \%$ difference in the proportion of children who received the concurrent therapy in the intervention and control groups.

\section{Types of participants}

We included children aged from six months to 16 years with AOM irrespective of the diagnostic criteria used. We excluded studies on children with grommets (ventilation tubes or tympanostomy tubes) in place and those in which children were hospitalised. (See Differences between protocol and review).

\section{Types of interventions}

We included trials of paracetamol and NSAIDs administered orally or rectally. We excluded trials of paracetamol or NSAIDS administered parenterally (intravenous administration).

\section{Types of outcome measures}

We analysed primary and secondary outcomes, but they were not used as a basis for including or excluding studies.

\section{Primary outcomes}

1. Proportion of children with pain (yes/no) as rated by parents or carers or children themselves at various time points ( 24 hours, 48 to 72 hours, 4 to 7 days);

2. Adverse events likely to be related to the use of paracetamol or NSAIDs (or both), such as kidney failure or dysfunction, liver failure or dysfunction, gastrointestinal complaints or bleeding, and hypersensitivity reactions such as erythema, urticaria (hives, skin itching) or anaphylactic shock.

\section{Secondary outcomes}

1. Proportion of children with at most mild pain (defined as pain less than or equal to $3 / 10$ on a 0 to 10 numerical pain rating scale or less than or equal to $30 \mathrm{~mm}$ on a 0 to $100 \mathrm{~mm}$ visual analogue scale) as rated by parents, carers or patients at various time points ( 24 hours, 48 to 72 hours, 4 to 7 days);

2. Mean time to resolution of pain;

3. Mean pain score at various time points ( 24 hours; 48 to 72 hours; 4 to 7 days) using validated pain scores;
4. Disease-specific quality of life as measured by a validated instrument (e.g. AOM Severity of Symptoms Scale (SOS) survey, OM-6 questionnaire);

5. Mean time to resolution of fever;

6. Proportion of children with fever at various time points (24 hours; 48 to 72 hours; 4 to 7 days);

7. Proportion of children with re-consultations at various time points;

8. Proportion of children with (delayed) antibiotic prescriptions at various time points;

9. Total days lost from nursery or school for children because of AOM;

10.Total days lost from work or education for parents and carers because of their child's AOM; and

11.Serious complications related to AOM such as acute mastoiditis and meningitis.

\section{Search methods for identification of studies}

The Cochrane Acute Respiratory Infections (ARI) Information Specialist conducted systematic searches for RCTs and controlled clinical trials. There were no language, publication year or publication status restrictions. We searched up to 19 August 2016.

\section{Electronic searches}

We searched the Cochrane Central Register of Controlled Trials (CENTRAL), Issue 7, July 2016, which contains the Acute Respiratory Infections Group's Specialised Register (Appendix 1), MEDLINE (1946 to August 2016) (Appendix 2), Embase (1947 to August 2016) (Appendix 3), CINAHL (1981 to August 2016) (Appendix 4), LILACS (1982 to August 2016) (Appendix 5) and Web of Science (1955 to August 2016) (Appendix 6). We used the Cochrane Highly Sensitive Search Strategy for identifying randomised trials in MEDLINE: sensitivity- and precision-maximising version (2008 revision); Ovid format and adapted the search strategy for Embase, CINAHL, LILACS and Web of Science searches.

\section{Searching other resources}

We searched the World Health Organization (WHO) International Clinical Trials Registry Platform (ICTRP), ClinicalTrials.gov, and the Netherlands Trial Registry (NTR) for completed and ongoing trials. We scanned the reference lists of identified publications for additional trials and contacted trial authors if necessary. We also searched MEDLINE, TRIP database and the Cochrane Library to retrieve any published systematic reviews relevant to this review and scanned their citations for additional trials. Furthermore, we searched the extended abstracts published in the Proceedings from the International Symposia on Recent Advances in Otitis Media (grey literature) for any additional trials.

\section{Data collection and analysis}

\section{Selection of studies}

Two review authors (AS, RPV) independently screened titles and abstracts and scanned citations of potentially relevant reviews retrieved from database searches. The same review authors independently reviewed the full text of potentially relevant studies for inclusion. We resolved any disagreements by discussion. See Figure 1. 


\section{Figure 1. Study flow diagram}

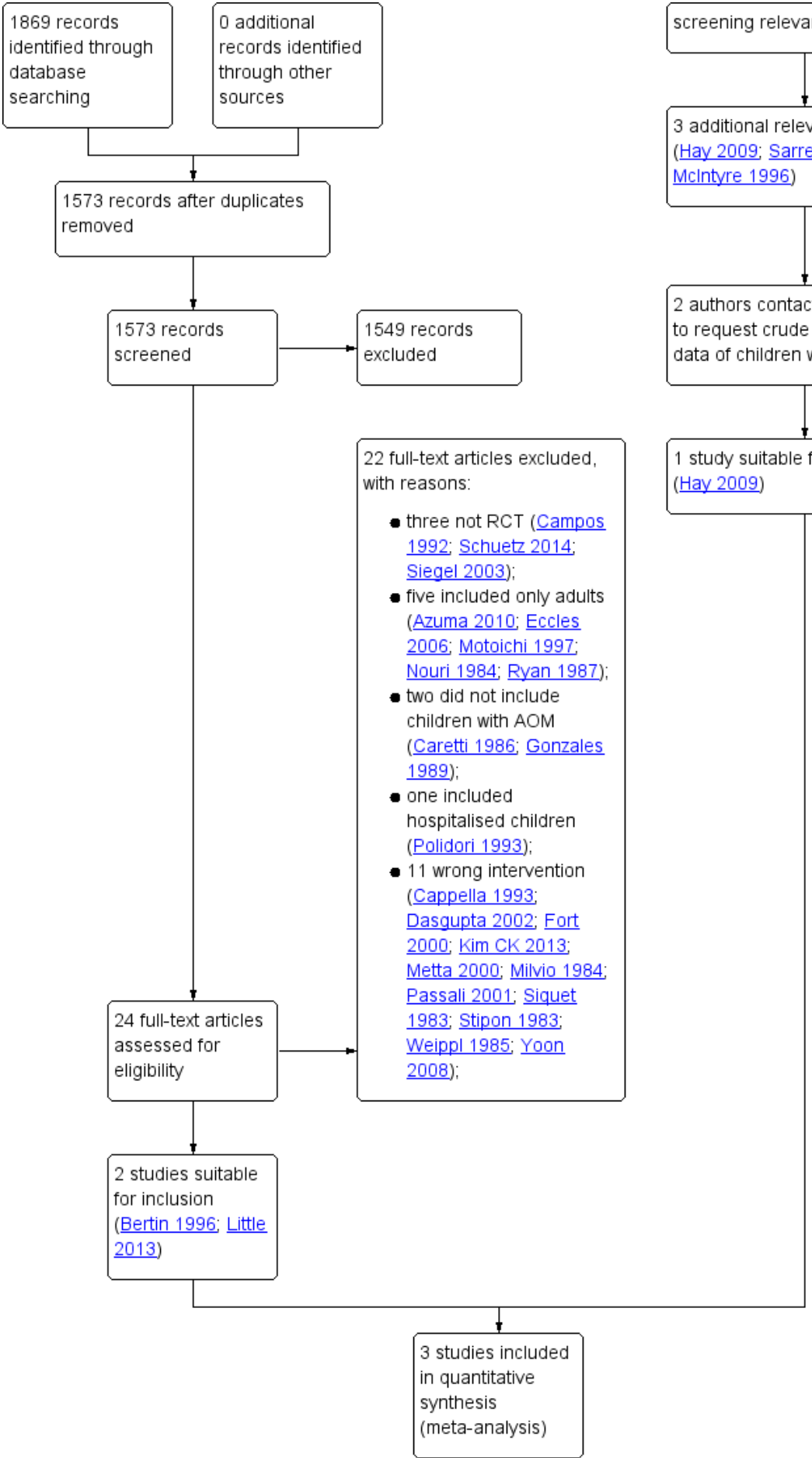

1 excluded (Mclntyre 1996); trial included hospitalised

children

1 excluded (Sarrell 2006); we did not succeed to receive the crude subgroup data of children with $\mathrm{AOM}$ from this trial

\section{Data extraction and management}

Two review authors (AS, RPV) independently extracted data from the included studies using standardised data extraction forms. We extracted the following information from each trial:

1. Study characteristics: setting, design, method of data-analysis.

2. Participants: study population, number of participants in each group, patient characteristics including age, gender, ethnicity.
3. Interventions: type of intervention used including timing and dosage and route of administration.

4. Outcomes: primary and secondary outcomes recorded, time points.

We resolved any disagreements by discussion.

Paracetamol (acetaminophen) or non-steroidal anti-inflammatory drugs, alone or combined, for pain relief in acute otitis media in 


\section{Assessment of risk of bias in included studies}

Two review authors (AS, RPV) independently assessed the methodological quality of the included trials. We resolved any disagreements by discussion. We assessed risk of bias using the 'Risk of bias' tool as described in Chapter 8 of theCochrane Handbook for Systematic Reviews of Interventions (Higgins 2011). We judged the following domains as high, low or unclear risk of bias:

1. sequence generation (selection bias).
2. Allocation concealment (selection bias).

3. Blinding of participants and personnel (performance bias).

4. Blinding of outcome assessment (detection bias).

5. Incomplete outcome data (attrition bias).

6. Selective outcome reporting (reporting bias).

7. Other sources of bias.

The results of the 'Risk of bias' assessment are presented in Figure 2 and Figure 3.

Figure 2. Risk of bias summary: review authors' judgements about each risk of bias item for each included study

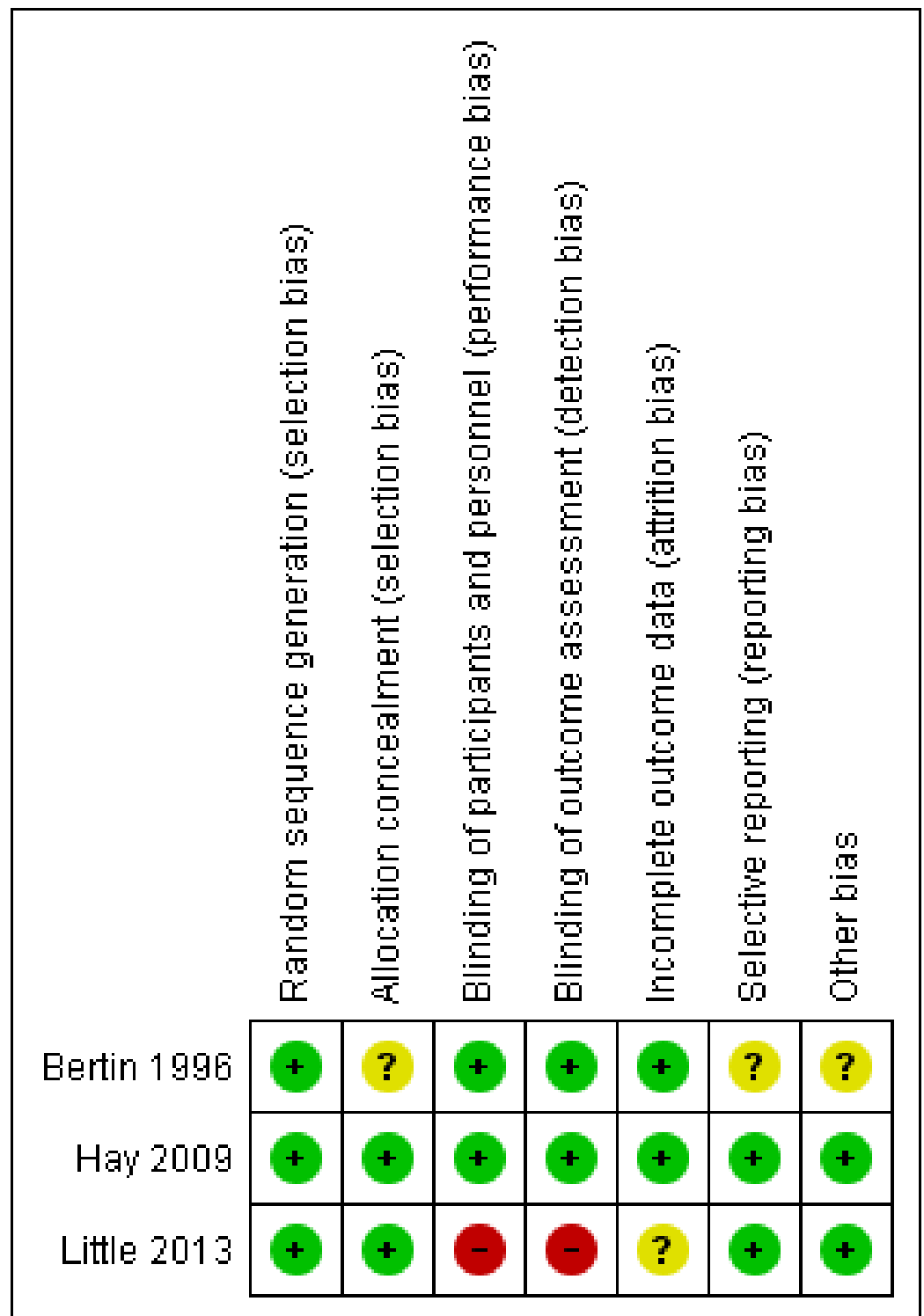

Paracetamol (acetaminophen) or non-steroidal anti-inflammatory drugs, alone or combined, for pain relief in acute otitis media in 
Figure 3. Risk of bias graph: review authors' judgements about each risk of bias item presented as percentages across all included studies

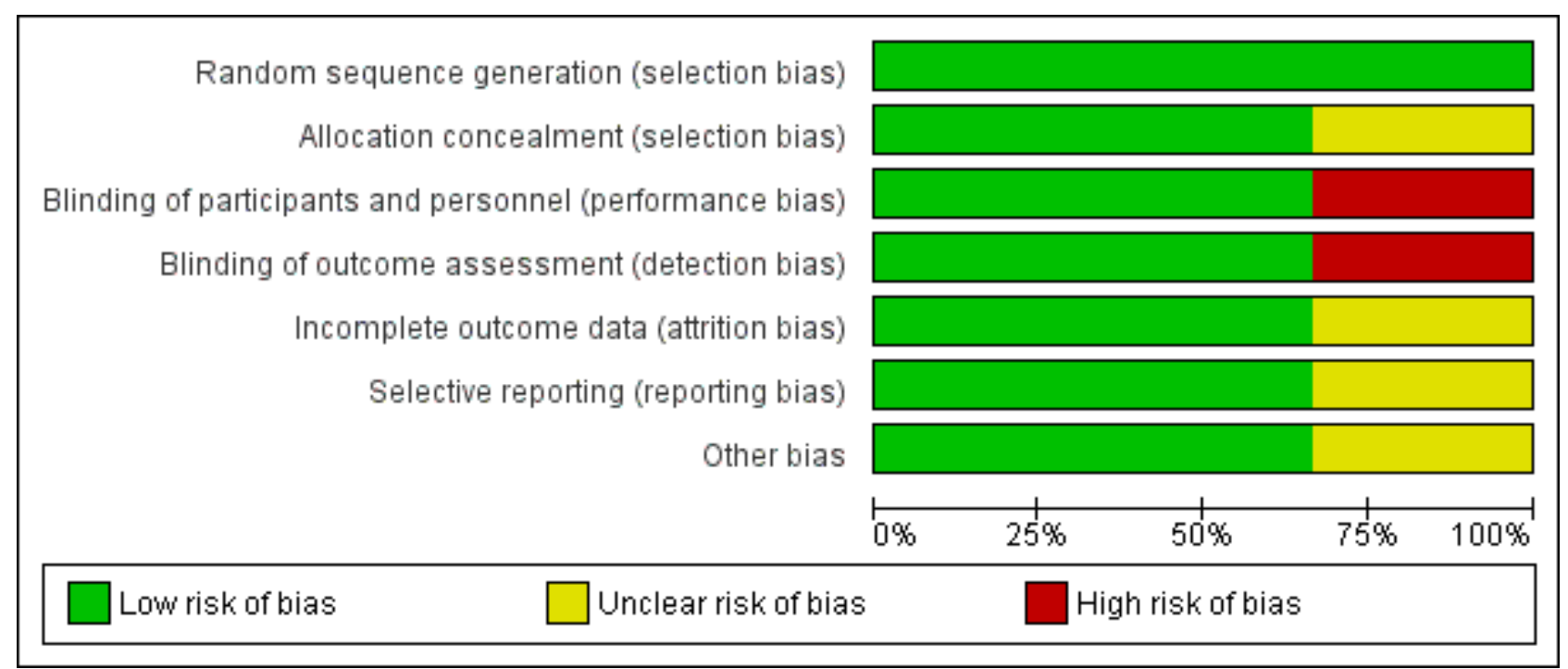

\section{Measures of treatment effect}

We expressed dichotomous outcomes as risk ratios (RRs) with accompanying $95 \%$ confidence intervals (Cls) and calculated the number needed to treat to benefit (NNTB). We expressed continuous outcome variables either as mean differences (MDs) if reported on the same scale or standardised mean differences (SMD) if different continuous scales were used, with accompanying 95\% Cls.

\section{Unit of analysis issues}

We did not identify any studies with non-standard designs, such as cross-over trials or cluster-randomised trials.

\section{Dealing with missing data}

In cases of missing data, we contacted corresponding authors of the included trials to provide additional information. In primary analyses, we analysed available data according to the intentionto-treat (ITT) principle, that is, we analysed all participants in the group to which they were originally allocated. For dichotomous outcomes, we proposed to assess the impact of incomplete data reporting by performing scenario analyses (best and worst-case scenarios). For mean ear pain score at various time points, we proposed to assess the impact of missing outcome data by using the baseline observation carried forward approach (Moore 2012).

\section{Assessment of heterogeneity}

We considered both clinical and statistical heterogeneity. We assessed the level of clinical diversity among trials by reviewing included studies for potential differences in study populations, interventions, and outcomes measured. We assessed statistical heterogeneity for each outcome by visual inspection of forest plots and using the $\mathrm{Chi}^{2}$ test, with a significance level set at $\mathrm{P}<0.10$, and the $I^{2}$ statistic (Higgins 2003); $I^{2}$ values of $50 \%$ or more suggest substantial heterogeneity (Higgins 2011).

Where there was substantial statistical heterogeneity, we proposed to carry out pre-specified subgroup analyses and sensitivity analyses based on the risk of bias (see Subgroup analysis and investigation of heterogeneity; Sensitivity analysis). If none of these analyses completely resolved statistical heterogeneity, we employed a random-effects (Der Simonian and Laird) model to provide a more conservative effect estimate.

\section{Assessment of reporting biases}

We searched the Internet and ClinicalTrials.gov (http:// clinicaltrials.gov/) for relevant study protocols to determine if all outcomes listed in study protocols had been published and if all outcomes reported were pre-defined. We intended to assess reporting biases by using funnel plots if there were sufficient included trials.

\section{Data synthesis}

We primarily performed available case analyses, so using data for every participant for whom the outcome was obtained, according to the ITT principle.

For both primary and secondary dichotomous outcomes measured at various time points, we primarily performed a meta-analysis using a wide window of one to seven days. In secondary analyses, we used the specific time point reported in most studies. We performed statistical analyses using Review Manager software (RevMan 2014)

For the comparison of NSAIDs plus background therapy (paracetamol) versus background therapy only, we performed a meta-analysis of studies comparing NSAIDs plus background therapy versus background therapy only.

For dichotomous data, we calculated RR with $95 \% \mathrm{Cls}$ using the Mantel-Haenszel method with a fixed-effect model if appropriate or the random-effects (Der Simonian and Laird) model where unexplained heterogeneity was found (see Assessment of heterogeneity). We also calculated the NNTB or number needed to harm (NNTH) based on the average risks of the control groups in the included studies (study population) (Higgins 2011).

Paracetamol (acetaminophen) or non-steroidal anti-inflammatory drugs, alone or combined, for pain relief in acute otitis media in 


\section{GRADE and 'Summary of findings' tables}

We used the GRADE (Atkins 2004) approach to rate the overall quality of evidence for any of the outcomes of interest reported in the included trials, and drew conclusions about the quality of evidence. There are four possible ratings: high, moderate, low and very low. The GRADE approach rates evidence from RCTs which do not have serious limitations as high quality. However, several factors can lead to the downgrading of the evidence. The degree of downgrading is determined by the seriousness of the these factors: study limitations, consistency of effect, imprecision, indirectness and publication bias to assess the quality of a body of evidence as it relates to the studies which contribute data to the meta-analyses for the prespecified outcomes. We used methods and recommendations described in Section 8.5 and Chapter 12 of the Cochrane Handbook for Systematic Reviews of Interventions (Higgins 2011) used GRADEproGDT software (GRADEproGDT 2015). We justified all decisions to downgrade the quality of studies using footnotes, and we made comments to aid the reader's understanding of the review where necessary.

We provided summary of findings tables for the main comparisons of interest paracetamol versus placebo, NSAIDs versus placebo and NSAIDs versus paracetamol including what we felt the seven most important outcomes:

1. Proportion of children with pain (yes/no) at various time points (24 hours, 48 to 72 hours, 4 to 7 days);

2. Adverse events;

3. Mean time to resolution of pain;

4. Mean pain score at various time points ( 24 hours; 48 to 72 hours; 4 to 7 days) using validated pain scores;

5. Proportion of children with fever at various time points (24 hours; 48 to 72 hours; 4 to 7 days);

6. Proportion of children with re-consultations at various time points; and

7. Proportion of children with (delayed) antibiotic prescriptions at various time points;

\section{Subgroup analysis and investigation of heterogeneity}

We planned to perform subgroup analysis for the following categories if sufficient data were available:

1. Age (up to 2 years versus 2 years and above).

2. Route of administration of analgesics (oral versus rectal).

3. Concurrent therapy (concurrent antibiotic therapy versus no concurrent antibiotic therapy); and

4. Definition of AOM (AOM diagnosis based solely on symptoms versus $A O M$ diagnosis based on symptoms and bulging of the eardrum or new onset of ear discharge not due to acute otitis externa).

\section{Sensitivity analysis}

To assess the robustness of review findings, we intended to perform a sensitivity analysis in which trials with high risk of bias were excluded. High risk of bias was defined as high risk of concealment of allocation bias or attrition bias.

For dichotomous outcomes, we intended to assess the impact of incomplete data reporting by performing scenario analyses (best and worst-case scenarios) and for mean ear pain score at various time points using the baseline observation carried forward approach in case of incomplete outcome reporting (see Dealing with missing data).

\section{RE S U L T S}

\section{Description of studies}

See: Characteristics of included studies; Characteristics of excluded studies; Characteristics of studies awaiting classification; Characteristics of ongoing studies.

\section{Results of the search}

We retrieved a total of 1869 records from our electronic database searches. Following removal of duplicates we assessed 1573 unique articles. After screening titles and abstracts, we identified 24 potentially eligible articles. After reviewing full text reports, we excluded 22 articles: three were non-randomised studies (Campos 1992; Schuetz 2014; Siegel 2003), five included only adults (Azuma 2010; Eccles 2006; Motoichi 1997; Nouri 1984; Ryan 1987), two did not include children with AOM (Caretti 1986; Gonzales 1989), one included hospitalised children (Polidori 1993) and 11 did not include relevant interventions and comparators (Cappella 1993; Dasgupta 2002; Fort 2000; Kim CK 2013; Metta 2000; Milvio 1984; Passali 2001; Siquet 1983; Stipon 1983; Weippl 1985; Yoon 2008). (See also: Excluded studies). We therefore included two studies from our electronic database searches in this review (Bertin 1996; Little 2013) (Figure 1). Little 2013 did not report subgroup data for children with AOM in the trial publication; data were provided by the first author of this trial (Paul Little).

After reviewing the reference lists of relevant systematic reviews, we identified three additional potentially relevant articles (Hay 2009; McIntyre 1996; Sarrell 2006). We excluded one study because it included hospitalised children (Mclntyre 1996). Since neither Hay 2009 nor Sarrell 2006 reported subgroup data for children with AOM, we contacted the lead trial authors. We did not succeed in obtaining additional data in relation to Sarrell 2006, but relevant data were provided by the first author (Alastair Hay) for Hay 2009. Adding this one to the two studies retrieved from our electronic database searches led to a total of three included studies (Bertin 1996; Hay 2009; Little 2013) (Figure 1).

We did neither identify additional relevant trials nor any completed studies after reviewing trials registries WHO ICTRP, ClinicalTrials.gov, and the NTR for completed and ongoing trials (search date 19 August 2016), but we did find one ongoing trial (PIMPOM study 2014; see Characteristics of ongoing studies).

\section{Included studies}

We included three studies that presented data for a total of 327 children with AOM (Bertin 1996; Hay 2009; Little 2013). Methods, participants, interventions and outcomes of the included studies are described in Characteristics of included studies.

\section{Design}

Two trials applied three arm, parallel group, double-blind design (Bertin 1996; Hay 2009); one was a 3 × 2 × 2 factorial, open-label, design (Little 2013).

Paracetamol (acetaminophen) or non-steroidal anti-inflammatory drugs, alone or combined, for pain relief in acute otitis media in 


\section{Participants and settings}

In Bertin 1996, all 219 children aged from one year to seven years were diagnosed with AOM. Hay 2009 included 156 febrile children aged from six months to six years of whom 26 were diagnosed with AOM; Little 2013 included 889 children aged three years and over with respiratory tract infections of whom 82 had AOM. We therefore included data from 327 children.

AOM diagnosis was based on the aspect of the eardrum in Bertin 1996, whereas AOM was diagnosed either by the general practitioner (GP) or research nurse without further specification of diagnostic criteria in Hay 2009 and Little 2013.

Little 2013 was performed in a primary care setting; Hay 2009 in the community, primary and secondary care settings; the setting was unclear in Bertin 1996 (all children were seen as outpatients in 4 centres without further specification).

\section{Interventions and comparators}

Bertin 1996 compared paracetamol ( $10 \mathrm{mg} / \mathrm{kg} 3$ times daily) versus NSAIDs (ibuprofen $10 \mathrm{mg} / \mathrm{kg} 3$ times daily) versus placebo. Hay 2009, a three arm, parallel group trial compared paracetamol (15 $\mathrm{mg} / \mathrm{kg}$ orally, maximum of 4 doses in 24 hours) versus NSAIDs (ibuprofen $10 \mathrm{mg} / \mathrm{kg}$, maximum of 3 doses in 24 hours) versus NSAID plus paracetamol. Little 2013 applied a $3 \times 2 \times 2$ factorial design and compared paracetamol versus NSAIDs (ibuprofen) versus NSAIDs (ibuprofen) plus paracetamol. Children in Little 2013 were randomised to both one of the three treatment groups but also to one of two dosing regimens (regularly or as required) and one of two steam inhalation therapy groups (steam versus no steam). Doses of paracetamol and ibuprofen used in this trial were the maximum recommended by the British National Formulary (which varies by age) (https://www.bnf.org/products/bnf-online/).

Bertin 1996 prescribed concurrent antibiotic therapy (cefaclor 15 $\mathrm{mg}$ to $30 \mathrm{mg} / \mathrm{kg}$ twice daily for 7 days). Furthermore, children with fever $>39^{\circ} \mathrm{C}$ could be given paracetamol ( $30 \mathrm{mg}$ to $60 \mathrm{mg}$ ) in addition to the studied treatments in Bertin 1996.

\section{Outcomes}

Relevant data derived from at least one trial could be extracted for all outcomes, except for the secondary outcomes days lost from nursery or school for children because of AOM and days lost from work or education for parents and carers because of their child's AOM.

In Bertin 1996 ear pain was reported as a dichotomous outcome (yes versus no). Hay 2009 assessed fever-associated discomfort using a validated comfort scale (no comfort; not quite normal; some pain/distress; crying/very distressed), whereas Little 2013 assessed ear pain using a validated symptom score (ranging from 0 to 6 with $0=$ no problem and $6=$ as bad as it could be).

\section{Funding sources}

In Bertin 1996, study medications were supplied by a pharmaceutical company (Ethypharm); no further details were provided about the role of this company in the design, conduct, analysis, or reporting of the trial. The other two trials (Hay 2009; Little 2013) were funded by governmental (non-commercial) grants. In Hay 2009, study medications were purchased from and provided by two companies (Pfizer and DHP Investigational
Medicinal Products); these companies had no role in the design, conduct, analysis, or reporting of the trial.

\section{Excluded studies}

We excluded 24 studies:

- three were non-randomised studies (Campos 1992; Schuetz 2014; Siegel 2003);

- five included only adults (Azuma 2010; Eccles 2006; Motoichi 1997; Nouri 1984; Ryan 1987);

- two did not include children with AOM (Caretti 1986; Gonzales 1989);

- two included hospitalised children (Mclntyre 1996; Polidori 1993);

- 11 did not include relevant interventions and comparators (Cappella 1993; Dasgupta 2002; Fort 2000; Kim CK 2013; Metta 2000; Milvio 1984; Passali 2001; Siquet 1983; Stipon 1983; Weippl 1985; Yoon 2008);

- one did not report crude subgroup data of children with AOM and we were unsuccessful in obtaining additional data from the authors (Sarrell 2006).

\section{Risk of bias in included studies}

The methodological quality of the included studies was generally high. Details of the risk of bias assessment of the included trials are summarised in Figure 2 and Figure 3.

\section{Allocation}

Random sequence generation was judged adequate in all three trials. Concealment of allocation was adequately described in Hay 2009 and Little 2013, but was unclear in Bertin 1996.

\section{Blinding}

The risk of bias for blinding of participants, personnel and outcome assessors (performance and detection bias) was low in Bertin 1996 and Hay 2009 and high in Little 2013.

\section{Incomplete outcome data}

Risk of attrition bias was low in Bertin 1996 and Hay 2009 and unclear in Little 2013.

\section{Selective reporting}

Risk of reporting bias was low in Hay 2009 and Little 2013. We could not retrieve the trial protocol for Bertin 1996 and were unable determine the risk of selective outcome reporting bias.

\section{Other potential sources of bias}

Risk of other potential sources of bias was low in Hay 2009 and Little 2013 and unclear in Bertin 1996.

\section{Effects of interventions}

See: Summary of findings for the main comparison Paracetamol versus placebo for acute otitis media in children; Summary of findings 2 NSAIDs versus placebo for acute otitis media in children; Summary of findings 3 NSAIDs versus paracetamol for acute otitis media in children

Paracetamol (acetaminophen) or non-steroidal anti-inflammatory drugs, alone or combined, for pain relief in acute otitis media in 


\section{Paracetamol versus placebo}

\section{Primary outcomes}

\section{Proportion of children with pain at 48 hours}

We included data from one trial for this outcome (148 randomised children, 148 (100\%) included in analysis) (Bertin 1996). At 48 hours, fewer children in the paracetamol group had pain than those allocated to placebo ( $10 \%$ versus $25 \%$, RR $0.38,95 \% \mathrm{Cl} 0.17$ to 0.85 ; NNTB 7) (Analysis 1.1; Figure 4).

Figure 4. Forest plot of comparison: 1 Paracetamol versus placebo, outcome: 1.1 Pain at 48 hours

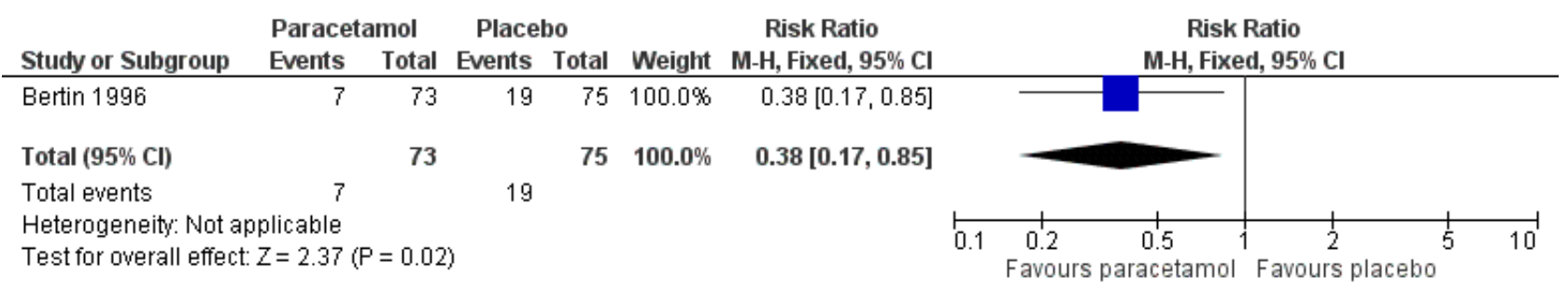

\section{Quality of evidence}

The evidence for this outcome was low quality; we downgraded it from high to low quality due to study limitations and questions about the applicability of evidence. All children received concurrent antibiotic therapy, and those with fever $>39{ }^{\circ} \mathrm{C}$ could be given paracetamol ( $30 \mathrm{mg}$ to $60 \mathrm{mg}$ ) in addition to the studied treatments. This may have substantially influenced trial findings.

\section{Adverse events likely to be related to the use of paracetamol}

We included data from one trial for this outcome (148 randomised children, 148 (100\%) included in analysis) (Bertin 1996). Adverse events were reported infrequently and did not significantly differ between children treated with paracetamol and those allocated to placebo (4\% versus 4\%, RR 1.03, 95\% $\mathrm{Cl} 0.21$ to 4.93 ) (Analysis 1.2).

\section{Quality of evidence}

The evidence for this outcome was very low quality; we downgraded it from high to low quality due to study limitations and imprecise effect estimate (small sample size and infrequent occurrence of the outcome).

\section{Secondary outcomes}

\section{Proportion of children with fever at 48 hours}

We included data from one trial for this outcome (148 randomised children, 148 (100\%) included in analysis) (Bertin 1996). At 48 hours, the proportion of children with fever did not significantly differ between the paracetamol and placebo groups ( $1 \%$ versus $1 \%$, RR $1.03,95 \% \mathrm{Cl} 0.07$ to 16.12 ) (Analysis 1.3 ).

\section{Quality of evidence}

The evidence for this outcome was very low quality; we downgraded it from high to very low quality due to study limitations, imprecise effect estimate (infrequent occurrence of the outcome) and questions about the applicability of evidence. All children received concurrent antibiotic therapy and those with fever $>39{ }^{\circ} \mathrm{C}$ could be given paracetamol (30 mg to $60 \mathrm{mg}$ ) in addition to the studied treatments. This may have substantially influenced trial findings.

\section{Other pre-specified secondary outcomes}

None of the other pre-specified secondary outcomes were reported for the comparison paracetamol versus placebo.

\section{NSAIDs (ibuprofen) versus placebo}

\section{Primary outcomes}

\section{Proportion of children with pain at 48 hours}

We included data from one trial for this outcome (146 randomised children, 146 (100\%) included in analysis) (Bertin 1996). At 48 hours, fewer children in the ibuprofen group had pain than those allocated to placebo ( $7 \%$ versus $25 \%$, RR $0.28,95 \% \mathrm{Cl} 0.11$ to 0.70 ; NNTB 6 ) (Analysis 2.1; Figure 5).

\section{Figure 5. Forest plot of comparison: 2 NSAIDs versus placebo, outcome: 2.1 Pain at 48 hours}

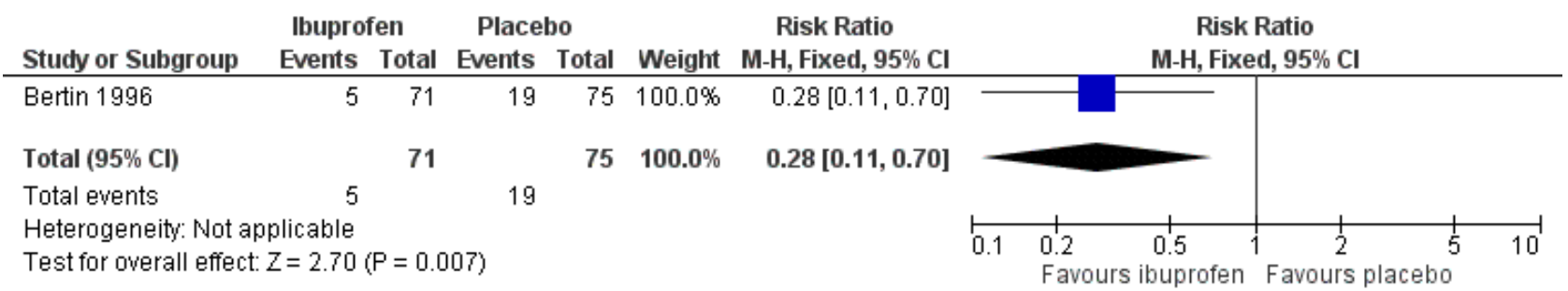

Paracetamol (acetaminophen) or non-steroidal anti-inflammatory drugs, alone or combined, for pain relief in acute otitis media in 


\section{Quality of evidence}

The evidence for this outcome was low quality; we downgraded it from high to low quality due to study limitations and questions about the applicability of evidence. All children received concurrent antibiotic therapy and those with fever $>39{ }^{\circ} \mathrm{C}$ could be given paracetamol ( $30 \mathrm{mg}$ to $60 \mathrm{mg}$ ) in addition to the studied treatments. This may have substantially influenced trial findings.

\section{Adverse events likely to be related to the use of NSAIDS (ibuprofen)}

We included data from one trial for this outcome (146 randomised children, 146 (100\%) included in analysis) (Bertin 1996). Adverse events were reported infrequently and did not significantly differ between children treated with ibuprofen and those allocated to placebo (7\% versus 4\%, RR $1.76,95 \% \mathrm{Cl} 0.44$ to 7.10 ) (Analysis 2.2).

\section{Quality of evidence}

The evidence for this outcome was very low quality; we downgraded it from high to very low quality due to study limitations and imprecise effect estimate (small sample size and infrequent occurrence of the outcome).

\section{Secondary outcomes}

\section{Proportion of children with fever at $\mathbf{4 8}$ hours}

We included data from one trial for this outcome (146 randomised children, 146 (100\%) included in analysis) (Bertin 1996). At 48 hours, the proportion of children with fever did not significantly differ between the ibuprofen and placebo groups ( $1 \%$ versus $1 \%$, RR 1.06 , $95 \% \mathrm{Cl} 0.07$ to 16.57 ) (Analysis 2.3).

\section{Quality of evidence}

The evidence for this outcome was very low quality; we downgraded it from high to very low quality due to study limitations, imprecise effect estimate (infrequent occurrence of the outcome) and questions about the applicability of evidence. All children received concurrent antibiotic therapy and those with fever $>39{ }^{\circ} \mathrm{C}$ could be given paracetamol (30 mg to $60 \mathrm{mg}$ ) in addition to the studied treatments. This may have substantially influenced trial findings.

\section{Other pre-specified secondary outcomes}

None of the other pre-specified secondary outcomes were reported for the comparison NSAIDs (ibuprofen) versus placebo.

\section{NSAIDs (ibuprofen) versus paracetamol}

\section{Primary outcomes}

\section{Proportion of children with pain at various time points}

\section{4 hours}

We pooled data from two trials for this outcome (71 randomised children, 39 (55\%) included in analysis) (Hay 2009; Little 2013). At 24 hours, the proportion of children with pain did not significantly differ between those treated with ibuprofen and paracetamol $(57 \%$ versus $78 \%$, RR $0.83,95 \% \mathrm{Cl} 0.59$ to $1.18, \mathrm{I}^{2}$ statistic $=0 \%$, fixedeffect model) (Analysis 3.1). Subgroup and sensitivity analyses were deemed not to be useful because of the low number of trials and included children.

\section{Quality of evidence}

The evidence for this outcome was very low quality; we downgraded it from high to very low quality due to study limitations and imprecise effect estimate (very small sample size).

\section{8 to 72 hours}

We pooled data from three trials for this outcome ( 215 randomised children, 183 (85\%) included in analysis) (Bertin 1996; Hay 2009; Little 2013). The proportion of children with pain at 48 to 72 hours did not significantly differ between those treated with ibuprofen and paracetamol ( $17 \%$ versus $18 \%$, RR $0.91,95 \% \mathrm{Cl} 0.54$ to $1.54 ; \mathrm{I}^{2}$ statistic $=0 \%$, fixed-effect model) (Analysis 3.2; Figure 6). Subgroup and sensitivity analyses were deemed not useful because of the low number of trials.

\section{Figure 6. Forest plot of comparison: 3 NSAIDs versus paracetamol, outcome: 3.2 Pain at 48 to 72 hours}

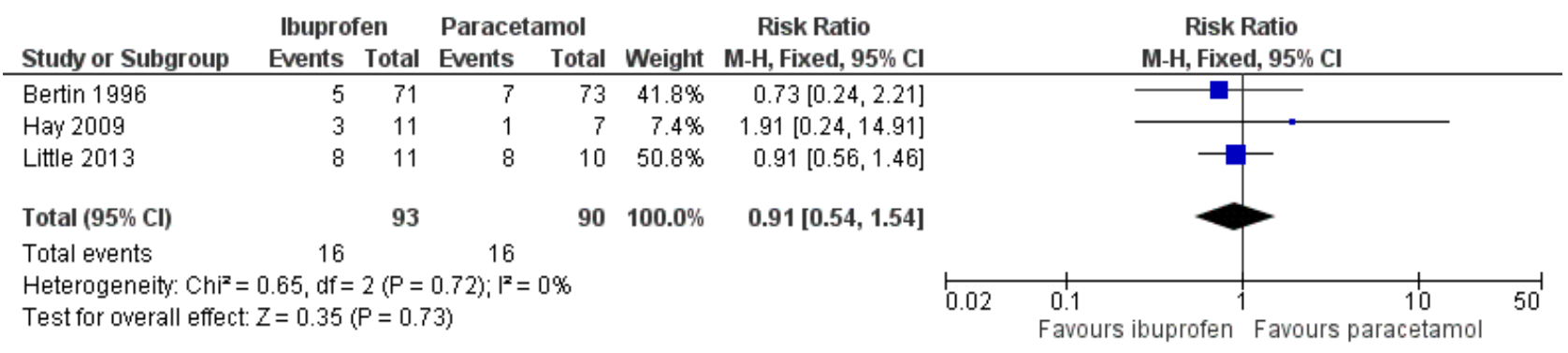

\section{Quality of evidence}

The evidence for this outcome was low quality; we downgraded it from high to low quality due to study limitations and questions about the applicability of evidence. All children in Bertin 1996 received concurrent antibiotic therapy and those with fever $>39$ ${ }^{\circ} \mathrm{C}$ could be given paracetamol ( $30 \mathrm{mg}$ to $60 \mathrm{mg}$ ) in addition to the studied treatments. This may have substantially influenced trial findings.

\section{Four to seven days}

We pooled data from two trials for this outcome (71 randomised children, 38 (54\%) children included in analysis) (Hay 2009; Little 2013). The proportion of children with pain at four to seven days did not significantly differ between those treated with ibuprofen and paracetamol ( $14 \%$ versus $19 \%$, RR $0.74,95 \% \mathrm{Cl} 0.17$ to 3.23 ; $\mathrm{I}^{2}$ statistic $=36 \%$, fixed-effect model) (Analysis 3.3). Subgroup and sensitivity analyses were deemed not to be useful because of the low number of trials and included children. 


\section{Quality of evidence}

The evidence for this outcome was very low quality; we downgraded it from high to very low quality due to study limitations and imprecise effect estimate (very small sample size).

\section{Adverse events likely to be related to the use of paracetamol or NSAIDs (ibuprofen)}

We pooled data from two trials for this outcome (197 randomised children; 197 (100\%) included in analysis) (Bertin 1996; Little 2013). Adverse events were reported infrequently and did not significantly differ between children treated with ibuprofen and those treated with paracetamol ( $5 \%$ versus $3 \%, \mathrm{RR} 1.71,0.43$ to $6.90 ; \mathrm{I}^{2}$ statistic $=$ $\mathrm{n} / \mathrm{a}$, random-effects model) (Analysis 3.4). Subgroup and sensitivity analyses were deemed not to be useful because of the low number of trials.

\section{Quality of evidence}

The evidence for this outcome was very low quality; we downgraded it from high to very low quality due to study limitations and imprecise effect estimate (small sample size and infrequent occurrence of the outcome).

\section{Secondary outcomes}

\section{Proportion of children with at most mild pain at various time points}

\section{4 hours}

We pooled data from two trials for this outcome (71 randomised children, 39 (55\%) included in analysis) (Hay 2009; Little 2013). No significant differences were observed between ibuprofen and paracetamol groups in the proportion of children with mild pain at 24 hours ( $18 \%$ versus $18 \%$, RR $1.08,95 \% \mathrm{Cl} 0.31$ to 3.73 ; $\mathrm{I}^{2}$ statistic $=0 \%$, fixed-effect model) (Analysis 3.5). Subgroup and sensitivity analyses were deemed not to be useful because of the low number of trials and included children.

\section{Quality of evidence}

The evidence for this outcome was very low quality; we downgraded it from high to very low quality due to study limitations and imprecise effect estimate (very small sample size).

\section{8 to 72 hours}

We pooled data from two trials for this outcome (71 randomised children, 39 (55\%) included in analysis) (Hay 2009; Little 2013). No significant differences were observed between ibuprofen and paracetamol groups in the proportion of children with mild pain at 48 to 72 hours ( $36 \%$ versus $29 \%$, RR $1.35,95 \% \mathrm{Cl} 0.62$ to 2.91 ; $\mathrm{I}^{2}$ statistic $=0 \%$, fixed-effect model) (Analysis 3.6). Subgroup and sensitivity analyses were deemed not to be useful because of the low number of trials and included children.

\section{Quality of evidence}

The evidence for this outcome was very low quality; we downgraded it from high to very low quality due to study limitations and imprecise effect estimate (very small sample size).

\section{Four to seven days}

We pooled data from two trials for this outcome (71 randomised children, 39 (55\%) included in analysis) (Hay 2009; Little 2013). No significant differences were observed between ibuprofen and paracetamol groups in the proportion of children with mild pain at four to seven days (23\% versus $29 \%$ ). Data did not enable pooling of trial results; the summary statistic relates only to Little 2013 (RR $0.91,95 \% \mathrm{Cl} 0.37$ to 2.23 ) (Analysis 3.7 ). Subgroup and sensitivity analyses were deemed not to be useful because of the low number of trials and included children.

\section{Quality of evidence}

The evidence for this outcome was very low quality; we downgraded it from high to very low quality due to study limitations and imprecise effect estimate (very small sample size).

\section{Mean time to resolution of pain}

None of the included trials reported on this pre-specified secondary outcome.

\section{Mean pain score at various time points}

\section{4 hours}

We pooled data from two trials for this outcome (71 randomised children, 39 (55\%) included in analysis) (Hay 2009; Little 2013). No differences were observed in mean pain scores at 24 hours between children treated with ibuprofen and paracetamol (MD 0.10, 95\% $\mathrm{Cl}-0.47$ to $0.67 ; \mathrm{I}^{2}$ statistic $=0 \%$, fixed-effect model) (Analysis 3.8). Subgroup and sensitivity analyses were deemed not to be useful because of the low number of trials and included children.

\section{Quality of evidence}

The evidence for this outcome was very low quality; we downgraded it from high to very low quality due to study limitations and imprecise effect estimate (very small sample size).

\section{8 to 72 hours}

We pooled data from two trials for this outcome (71 randomised children, 39 (55\%) included in analysis) (Hay 2009; Little 2013). No differences were observed in mean pain scores at 48 to 72 hours between children treated with ibuprofen and paracetamol (MD $0.19,95 \% \mathrm{Cl}-0.27$ to $0.65 ; \mathrm{I}^{2}$ statistic $=0 \%$, fixed-effect model) (Analysis 3.9). Subgroup and sensitivity analyses were deemed not to be useful because of the low number of trials and included children.

\section{Quality of evidence}

The evidence for this outcome was very low quality; we downgraded it from high to very low quality due to study limitations and imprecise effect estimate (very small sample size).

\section{4 to 7 days}

We pooled data from two trials for this outcome (71 randomised children, 31 (44\%) included in analysis) (Hay 2009; Little 2013). No differences were observed in mean pain scores at four to seven days between children treated with ibuprofen and paracetamol. Data did not enable pooling of trial results; the summary statistic relates only to Little 2013 (MD $-0.30,95 \% \mathrm{Cl}-2.38$ to 1.78 ) (Analysis 3.10). Subgroup and sensitivity analyses were deemed not to be useful because of the low number of trials and included children.

Paracetamol (acetaminophen) or non-steroidal anti-inflammatory drugs, alone or combined, for pain relief in acute otitis media in 


\section{Quality of evidence}

The evidence for this outcome was very low quality; we downgraded it from high to very low quality due to study limitations and imprecise effect estimate (very small sample size).

\section{Disease-specific quality of life as measured by a validated instrument}

None of the included trials reported on this pre-specified secondary outcome.

\section{Mean time to resolution of fever}

None of the included trials reported on this pre-specified secondary outcome.

\section{Proportion of children with fever at various time points}

\section{4 hours}

We pooled data from two trials for this outcome (71 randomised children, 39 (55\%) included in analysis) (Hay 2009; Little 2013). No difference was observed in the proportion of children with fever at 24 hours between those treated with ibuprofen and paracetamol ( $18 \%$ versus $29 \%$, RR $0.69,95 \% \mathrm{Cl} 0.24$ to $2.00 ; I^{2}$ statistic $=0 \%$, fixed effect model) (Analysis 3.11). Subgroup and sensitivity analyses were deemed not to be useful because of the low number of trials and included children.

\section{Quality of evidence}

The evidence for this outcome was very low quality; we downgraded it from high to very low quality due to study limitations and imprecise effect estimate (very small sample size).

\section{8 to 72 hours}

We pooled data from three trials for this outcome $(215$ randomised children, 182 (85\%) included in analysis) (Bertin 1996; Hay 2009; Little 2013). No difference was observed in the proportion of children with fever at 48 to 72 hours between those treated with ibuprofen and paracetamol ( $4 \%$ versus $3 \%, \mathrm{RR} 1.18,95 \% \mathrm{Cl} 0.31$ to $4.44 ; I^{2}$ statistic $=0 \%$, fixed-effect model) (Analysis 3.12). Subgroup and sensitivity analyses were deemed not to be useful because of the low number of trials.

\section{Quality of evidence}

The evidence for this outcome was low quality; we downgraded it from high to low quality due to study limitations and questions about the applicability of evidence. All children in Bertin 1996 received concurrent antibiotic therapy and those with fever $>39$ ${ }^{\circ} \mathrm{C}$ could be given paracetamol ( $30 \mathrm{mg}$ to $60 \mathrm{mg}$ ) in addition to the studied treatments. This may have substantially influenced trial findings.

\section{4 to 7 days}

We pooled data from two trials for this outcome (71 randomised children, 39 (55\%) included in analysis) (Hay 2009; Little 2013). No difference was observed in the proportion of children with fever at four to seven days between those treated with ibuprofen and paracetamol (5\% versus $0 \%)$. Data did not enable pooling of trial results; the summary statistic relates only to Little 2013 (RR 2.75, $95 \% \mathrm{Cl} 0.12$ to 60.70 ) (Analysis 3.13). Subgroup and sensitivity analyses were deemed not to be useful because of the low number of trials and included children.

\section{Quality of evidence}

The evidence for this outcome was very low quality; we downgraded it from high to very low quality due to study limitations and imprecise effect estimate (very small sample size).

\section{Proportion of children with re-consultations}

We included data from one trial for this outcome (53 randomised children, 53 (100\%) included in analysis) (Little 2013). No difference was observed in the proportion of children with re-consultations at day 28 between those treated with ibuprofen and paracetamol (92\% versus $81 \%$, RR $1.13,95 \% \mathrm{Cl} 0.92$ to 1.40 ) (Analysis 3.14).

\section{Quality of evidence}

The evidence for this outcome was very low quality; we downgraded it from high to very low quality due to study limitations and imprecise effect estimate (very small sample size).

\section{Proportion of children with (delayed) antibiotic prescriptions}

We included data from one trial for this outcome (53 randomised children, 53 (100\%) included in analysis) (Little 2013). No difference was observed in the proportion of children with delayed antibiotics between those treated with ibuprofen and paracetamol (54\% versus $41 \%$, RR $1.32,95 \% \mathrm{Cl} 0.74$ to 2.35 ) (Analysis 3.15).

\section{Quality of evidence}

The evidence for this outcome was very low quality; we downgraded it from high to very low quality due to study limitations and imprecise effect estimate (very small sample size).

\section{Total days lost from nursery or school for children because of AOM}

None of the included trials reported on this pre-specified secondary outcome.

\section{Total days lost from work or education for parents and carers because of their child's AOM}

None of the included trials reported on this pre-specified secondary outcome.

\section{Serious complications}

We pooled data from two trials for this outcome (71 randomised children, 71 (100\%) included in analysis) (Hay 2009; Little 2013). No serious complications related to AOM were reported in either of the trials. Subgroup and sensitivity analyses were deemed not to be useful because of the low number of trials and included children.

\section{Quality of evidence}

The evidence for this outcome was very low quality; we downgraded it from high to very low quality due to study limitations and imprecise effect estimate (small sample size and infrequent occurrence of the outcome). 
NSAIDs (ibuprofen) and paracetamol versus paracetamol

\section{Primary outcomes}

\section{Proportion of children with pain at various time points}

\section{4 hours}

We pooled data from two trials for this outcome $(71$ randomised children, 41 (58\%) included in analysis) (Hay 2009; Little 2013). At 24 hours, the proportion of children with pain did not significantly differ between those treated with ibuprofen and paracetamol versus paracetamol alone (79\% versus $71 \%$, RR $1.07,95 \% \mathrm{Cl} 0.78$ to $1.47, \mathrm{I}^{2}$ statistic $=0 \%$, fixed-effect model) (Analysis 4.1). Subgroup and sensitivity analyses were deemed not to be useful because of the low number of trials and included children.

\section{Quality of evidence}

The evidence for this outcome was very low quality; we downgraded it from high to very low quality due to study limitations and imprecise effect estimate (very small sample size).

\section{8 to 72 hours}

We pooled data from two trials for this outcome (71 randomised children, 41 (58\%) included in analysis) (Hay 2009; Little 2013). At 48 to 72 hours, the proportion of children with pain did not significantly differ between those treated with ibuprofen and paracetamol versus paracetamol alone $(42 \%$ versus $53 \%$, RR 0.71 , $95 \% \mathrm{Cl} 0.42$ to $1.20, \mathrm{I}^{2}$ statistic $=0 \%$, fixed-effect model) (Analysis 4.2). Subgroup and sensitivity analyses were deemed not to be useful because of the low number of trials and included children.

\section{Quality of evidence}

The evidence for this outcome was very low quality; we downgraded it from high to very low quality due to study limitations and imprecise effect estimate (very small sample size).

\section{4 to 7 days}

We pooled data from two trials for this outcome (71 randomised children, 41 (58\%) included in analysis) were combined (Hay 2009; Little 2013). At four to seven days, the proportion of children with pain did not significantly differ between those treated with ibuprofen and paracetamol versus paracetamol alone (33\% versus $18 \%$, RR $1.65,95 \% \mathrm{Cl} 0.58$ to $4.72, \mathrm{I}^{2}$ statistic $=0 \%$, fixed-effect model) (Analysis 4.3). Subgroup and sensitivity analyses were deemed not useful because of the low number of trials and included children.

\section{Quality of evidence}

The evidence for this outcome was very low quality; we downgraded it from high to very low quality due to study limitations and imprecise effect estimate (very small sample size).

\section{Adverse events likely to be related to the use NSAIDs (ibuprofen) and paracetamol or paracetamol alone}

We included data from one trial (56 randomised children, 56 (100\%) included in analysis) (Little 2013). No adverse events were reported in this trial (Analysis 4.4).

\section{Quality of evidence}

The evidence for this outcome was very low quality; we downgraded it from high to low quality due to study limitations and imprecise effect estimate (very small sample size and infrequent occurrence of the outcome).

\section{Secondary outcomes}

\section{Proportion of children with at most mild pain at various time points}

\section{4 hours}

We pooled data from two trials for this outcome (71 randomised children, 41 (58\%) included in analysis) (Hay 2009; Little 2013). At 24 hours, the proportion of children with at most mild pain did not significantly differ between those treated with ibuprofen and paracetamol versus paracetamol alone ( $4 \%$ versus $18 \%)$. Data did not enable pooling of the trial results; the summary statistic relates only to Little 2013 (RR $0.21,95 \% \mathrm{Cl} 0.02$ to 1.74) (Analysis 4.5). Subgroup and sensitivity analyses were deemed not to be useful because of the low number of trials and included children.

\section{Quality of evidence}

The evidence for this outcome was very low quality; we downgraded it from high to very low quality due to study limitations and imprecise effect estimate (very small sample size).

\section{8 to 72 hours}

We pooled data from two trials for this outcome (71 randomised children, 41 (58\%) included in analysis) (Hay 2009; Little 2013). At 48 to 72 hours, the proportion of children with at most mild pain did not significantly differ between those treated with ibuprofen and paracetamol versus paracetamol alone ( $21 \%$ versus $29 \%)$. Data did not enable pooling of trial results; the summary statistic relates only to Little 2013 (RR $0.63,95 \%$ Cl 0.24 to 1.62) (Analysis 4.6). Subgroup and sensitivity analyses were deemed not to be useful because of the low number of trials and included children.

\section{Quality of evidence}

The evidence for this outcome was very low quality; we downgraded it from high to very low quality due to study limitations and imprecise effect estimate (very small sample size).

\section{4 to 7 days}

We pooled data from two trials for this outcome (71 randomised children, 41 (58\%) included in analysis) (Hay 2009; Little 2013). At four to seven days, the proportion of children with at most mild pain did not significantly differ between those treated with ibuprofen and paracetamol versus paracetamol alone ( $17 \%$ versus $29 \%)$. Data did not enable pooling of trial results; the summary statistic relates only to Little 2013 (RR $0.50,95 \% \mathrm{Cl} 0.17$ to 1.43) (Analysis 4.7). Subgroup and sensitivity analyses were deemed not to be useful because of the low number of trials and included children.

\section{Quality of evidence}

The evidence for this outcome was very low quality; we downgraded it from high to very low quality due to study limitations and imprecise effect estimate (very small sample size).

\section{Mean time to resolution of pain}

None of the included trials reported on this pre-specified secondary outcome. 


\section{Mean pain score at various time points}

\section{4 hours}

We pooled data from two trials for this outcome (71 randomised children, 40 (56\%) included in analysis) (Hay 2009; Little 2013). No differences were observed in mean pain scores at 24 hours between children treated with treated with ibuprofen and paracetamol versus paracetamol alone (MD $0.32,95 \% \mathrm{Cl}-0.59$ to $1.23 ; \mathrm{I}^{2}$ statistic $=61 \%$, random-effects model) (Analysis 4.8). Subgroup and sensitivity analyses were deemed not to be useful because of the low number of trials and included children.

\section{Quality of evidence}

The evidence for this outcome was very low quality; we downgraded it from high to very low quality due to study limitations and imprecise effect estimate (very small sample size).

\section{8 to 72 hours}

We pooled data from two trials for this outcome (71 randomised children, 40 (56\%) included in analysis) (Hay 2009; Little 2013). No differences were observed in mean pain scores at 48 to 72 hours between children treated with ibuprofen and paracetamol versus paracetamol alone. Data did not enable pooling of trial results; the summary statistic relates only to Little 2013 (MD 0.60, 95\% Cl -0.77 to 1.97 ) (Analysis 4.9). Subgroup and sensitivity analyses were deemed not to be useful because of the low number of trials and included children.

\section{Quality of evidence}

The evidence for this outcome was very low quality; we downgraded it from high to very low quality due to study limitations and imprecise effect estimate (very small sample size).

\section{4 to 7 days}

We pooled data from two trials for this outcome (71 randomised children, 33 (46\%) included in analysis) (Hay 2009; Little 2013). No differences were observed in mean pain scores at four to seven days children treated with ibuprofen and paracetamol versus paracetamol alone. Data did not enable pooling of trial results; the summary statistic relates only to Little 2013 (MD 0.70, 95\% Cl -1.01 to 2.41) (Analysis 4.10). Subgroup and sensitivity analyses were deemed not to be useful because of the low number of trials and included children.

\section{Quality of evidence}

The evidence for this outcome was very low quality; we downgraded it from high to very low quality due to study limitations and imprecise effect estimate (very small sample size).

\section{Disease-specific quality of life as measured by a validated instrument}

None of the included trials reported on this pre-specified secondary outcome.

\section{Mean time to resolution of fever}

None of the included trials reported on this pre-specified secondary outcome.

\section{Proportion of children with fever at various time points}

\section{4 hours}

We pooled data from two trials for this outcome (71 randomised children, 41 (58\%) included in analysis) (Hay 2009; Little 2013). No difference was observed in the proportion of children with fever at 24 hours between those treated with ibuprofen and paracetamol versus paracetamol alone ( $50 \%$ versus $29 \%$, RR $1.48,95 \% \mathrm{Cl} 0.73$ to 2.99; $\mathrm{I}^{2}$ statistic $=0 \%$, fixed-effect model) (Analysis 4.11). Subgroup and sensitivity analyses were deemed not to be useful because of the low number of trials and included children.

\section{Quality of evidence}

The evidence for this outcome was of very low quality; we downgraded it from high to very low quality due to study limitations and imprecise effect estimate (very small sample size).

\section{8 to 72 hours}

We pooled data from two trials for this outcome (71 randomised children, 41 (58\%) included in analysis) (Hay 2009; Little 2013). No difference was observed in the proportion of children with fever at 48 to 72 hours between those treated with ibuprofen and paracetamol versus paracetamol alone ( $29 \%$ versus $12 \%$, RR 2.13 , $95 \% \mathrm{Cl} 0.60$ to $7.60 ; \mathrm{I}^{2}$ statistic $=4 \%$, fixed-effect model) (Analysis 4.12). Subgroup and sensitivity analyses were deemed not to be useful because of the low number of trials.

\section{Quality of evidence}

The evidence for this outcome was very low quality; we downgraded it from high to very low quality due to study limitations and imprecise effect estimate (very small sample size).

\section{4 to 7 days}

We pooled data from two trials for this outcome (71 randomised children, 41 (58\%) included in analysis) (Hay 2009; Little 2013). None of the participants in either group had fever at four to seven days (Analysis 4.13). Subgroup and sensitivity analyses were deemed not to be useful because of the low number of trials and included children.

\section{Quality of evidence}

The evidence for this outcome was very low quality; we downgraded it from high to very low quality due to study limitations and imprecise effect estimate (very small sample size).

\section{Proportion of children with re-consultations}

We included data from one trial (56 randomised children, 56 (100\%) included in analysis) (Little 2013). No difference was observed in the proportion of children with re-consultations at day 28 between those treated with ibuprofen and paracetamol versus paracetamol alone (66\% versus $81 \%$, RR $0.80,95 \% \mathrm{Cl} 0.58$ to 1.11 ) (Analysis 4.14 ).

\section{Quality of evidence}

The evidence for this outcome was very low quality; we downgraded it from high to very low quality due to study limitations and imprecise effect estimate (very small sample size).

\section{Proportion of children with (delayed) antibiotic prescriptions}

We included data from one trial (56 randomised children, 56 (100\%) included in analysis) (Little 2013). No difference was observed in

Paracetamol (acetaminophen) or non-steroidal anti-inflammatory drugs, alone or combined, for pain relief in acute otitis media in 
the proportion of children with delayed antibiotics between those treated with ibuprofen and paracetamol versus paracetamol alone (52\% versus $41 \%$, RR $1.27,95 \% \mathrm{Cl} 0.71$ to 2.26 ) (Analysis 4.15).

\section{Quality of evidence}

The evidence for this outcome was very low quality; we downgraded it from high to very low quality due to study limitations and imprecise effect estimate (very small sample size).

\section{Total days lost from nursery or school for children because of AOM}

None of the included trials reported on this pre-specified secondary outcome.

\section{Total days lost from work or education for parents and carers because of their child's AOM}

None of the included trials reported on this pre-specified secondary outcome.

\section{Serious complications}

We pooled data from two trials for this outcome (71 randomised children, 71 (100\%) included in analysis) (Hay 2009; Little 2013). No serious complications related to AOM were reported in either of the trials (Analysis 4.16). Subgroup and sensitivity analyses were deemed not to be useful because of the low number of trials and included children.

\section{Quality of evidence}

The evidence for this outcome was very low quality; we downgraded it from high to very low quality due to study limitations and imprecise effect estimate (small sample size and infrequent occurrence of the outcome).

\section{DISCUSSION}

\section{Summary of main results}

Current evidence on the effectiveness of paracetamol or NSAIDs, alone or combined, in relieving pain in children with AOM is limited.

We included three RCTs (327 children) with low to moderate risk of bias. One RCT compared paracetamol versus ibuprofen versus placebo in 219 children with AOM. In this trial, children received concurrent antibiotic therapy and those with fever $>39^{\circ} \mathrm{C}$ could have received paracetamol (30 $\mathrm{mg}$ to $60 \mathrm{mg}$ ) in addition to the studied treatments. Authors of two RCTs comparing paracetamol versus ibuprofen versus paracetamol and ibuprofen in children with fever and patients with respiratory tract infections provided crude subgroup data on children with AOM (26 and 82 children, respectively).

We found low quality evidence, derived from one trial, that both paracetamol and ibuprofen as monotherapies were more effective than placebo in relieving pain at 48 hours (paracetamol versus placebo: proportion of children with pain $10 \%$ versus $25 \%$, NNTB 7 ; ibuprofen versus placebo: proportion of children with pain $7 \%$ versus $25 \%$, NNTB 6).

Adverse events did not significantly differ between children treated with either paracetamol, ibuprofen or placebo. However, this finding should be interpreted with caution because it occurred infrequently and limited numbers of participants' data were available for analysis.

We found insufficient evidence of a difference between ibuprofen and paracetamol in relieving short-term ear pain.

We could not draw any firm conclusions on the effectiveness of ibuprofen plus paracetamol versus paracetamol alone in relieving ear pain in children with $\mathrm{AOM}$ mainly because of the very limited participants' data available for analysis.

\section{Overall completeness and applicability of evidence}

We included one trial comparing the effectiveness of paracetamol, ibuprofen and placebo in children with AOM as diagnosed by otoscopy (Bertin 1996). All trial participants, however, received cotreatment with antibiotics (cefaclor 15 to $30 \mathrm{mg} / \mathrm{kg}$ twice daily for 7 days) which is no longer routinely recommended for use in the management of children with AOM. Although oral antibiotics have only marginal beneficial effect in relieving ear pain in children with AOM (Venekamp 2015), co-treatment with antibiotics may potentially have influenced the trial findings.

For the other included trials (Hay 2009; Little 2013), we included subgroup data from children with fever and patients with respiratory tract infections. In these trials, AOM was diagnosed either by the GP or research nurse without further specification of diagnostic criteria applied.

Furthermore, the dosage of paracetamol used in the double-blind randomised trial comparing paracetamol versus ibuprofen versus placebo was relatively low (10 mg/kg 3 times daily) (Bertin 1996). This may have underestimated the effect of paracetamol in this trial. In the same trial (Bertin 1996), children with fever $>39^{\circ} \mathrm{C}$ could be given paracetamol ( $30 \mathrm{mg}$ to $60 \mathrm{mg}$ ) in addition to the studied treatments which may have substantially influenced trial findings. As such, the overall degree of completeness and applicability of evidence is low.

\section{Quality of the evidence}

The quality of the evidence for primary outcomes looking at effectiveness in the trial comparing paracetamol versus placebo and ibuprofen versus placebo was low, whereas the quality of evidence for adverse events and secondary effectiveness outcomes was very low.

The quality of the evidence for primary outcomes looking at effectiveness in the trials comparing ibuprofen versus paracetamol varied from low to very low quality, whereas the quality of evidence for adverse events and secondary effectiveness outcomes was mostly very low.

The quality of evidence for all outcomes in the trials comparing ibuprofen plus paracetamol versus paracetamol alone was very low.

\section{Potential biases in the review process}

We used a broad search strategy (not only including otitis media but also upper respiratory tract infection as search terms) without language or publication restrictions. For feasibility purposes we did not include fever in our search strategy, but we systematically screened reference lists of all relevant reviews on the effectiveness of paracetamol and/or NSAIDs for children with fever including

Paracetamol (acetaminophen) or non-steroidal anti-inflammatory drugs, alone or combined, for pain relief in acute otitis media in 
relevant Cochrane reviews (Meremikwu 2005; Wong 2013). After screening reference lists of these reviews, we found three potentially relevant trials that were not retrieved from our database searches (Hay 2009; Sarrell 2006; McIntyre 1996). We therefore feel confident that our review includes all relevant trials.

We were unable to retrieve AOM subgroup data from one potentially relevant trial (Sarrell 2006). However, it is unlikely these subgroup data would have a major impact on our review findings.

\section{Agreements and disagreements with other studies or reviews}

No previous review has been undertaken to assess the effectiveness of paracetamol or NSAIDs, alone or combined, in children with AOM. Previous Cochrane reviews on paracetamol or NSAIDs (or both) focused either on children with fever due to infectious diseases (Meremikwu 2005; Wong 2013), or included both children and adults with the common cold (Kim 2013). For children with fever, the reviews found only few trials comparing paracetamol against placebo (Meremikwu 2005), some evidence that both alternating and combined antipyretic therapy may be more effective at reducing temperatures than monotherapy alone and inconclusive evidence for measures of child discomfort (Wong 2013). For the common cold, the review concluded that "NSAIDs are somewhat effective in relieving discomfort caused by a cold but there is no clear evidence of their effect in easing respiratory symptoms" (Kim 2013).

\section{AUTHORS' CONCLUSIONS}

\section{Implications for practice}

Current evidence on the effectiveness of paracetamol or NSAIDs, alone or combined, in relieving pain in children with AOM is limited.

Data from one trial indicated that both paracetamol and ibuprofen as monotherapies were more effective than placebo in relieving ear pain at 48 hours in children with AOM. However, quality of evidence was judged as low due to study limitations and questions about the applicability of evidence.

Low to very low quality evidence suggested no difference between ibuprofen and paracetamol in relieving short-term ear pain in children with AOM. However, these findings should be interpreted very carefully since study limitations, very small sample size and questions about applicability of evidence, substantially affected our confidence in the results.

Current available evidence on the effectiveness of ibuprofen plus paracetamol versus paracetamol alone is insufficient to draw any firm conclusions.

\section{Implications for research}

Despite explicit guideline recommendations on the use of analgesics in children with AOM (Lieberthal 2013), analgesics are infrequently recommended to parents of children with AOM in daily practice (Pulkki 2006). Moreover, semi structured interviews with Australian parents of children who had recently visited their GP with $A O M$ revealed that parents considered analgesics insufficient as stand-alone treatment (Hansen 2015). Increasing parental knowledge and physicians' adherence to guidelines on the use of analgesics in childhood AOM seems warranted since suboptimal management of ear pain may lead to unnecessary discomfort of the child, sleepless nights, and days off work for parents, and preventable doctor re-consultations because of persisting AOM symptoms. RCTs assessing the effectiveness of interventions aimed at both physicians and parents involved in the care of children with AOM are needed to evaluate whether optimised pain management (paracetamol at fixed time intervals in an appropriate dose instead of as required, and ibuprofen as rescue medication) provides any benefit over care as usual in relieving AOM symptoms and reducing re-consultations and (delayed) antibiotic prescriptions.

Further RCTs are also needed to assess the effectiveness of ibuprofen as adjunct to paracetamol versus paracetamol alone and to establish whether other analgesics such as anaesthetic eardrops are beneficial in relieving ear pain in children with AOM.

\section{ACKNOWLEDGEMENTS}

We gratefully acknowledge the assistance received from the staff at the Cochrane Acute Respiratory Infections editorial base and thank Sarah Thorning for designing the initial search strategy and Justin Clark for his support with the updated search strategy and searches. We also thank the following people for commenting on the draft review: Sallie Bernard, Tam Watson, Sebastian Straube, Sheena Derry, Conor Teljeur, and Tom Fahey. 


\section{R E F E R E N C E S}

\section{References to studies included in this review}

\section{Bertin 1996 \{published data only\}}

Bertin L, Pons G, d'Athis P, Duhamel JF, Maudelonde C, Lasfargues $\mathrm{G}$. A randomized, double-blind, multicentre controlled trial of ibuprofen versus acetaminophen and placebo for symptoms of acute otitis media in children. Fundamental \& Clinical Pharmacology 1996;10(4):387-92.

Hay 2009 \{published data only\}

* Hay AD, Redmond NM, Costelloe C, Montgomery AA, Fletcher M, Hollinghurst S, et al. Paracetamol and ibuprofen for the treatment of fever in children: the PITCH randomised controlled trial. Health Technology Assessment 2009;13(27):iii-iv, ix-x, 1-163.

Hollinghurst S, Redmond N, Costelloe C, Montgomery A, Fletcher M, Peters TJ, et al. Paracetamol plus ibuprofen for the treatment of fever in children (PITCH): economic evaluation of a randomised controlled trial. BMJ 2008;337:a1490.

\section{Little 2013 \{published data only\}}

Little P, Moore M, Kelly J, Williamson I, Leydon G, McDermott L, et al. Ibuprofen, paracetamol, and steam for patients with respiratory tract infections in primary care: pragmatic randomised factorial trial. BMJ 2013;347:f6041.

\section{References to studies excluded from this review}

\section{Azuma 2010 \{published data only\}}

Azuma A, Kudoh S, Nakashima M, Nagatake T. A double-blind study of zaltoprofen for the treatment of upper respiratory tract infection. Pharmacology 2010;85(1):41-7.

\section{Campos 1992 \{published data only\}}

Campos L, Díaz Gómez M, Ondiviela R, Masorra F. Naproxen sodium in the treatment of otitis [Spanish]. Atencion Primaria 1992;9(6):314, 316-7.

\section{Cappella 1993 \{published data only\}}

Cappella L, Guerra A, Laudizi L, Cavazzuti GB. Efficacy and tolerability of nimesulide and lysine-acetylsalicylate in the treatment of paediatric acute upper respiratory tract inflammation. Drugs 1993;46(Suppl 1):222-5.

\section{Caretti 1986 \{published data only\}}

Caretti JP. Single-blind study of an anti-inflammatory agent v. paracetamol in acute infections of the oral cavity and upper respiratory tract. Clinical Trials Journal 1986;23(6):372-81.

\section{Dasgupta 2002 \{published data only\}}

Dasgupta KS, Deshpande AS, Vedi JN, Patel S. Evaluation of efficacy of nizer versus nimesulide tablets in otitis media. Journal of the Indian Medical Association 2002;100(10):619.

\section{Eccles 2006 \{published data only\}}

Eccles R, Jawad M, Jawad S, Ridge D, North M, Jones E, et al. Efficacy of a paracetamol-pseudoephedrine combination for treatment of nasal congestion and pain-related symptoms in upper respiratory tract infection. Current Medical Research and Opinion 2006;22(12):2411-8.

Fort 2000 \{published data only\}

Fort G. Analgesia in otorhinolaryngological diseases: Lysine clonixinate versus ibuprofen. Prensa Medica Argentina 2000;87(4):409-18.

\section{Gonzales 1989 \{published data only\}}

Lozano Gonzalez CH, Flores Tamez, ME. Clinical assessment of the antipyretic and analgesic effectiveness, as well as the rectal tolerance, of a new association: Naproxen sodium + paracetamol, compared to paracetamol alone, in the treatment of respiratory tract infections. Compendium de Investigaciones Clinicas Latinoamericanas 1989;9(1):27-31.

Kim CK 2013 \{published data only\}

Kim CK, Callaway Z, Choung JT, Yu JH, Shim KS, Kwon EM. Dexibuprofen for fever in children with upper respiratory tract infection. Pediatrics International 2013;55(4):443-9.

McIntyre 1996 \{published data only\} Mclntyre J, Hull D. Comparing efficacy and tolerability of ibuprofen and paracetamol in fever. Archives of Disease in Childhood 1996;74(2):164

\section{Metta 2000 \{published data only\}}

Metta H, Haidar N, Mendoza JJ, Webb E, Azcarate V, Rocatti C, et al. Lysine clonixinate vs. ibuprofen in otorhinolaryngology. Prensa Médica Argentina 2000;87(9):906-18.

Milvio 1984 \{published data only\}

Milvio C. Nimesulide for the treatment of painful inflammatory process in the ear, nose and throat areas: a double-blind controlled study with benzydamine. Journal of International Medical Research 1984;12(6):327-32.

Motoichi 1997 \{published data only\}

Motoichi T, Takashi F, Junzaburo K, Riichiro M, Shyoji K, Takuzo S. Phase III study of anti-inflammatory agent, 2phenyl-5-benzothiazoleacetic acid (K-308) - a double blind controlled trial on acute upper respiratory infections [Japanese]. Rinsho Hyoka (Clinical Evaluation) 1997;5(1):7-21.

Nouri 1984 \{published data only\}

Nouri, ME. Nimesulide for treatment of acute inflammation of the upper respiratory tract. Clinical Therapeutics 1984;6(2):142-50

Passali 2001 \{published data only\} Passali D, Balli R, Scotti A, Oldani V. Controlled, double-blind, randomized comparison of nimesulide $ß$-cyclodextrin and morniflumate in acute otitis. Current Therapeutic Research 2001;62(2):153-66.

\section{Polidori 1993 \{published data only\}}

Polidori G, Titti G, Pieragostini P, Comito A, Scaricabarozzi I. A comparison of nimesulide and paracetamol in the treatment

Paracetamol (acetaminophen) or non-steroidal anti-inflammatory drugs, alone or combined, for pain relief in acute otitis media in 
of fever due to inflammatory diseases of the upper respiratory tract in children. Drugs 1993;46(Suppl 1):231-3.

\section{Ryan 1987 \{published data only\}}

Ryan PB, Rush DR, Nicholas TA, Graham DG. A double-blind comparison of fenoprofen calcium, acetaminophen, and placebo in the palliative treatment of common nonbacterial upper respiratory infections. Current Therapeutic Research 1987;41(1):17-23.

\section{Sarrell 2006 \{published data only\}}

Sarrell EM, Wielunsky E, Cohen HA. Antipyretic treatment in young children with fever: acetaminophen, ibuprofen, or both alternating in a randomized, double-blind study. Archives of Pediatrics and Adolescent Medicine 2006;160(2):197-202.

\section{Schuetz 2014 \{published data only\}}

Schuetz P. Randomised controlled trial: Neither ibuprofen nor steam improves symptom control compared with paracetamo in patients with acute respiratory tract infections in primary care. Evidence-Based Medicine 2014;19(3):102.

\section{Siegel 2003 \{published data only\}}

Siegel RM, Kiely M, Bien JP, Joseph EC, Davis JB, Mendel SG. Treatment of otitis media with observation and a safety-net antibiotic prescription. Pediatrics 2003;112(3 Pt 1):527-31.

\section{Siquet 1983 \{published data only\}}

Siquet J. Fentiazac suspension in the treatment of acute inflammation of the upper respiratory tract in children. Clinical Trials Journal 1983;20(6):305-12.

\section{Stipon 1983 \{published data only\}}

Stipon, JP, Le Bihan Y, de Rotalier P. Evaluation of the analgesic effect of UP 341-01 in patients presenting with acute pain in ORL [French]. Semaine des Hopitaux 1983;59(39):2735-8.

\section{Weippl 1985 \{published data only\}}

Weippl G, Michos N, Stocker H. Clinical experience and results of treatment with suprofen in pediatrics. 4th communication: Assessment of pain in babies and infants/Analgesic effect of suprofen syrup in otitis media. Arzneimittel-Forschung 1985;35(11):1732-4.

\section{Yoon 2008 \{published data only\}}

Yoon JS, Jeong DC, Oh JW, Lee KY, Lee HS, Koh YY, et al. The effects and safety of dexibuprofen compared with ibuprofen in febrile children caused by upper respiratory tract infection. British Journal of Clinical Pharmacology 2008;66(6):854-60.

\section{References to ongoing studies}

PIM-POM study 2014 \{published data only\}

Pain Intensity Monitoring in Paediatric Otitis Media (PIM-POM) study. Ongoing study January 2015.

\section{Additional references}

\section{Ashworth 2005}

Ashworth M, Charlton J, Ballard K, Latinovic R, Gulliford M. Variations in antibiotic prescribing and consultation rates for acute respiratory infection in UK general practices 1995-2000. British Journal of General Practice 2005;55(517):603-8.

\section{Atkins 2004}

Atkins D, Best D, Briss PA, Eccles M, Falck-Ytter Y, Flottorp S, et al. GRADE Working Group. Grading quality of evidence and strength of recommendations. BMJ 2004;328(7454):1490.

\section{Barber 2014}

Barber C, Ille S, Vergison A, Coates H. Acute otitis media in young children - what do parents say?. International Journal of Pediatric Otorhinolaryngology 2014;78(2):300-6.

\section{Bluestone 2007}

Bluestone C, Klein J. Definitions, terminology, and classification. In: Bluestone CD, Klein JO editor(s). Otitis Media in Infants and Children. 4th Edition. Hamilton, Canada: BC Decker, 2007:1-19.

\section{Bruno 2014}

Bruno A, Tacconelli S, Patrignani P. Variability in the response to non-steroidal anti-inflammatory drugs: mechanisms and perspectives. Basic and Clinical Pharmacology and Toxicology 2014;114(1):56-63.

\section{CEDAR}

CEDAR trial authors. Children's drops for ear pain in acute otitis media: the CEDAR randomised controlled trial. http:// www.isrctn.com/ISRCTN09599764.

\section{Foxlee 2006}

Foxlee R, Johansson A, Wejfalk J, Dawkins J, Dooley L, Del Mar C. Topical analgesia for acute otitis media. Cochrane Database of Systematic Reviews 2006, Issue 3. [DOI: 10.1002/14651858.CD005657]

\section{GRADEproGDT 2015 [Computer program]}

GRADEproGDT. GRADEpro Guideline Development Tool. www.guidelinedevelopment.org. Hamilton: McMaster University (developed by Evidence Prime, Inc.), 2015.

\section{Greenberg 2003}

Greenberg D, Bilenko N, Liss Z, Shagan T, Zamir O, Dagan R. The burden of acute otitis media on the patient and the family. European Journal of Pediatrics 2003;162(9):576-81.

\section{Grijalva 2009}

Grijalva CG, Nuorti JP, Griffin MR. Antibiotic prescription rates for acute respiratory tract infections in US ambulatory settings. JAMA 2009;302(7):758-66.

\section{Hansen 2015}

Hansen MP, Howlett J, Del Mar C, Hoffmann TC. Parents' beliefs and knowledge about the management of acute otitis media: a qualitative study. BMC Family Practice 2015;16:82. 


\section{Higgins 2003}

Higgins JPT, Thompson SG, Deeks JJ, Altman DG. Measuring inconsistency in meta-analysis. BMJ 2003;327(7414):557-60.

\section{Higgins 2011}

Higgins JPT, Green S (editors). Cochrane Handbook for Systematic Reviews of Interventions Version 5.1.0 [updated March 2011]. The Cochrane Collaboration, 2011. Available from www.cochrane-handbook.org.

\section{Kim 2013}

Kim SY, Chang YJ, Cho HM, Hwang YW, Moon YS. Nonsteroidal anti-inflammatory drugs for the common cold. Cochrane Database of Systematic Reviews 2013, Issue 6. [DOI: 10.1002/14651858.CD006362.pub3]

\section{Lieberthal 2013}

Lieberthal AS, Carroll AE, Chonmaitree T, Ganiats TG, Hoberman A, Jackson MA, et al. The diagnosis and management of acute otitis media. Pediatrics 2013;131(3):e964-e99.

\section{Liese 2014}

Liese JG, Silfverdal SA, Ciaquinto C, Carmona A, Larcombe JH, Garcia-Sicilia J, et al. Incidence and clinical presentation of acute otitis media in children aged $<6$ years in European medical practices. Epidemiology and Infection 2014;142(8):1778-88.

\section{Marzuillo 2014}

Marzuillo P, Guarino S, Barbi E. Paracetamol: a focus for the general pediatrician. European Journal of Pediatrics 2014;173(4):415-25.

\section{Meremikwu 2005}

Meremikwu M, Marson AG. Paracetamol versus placebo or physical methods for treating fever in children. Cochrane Database of Systematic Reviews 2005, Issue 1. [DOI: 10.1002/14651858.CD003676]

\section{Moore 2012}

Moore RA, Straube S, Eccleston C, Derry S, Aldington D, Wiffen P, et al. Estimate at your peril: imputation methods for patient withdrawal can bias efficacy outcomes in chronic pain trials using responder analyses. Pain 2012;153(2):265-8.

\section{Pulkki 2006}

Pulkki J, Huikko S, Rautakorpi U-M, Honkanen P, Klaukka T, Mäkelä M, et al. Management of pain in acute otitis media in Finnish primary care. Scandinavian Journal of Infectious Diseases 2006;38(4):265-7.

\section{Rainsford 2009}

Rainsford KD. Ibuprofen: pharmacology, efficacy and safety. Inflammopharmacology 2009;17(6):275-342.

\section{RevMan 2014 [Computer program]}

Nordic Cochrane Centre, The Cochrane Collaboration. Review Manager 5 (RevMan 5) . 2014.. Version Version 5.3. Copenhagen: Nordic Cochrane Centre, The Cochrane Collaboration, 2014.

\section{Rovers 2006}

Rovers MM, Glasziou P, Appelman CL, Burke P, McCormick DP, Damoiseaux RA, et al. Antibiotics for acute otitis media: a meta-analysis with individual patient data. Lancet 2006;368(9545):1429-35.

\section{Schechter 2003}

Schechter NL. Management of common pain problems in the primary care pediatric setting. In: Schechter NL, Berde CB, Yaster M editor(s). Pain in Infants and Adolescents. 2nd Edition. Philadelphia, PA: Lippincott Williams \& Wilkins, 2003:693-706.

\section{Sordillo 2015}

Sordillo JE, Scirica CV, Rifas-Shiman SL, Gillman MW, Bunyavanich S, Camargo CA Jr, et al. Prenatal and infant exposure to acetaminophen and ibuprofen and the risk for wheeze and asthma in children. Journal of Allergy and Clinical Immunology 2015;135(2):441-8. [DOI: 10.1016/ j.jaci.2014.07.065]

\section{Southey 2009}

Southey ER, Soares-Weiser K, Kleijnen J. Systematic review and meta-analysis of the clinical safety and tolerability of ibuprofen compared with paracetamol in paediatric pain and fever. Current Medical Research and Opinion 2009;25(9):2207-22.

\section{Teele 1989}

Teele DW, Klein JO, Rosner B. Epidemiology of otitis media during the first seven years of life in children in greater Boston: a prospective, cohort study. Journal of Infectious Diseases 1989;160(1):83-94.

\section{van den Anker 2013}

van den Anker JN. Optimising the management of fever and pain in children. International Journal of Clinical Practice. Supplement 2013;178:26-32.

\section{Venekamp 2015}

Venekamp RP, Sanders SL, Glasziou PP, Del Mar CB, Rovers MM. Antibiotics for acute otitis media in children. Cochrane Database of Systematic Reviews 2015, Issue 6. [DOI: 10.1002/14651858.CD000219.pub4]

\section{Wong 2013}

Wong T, Stang AS, Ganshorn H, Hartling L, Maconochie IK, Thomsen AM, et al. Combined and alternating paracetamol and ibuprofen therapy for febrile children. Cochrane Database of Systematic Reviews 2013, Issue 10. [DOI: 10.1002/14651858.CD009572.pub2]

\section{References to other published versions of this review \\ Sjoukes 2015}

Sjoukes A, Venekamp RP, van de Pol AC, Schilder AGM, Damoiseaux RAMJ. Paracetamol (acetaminophen) or nonsteroidal anti-inflammatory drugs, alone or combined for pain relief in acute otitis media in children. Cochrane Database of Systematic Reviews 2015, Issue 2. [DOI: 10.1002/14651858.CD011534] 
* Indicates the major publication for the study

\section{CHARACTERISTICS OF STUDIES}

Characteristics of included studies [ordered by study ID]

Bertin 1996

\begin{tabular}{ll}
\hline Methods & Allocation: randomised \\
& Design: 3 -arm, parallel group, double-blind design \\
\hline Number: 219 children (219 included in analysis) \\
Age: 1 year to 6.75 years \\
Gender: 96 female (44\%), 123 male (56\%) \\
Setting: children seen as outpatients in four centres \\
Inclusion criteria: the diagnosis of AOM was based on the aspect of the tympanic membrane using a \\
semi-quantitative scale (“tympanic score") from 0 to 6. The tympanic score had to be $\geq 3$ for at least one \\
ear for patients to be eligible \\
Exclusion criteria: cardiac; hepatic or renal disorders; gastroduodenal disease; known hypersensi- \\
tivity to NSAIDs and penicillins or receiving either antibiotic; analgesic; diuretic or anti-inflammatory \\
drugs within one week before the study. Patients with AOM requiring myringotomy, or with chronic oti- \\
tis were not eligible
\end{tabular}

Interventions Intervention group 1: NSAIDs (ibuprofen) $10 \mathrm{mg} / \mathrm{kg}$ orally, 3 times daily, for 48 hours. $\mathrm{N}=71$

Intervention group 2: PCM $10 \mathrm{mg} / \mathrm{kg}$ orally, 3 times daily, for 48 hours. $\mathrm{N}=73$

Comparator group: placebo orally, 3 times daily, for 48 hours. $\mathrm{N}=75$

Use of additional interventions: All children received antibiotics: Cefaclor $15-30 \mathrm{mg} / \mathrm{kg}$ orally, two times daily, for 7 days. In case of fever $\geq 39^{\circ} \mathrm{C}$, children could be given acetaminophen ( $30 \mathrm{mg}$ to $60 \mathrm{mg} /$ $\mathrm{kg} /$ day) additionally to the studied treatment. In case of fever $\geq 39^{\circ} \mathrm{C}$ external cooling techniques (e.g. sponging) were allowed

Outcomes

Primary outcome: aspect of the tympanic membrane, as described with the tympanic score

Secondary outcomes: ear pain, rectal temperature, quality of life (based on appetite, sleep and playing activity), tolerance

\section{Outcome assessment:}

Evaluation of ear pain: dichotomous ( $0=$ no pain; pain in the ear $=1)$

Fever (rectal temperature): $0=<37^{\circ} \mathrm{C}, 1=37.1^{\circ} \mathrm{C}$ to $38.4^{\circ} \mathrm{C}$, and $2=>38.5^{\circ} \mathrm{C}$

Tolerance: presence or absence of nausea, vomiting, abdominal pain and cutaneous rash

\begin{tabular}{ll}
\hline Funding sources & All treatments were supplied by Ethypharm \\
\hline Declaration of interest & No information provided \\
\hline Notes & Participants lost to follow-up total: according to tables, no children were lost to follow-up \\
& $\begin{array}{l}\text { Paracetamol has been prescribed } 10 \mathrm{mg} / \mathrm{kg}, \text { three times daily. Nowadays this would be considered as a } \\
\text { suboptimal dosage }\end{array}$ \\
\hline
\end{tabular}

\section{Risk of bias}

Paracetamol (acetaminophen) or non-steroidal anti-inflammatory drugs, alone or combined, for pain relief in acute otitis media in 
Bertin 1996 (Continued)

\begin{tabular}{|c|c|c|}
\hline Bias & Authors' judgement & Support for judgement \\
\hline $\begin{array}{l}\text { Random sequence genera- } \\
\text { tion (selection bias) }\end{array}$ & Low risk & Patients were randomised using a computer-generated list \\
\hline $\begin{array}{l}\text { Allocation concealment } \\
\text { (selection bias) }\end{array}$ & Unclear risk & Method not described \\
\hline $\begin{array}{l}\text { Blinding of participants } \\
\text { and personnel (perfor- } \\
\text { mance bias) } \\
\text { All outcomes }\end{array}$ & Low risk & $\begin{array}{l}\text { Quote: "Participants were given ibuprofen microgranules (in packets of } 100 \text { or } \\
200 \mathrm{mg} \text { ), or identically looking acetaminophen and placebo microgranules." }\end{array}$ \\
\hline $\begin{array}{l}\text { Blinding of outcome as- } \\
\text { sessment (detection bias) } \\
\text { All outcomes }\end{array}$ & Low risk & $\begin{array}{l}\text { Double-blind; Subjective outcomes relevant for this review were assessed by } \\
\text { parents/children. Blinding of participants was adequate }\end{array}$ \\
\hline $\begin{array}{l}\text { Incomplete outcome data } \\
\text { (attrition bias) } \\
\text { All outcomes }\end{array}$ & Low risk & $\begin{array}{l}\text { Loss to follow-up has not been explicitly described. However, following infor- } \\
\text { mation provided in the tables, no children were lost to follow-up }\end{array}$ \\
\hline $\begin{array}{l}\text { Selective reporting (re- } \\
\text { porting bias) }\end{array}$ & Unclear risk & $\begin{array}{l}\text { No protocol available; insufficient information to permit a judgement of low or } \\
\text { high risk. Both positive and negative outcomes, however, have been reported } \\
\text { in the paper }\end{array}$ \\
\hline Other bias & Unclear risk & $\begin{array}{l}\text { Baseline characteristics: balanced } \\
\text { All children were included in analysis; unclear whether ITT analysis was per- } \\
\text { formed } \\
\text { Formal sample size calculations were performed } \\
\text { Compliance of treatment: no information provided }\end{array}$ \\
\hline
\end{tabular}

Hay 2009

Allocation: randomised
Design: three-arm, parallel group, double-blind design
Number: 156 children, 26 children diagnosed with AOM
Age: between 0.5 to 6 years
Gender: 68 female (44\%), 88 male (56\%)
Setting: community, primary care (including out-of-hours services) and secondary care (emergency de-
partment of a children's hospital)
Inclusion criteria: children aged between 6 months and 6 years with fever $\geq 37.8^{\circ} \mathrm{C}$ and $\leq 41^{\circ} \mathrm{C}$ due to
an illness that could be managed at home
Exclusion criteria: previous participation in the PITCH trial or in another drug trial in the previous 30
days; weight 7 kg or less; illness requiring hospital admission; epilepsy or other chronic neurological
disease; allergy or intolerance to the study medication; known study medicine contraindication; skin
conditions precluding the use of adhesive tape; peptic ulceration or bleeding; known diagnosis or any
ongoing investigating into suspected cardiac disease pulmonary disease, liver disease, kidney disease;
and parents/legal guardians who could not read or write English

Interventions

Intervention group 1: NSAIDs (ibuprofen) $10 \mathrm{mg} / \mathrm{kg}$ orally, repeated every 6-8 hours (max 3 doses in 24 hours), for 48 hours. $\mathrm{N}=11 / 52$ diagnosed with AOM

Paracetamol (acetaminophen) or non-steroidal anti-inflammatory drugs, alone or combined, for pain relief in acute otitis media in 
Hay 2009 (Continued)

Intervention group 2: PCM $15 \mathrm{mg} / \mathrm{kg}$ orally repeated every 4 to 6 hours (max 4 doses in 24 hours), for 48 hours. $N=7 / 52$ diagnosed with $A O M$

Comparator group: PCM + NSAIDs combined. Ibuprofen $10 \mathrm{mg} / \mathrm{kg}$ orally, repeated every 6 to 8 hours, and PCM $15 \mathrm{mg} / \mathrm{kg}$ orally repeated every 4 to 6 hours, for 48 hours. $\mathrm{N}=8 / 52$ diagnosed with AOM

Use of additional interventions: All children received a standardised advice sheet regarding fever in children, with the advice to: 1) use the study medicine as instructed; 2) keep the child lightly dressed in a room with normal temperature; and 3 ) give cool drinks

Outcomes

Primary outcomes: time without fever within the first four hours and the proportion of children scoring no fever-associated discomfort at 48 hours

Secondary outcomes: time until first fever clearance, time without fever within the first 24 hours, activity, appetite, sleep, adverse effects and costs (including lost days of work for parents and daycare/school for children)

\section{Outcome assessment:}

Time without fever: number of minutes in the first 24 hours using a continuous axillary thermometer. Temperature was also assessed using an axillary digital thermometer at 4, 16, 24, 48 hours at day 5.

Fever-associated discomfort at 48 hours: validated comfort scale (no comfort; not quite normal; some pain/distress; crying/very distressed) completed by parents in a symptom diary at $0,2,4,16,24,32,40$ and 48 hours and day 5

Time until first fever clearance: time in minutes until the temperature first fell below the fever threshold of $37.2^{\circ} \mathrm{C}$ using a continuous axillary thermometer

Adverse effects: measured at 24 hours, 48 hours and at day 5

Lost days of work for parents and daycare/school for children: a research nurse visited the child at baseline, 24-hours, 48-hours and performed a telephone call at day 5

The number of children treated with antibiotics were recorded

The number of return visits were recorded as part of the economic evaluation

Funding sources

The study was funded by the NIHR HTA programme. The active drugs and matched placebos were purchased from and provided by Pfizer and DHP Investigational Medicinal Products.

Declaration of interest

Quote: "The views and opinions expressed in the paper did not necessarily reflect those of the NIHR HTA, NCCRCD, or Department of Health." Pfizer and DHP Investigational Medicinal Products had no role in the design, conduct, analysis, or reporting of the trial

Notes

Participants lost to follow-up total: $3 / 156(2 \%)$ for time without fever within the first four hours and $0 / 156$ for fever-associated discomfort at 48 hours

Participants lost to follow-up NSAID group: 1/52 (2\%). No reasons were provided

Participants lost to follow-up PCM group: 0/52 children

Participants lost to follow-up NSAID + PCM group: 2/52 children (4\%). No reasons were provided

The diagnose AOM was made by the GP. No further details were provided on the diagnostic criteria

\section{Risk of bias}

\begin{tabular}{lll}
\hline Bias & Authors' judgement & Support for judgement \\
\hline $\begin{array}{ll}\text { Random sequence genera- } \\
\text { tion (selection bias) }\end{array}$ & Low risk & $\begin{array}{l}\text { Quotes: "The randomisation sequence was generated via a remote, automat- } \\
\text { ed telephone service provided by the Health Services Research Unit at the Uni- }\end{array}$
\end{tabular}

Paracetamol (acetaminophen) or non-steroidal anti-inflammatory drugs, alone or combined, for pain relief in acute otitis media in 
Hay 2009 (Continued)

versity of Aberdeen." "Eligible children were randomised with a block size of six and stratified according to five minimisation variables, ..."

\begin{tabular}{ll}
\hline $\begin{array}{l}\text { Allocation concealment } \\
\text { (selection bias) }\end{array}$ & Quote: "The study medicines were provided by Pfizer Ltd and sent to DHP Ltd, \\
& a manufacturer of clinical trials medicines. DHP was aware of the randomisa- \\
& tion procedure and the company was asked to supply the study medicines to \\
the trial fully concealed."
\end{tabular}

$\begin{array}{ll}\begin{array}{l}\text { Blinding of participants } \\ \text { and personnel (perfor- }\end{array} & \text { Quotes: "Study medicines were provided in a white cardboard pack containing } \\ \text { mance bias) } & \text { the two bottles, one of paracetamol/placebo and one of ibuprofen/placebo } \\ \text { All outcomes } & \text { suspensions. The identity of the next treatment allocation was concealed from } \\ & \text { research nurses by the fact that they carried at least one unopened box of six } \\ & \text { medicine packs during any randomisation visit." "After inputting participant } \\ \text { information required for randomisation, the research nurses were informed } & \text { which pack to give to the child." }\end{array}$

\begin{tabular}{|c|c|c|}
\hline $\begin{array}{l}\text { Blinding of outcome as- } \\
\text { sessment (detection bias) } \\
\text { All outcomes }\end{array}$ & Low risk & $\begin{array}{l}\text { Quote: "The parents, principal investigator, trial co-ordinator, research nurses } \\
\text { and project administrator were all blinded to the study medicines allocated to } \\
\text { randomised children throughout the recruitment and analysis periods." }\end{array}$ \\
\hline
\end{tabular}

\begin{tabular}{ll}
\hline $\begin{array}{l}\text { Incomplete outcome data } \\
\text { (attrition bias) }\end{array}$ & Low risk
\end{tabular}$\quad \begin{aligned} & \text { For discomfort there was no lost to follow-up, whereas } 3 \text { children (2\%) were } \\
& \text { lost to follow-up for time without fever }\end{aligned}$

All outcomes lost to follow-up for time without fever

Selective reporting (re- Low risk All outcomes have been described according to the protocol
porting bias)

\begin{tabular}{ll}
\hline Other bias & Baseline characteristics: balanced \\
& ITT analysis performed \\
& Formal sample size calculations were performed. However they did not \\
achieve their original sample size ( 831 children) & Compliance of treatment: Quote: "First, in the first 24 hours, parents admin- \\
istered the minimum intended doses of paracetamol or placebo (four doses) & to $42 \%$ to $65 \%$ of children and of ibuprofen or placebo (three doses) to $71 \%$ to \\
& $75 \%$ of children. This suggests that three times daily dosing is superior or more \\
likely to be adhered to than four times daily dosing and may have contributed & towards greater ibuprofen efficacy."
\end{tabular}

\section{Little 2013}

$\begin{array}{ll}\text { Methods } & \text { Allocation: randomised } \\ \text { Design: parallel, open } 3 \times 2 \times 2 \text { factorial trial }\end{array}$

Participants Number: 889 participants, 82 diagnosed with AOM

Age: three years and older

Gender: 540 female (61\%), 349 male (39\%)

Setting: patients presented to a GP or nurse in primary care (in total 53 GPs and practice nurses in 25 practices)

Inclusion criteria: patients aged three years and older presenting to a GP or nurse in primary care with a respiratory tract infection diagnosed by the health professional 
Little 2013 (Continued)

Exclusion criteria: asthma (unless it was not sensitive to ibuprofen or aspirin); peptic ulcer; hypersensitivity to analgesics; inability to complete outcomes; conditions requiring hospital admission; immunodeficiency; pregnancy; and breastfeeding

Intervention group 1: NSAIDs (ibuprofen). N = 26/290 diagnosed with AOM
Intervention group 2: PCM. N=27/302 diagnosed with AOM
Comparator group: PCM + NSAIDs (ibuprofen) alternating. N=29/254 diagnosed with AOM
The dose of paracetamol and ibuprofen used in this trial were the maximum recommended by the
British National Formulary (which varies by age)
Use of additional interventions: Patients were not only randomised to the three drug groups, but also
to two dosing groups and two steam groups. The dosing advice groups were to use drugs regularly four
times for at least three days or to take drugs as required. The steam advice was to inhale with steam for
at least 15 minutes (five minutes three times a day) or no steam inhalation

Outcomes Primary outcome: symptom control

Secondary outcomes: side effects (rash, diarrhoea, vomiting, abdominal pain), temperature, antibiotic use, return visits

\section{Outcome assessment:}

Symptom control: mean symptom severity at the end of each day, averaged over days two to four of a two week symptom diary using a format for rating symptoms ( $0=$ no problem, $6=$ as bad as it could be)

Side effects: such as vomiting, diarrhoea, rash or abdominal pain, reported in a two week symptom diary

Temperature: mean morning and evening temperature reading with Tempadot thermometers (orally where possible) averaged over days two to four

Antibiotic use: documented in the diary. Randomisation was stratified by antibiotic prescription strategy (immediate versus delayed)

Return visit: a return with a symptom or diagnosis of respiratory tract infection recorded with a structured pro forma by a member of the research team. Complications were defined as a new consultation documented in the notes within 28 days

Funding sources The study was funded by the National Institute for Health Research Programme Grants for Applied Research programme

Declaration of interest All authors declared none

Notes

Participants lost to follow-up total: 138/889 (16\%) for symptom severity

Participants lost to follow-up NSAID group: 43/297 (15\%)

Participants lost to follow-up PCM group: 51/305 children (17\%)

Participants lost to follow-up NSAID + PCM group: 49/287 (15\%)

The diagnose AOM was made by the GP or research nurse. No further details were provided on the diagnostic criteria

There was no advice regarding the dose of paracetamol and ibuprofen

\section{Risk of bias}


Little 2013 (Continued)

Random sequence genera- Low risk tion (selection bias)
Quotes: "A statistician independent of the study team coordinated the randomisation, .." "Patients were randomised to one of 12 advice groups"...", with computer generated random number tables to determine one of 12 advice slips contained in sealed numbered envelopes."

\begin{tabular}{ll}
\hline $\begin{array}{l}\text { Allocation concealment } \\
\text { (selection bias) }\end{array}$ & Low risk \\
& $\begin{array}{l}\text { Quote: "..the clinician took the next pack off the shelf that contained pre-ran- } \\
\text { domised advice sheets". As described above the advice slips were contained in } \\
\text { sealed numbered envelopes }\end{array}$
\end{tabular}

\begin{tabular}{|c|c|c|}
\hline $\begin{array}{l}\text { Blinding of participants } \\
\text { and personnel (perfor- } \\
\text { mance bias) } \\
\text { All outcomes }\end{array}$ & High risk & Not blinded \\
\hline
\end{tabular}

\begin{tabular}{|c|c|c|}
\hline $\begin{array}{l}\text { Blinding of outcome as- } \\
\text { sessment (detection bias) } \\
\text { All outcomes }\end{array}$ & High risk & Not blinded \\
\hline $\begin{array}{l}\text { Incomplete outcome data } \\
\text { (attrition bias) } \\
\text { All outcomes }\end{array}$ & Unclear risk & $\begin{array}{l}\text { 138/889 (16\%) for symptom severity; } \\
\text { Quote: "The characteristics of patients in whom the primary outcome was not } \\
\text { documented were similar to those followed up ..." }\end{array}$ \\
\hline $\begin{array}{l}\text { Selective reporting (re- } \\
\text { porting bias) }\end{array}$ & Low risk & All outcomes have been described according to the protocol \\
\hline Other bias & Low risk & $\begin{array}{l}\text { Baseline characteristics: balanced } \\
\text { ITT analysis with complete data (no imputation of missing data) } \\
\text { Formal sample size calculations were performed } \\
\text { Compliance of treatment: Quote: "From the main diary data for paraceta- } \\
\text { mol use, patients took a mean of } 4.2 \text { doses a day for the first three days in the } \\
\text { paracetamol group, } 3.5 \text { in the combined group, and } 0.4 \text { in the ibuprofen group. } \\
\text { For ibuprofen, patients took a mean of } 0.3 \text { doses in the paracetamol group, } 2.9 \\
\text { in the ibuprofen group, and } 2.7 \text { in the combined group. Steam inhalation was } \\
\text { reported a mean of } 1.6 \text { times a day in the steam group for days two and three } \\
\text { and } 0.1 \text { times in the no steam group. Advice to use analgesic regularly com- } \\
\text { pared with as required made little difference to the amount of analgesia used } \\
\text { for either paracetamol ( } 2.8 \text { doses } v 2.4 \text { doses) or ibuprofen ( } 2.0 \text { doses } v 1.9 \text { dos- } \\
\text { es)." }\end{array}$ \\
\hline
\end{tabular}

AOM: acute otitis media

GP: general practitioner

NSAID: non-steroidal anti-inflammatory drug

PCM: paracetamol

ITT: intention-to-treat

Characteristics of excluded studies [ordered by study ID]

\begin{tabular}{ll}
\hline Study & Reason for exclusion \\
\hline Azuma 2010 & PARTICIPANTS \\
& Adults only (no children included) \\
\hline Campos 1992 & ALLOCATION \\
& Non-randomised study \\
\hline
\end{tabular}

Paracetamol (acetaminophen) or non-steroidal anti-inflammatory drugs, alone or combined, for pain relief in acute otitis media in 


\begin{tabular}{ll}
\hline Study & Reason for exclusion \\
\hline
\end{tabular}

Trial comparing nimesulide (NSAID) versus lysine-acetyl salicylate

\section{Caretti 1986}

\section{PARTICIPANTS}

Study did not include children with AOM (only tonsillitis and pharyngitis)

\begin{tabular}{ll}
\hline Dasgupta 2002 & INTERVENTIONS \\
& Trial comparing nizer (NSAID) versus nimesulide (NSAID)
\end{tabular}

\begin{tabular}{ll}
\hline Eccles 2006 & PARTICIPANTS \\
& Adults only (no children included)
\end{tabular}

$$
\text { Fort } 2000
$$

INTERVENTIONS

Trial comparing ibuprofen (NSAID) versus Lysine clonixinate (NSAID)

\begin{tabular}{ll}
\hline Gonzales 1989 & PARTICIPANTS \\
& $\begin{array}{l}\text { Study did not include children with AOM (only tonsillitis, pharyngitis, tracheitis, bronchitis and } \\
\text { pneumonia) }\end{array}$
\end{tabular}

Kim CK 2013

\section{INTERVENTIONS}

Trial comparing dexibuprofen (NSAID) 3.5 or $7 \mathrm{mg} / \mathrm{kg}$ versus ibuprofen 5 or $10 \mathrm{mg} / \mathrm{kg}$ (NSAID)

\begin{tabular}{|c|c|}
\hline \multirow[t]{2}{*}{ McIntyre 1996} & PARTICIPANTS \\
\hline & Trial included hospitalised children \\
\hline \multirow[t]{2}{*}{ Metta 2000} & INTERVENTIONS \\
\hline & Trial comparing ibuprofen (NSAID) versus Lysine clonixinate (NSAID) \\
\hline \multirow[t]{2}{*}{ Milvio 1984} & INTERVENTIONS \\
\hline & Trial comparing nimesulide (NSAID) versus benzydamine (NSAID) \\
\hline \multirow[t]{2}{*}{ Motoichi 1997} & PARTICIPANTS \\
\hline & Adults only (no children included) \\
\hline \multirow[t]{2}{*}{ Nouri 1984} & PARTICIPANTS \\
\hline & Adults only (no children included) \\
\hline \multirow[t]{2}{*}{ Passali 2001} & INTERVENTIONS \\
\hline & Trial comparing nimesulide (\NSAID) versus morniflumate (NSAID) \\
\hline \multirow[t]{2}{*}{ Polidori 1993} & PARTICIPANTS \\
\hline & Trial included both outpatient and hospitalised children \\
\hline \multirow[t]{2}{*}{ Ryan 1987} & PARTICIPANTS \\
\hline & Adults only (no children included) \\
\hline
\end{tabular}

Paracetamol (acetaminophen) or non-steroidal anti-inflammatory drugs, alone or combined, for pain relief in acute otitis media in 


\begin{tabular}{ll}
\hline Study & Reason for exclusion \\
\hline
\end{tabular}

Sarrell 2006

OTHER

We did not succeed to receive the crude subgroup data of children with AOM from this trial

\begin{tabular}{ll}
\hline Schuetz $2014 \quad$ ALLOCATION \\
Non-randomised study
\end{tabular}

Siegel 2003

ALLOCATION

Non-randomised study

\section{INTERVENTIONS}

Trial comparing fentiazac (NSAID) versus ibuprofen (NSAID)

\begin{tabular}{|c|c|}
\hline \multirow[t]{2}{*}{ Stipon 1983} & INTERVENTIONS \\
\hline & $\begin{array}{l}\text { Trial comparing an intravenous injection of UP } 341.01 \text { (bio-precursor of paracetamol) } 1 \text { gram ver- } \\
\text { sus } 2 \text { gram }\end{array}$ \\
\hline
\end{tabular}

Weippl 1985

INTERVENTIONS

Trial comparing suprofen (NSAID) versus lidocaine + phenazone ear drops

Yoon 2008 INTERVENTIONS

Trial comparing dexibuprofen (NSAID) 5 or $7 \mathrm{mg} / \mathrm{kg}$ versus $10 \mathrm{mg}$ ibuprofen (NSAID)

\section{Characteristics of ongoing studies [ordered by study ID]}

PIM-POM study 2014

Trial name or title

\begin{tabular}{ll}
\hline Methods & Cluster randomised controlled trial \\
\hline Participants & $\begin{array}{l}\text { Children aged } 6 \text { months to } 10 \text { years presenting to their general practitioner (GP) with ear pain re- } \\
\text { sulting in a GP diagnosis of AOM according to the diagnostic criteria of the practice guideline "AOM } \\
\text { in children" issued by the Dutch College of GPs }\end{array}$
\end{tabular}

Interventions

\begin{abstract}
Intervention group: a primary-care based multifaceted intervention: 1) a blended learning targeted at general practitioners (GPs) consisting of an Internet-based training combined with a face-toface visit with the study physician; 2) an interactive parent information leaflet; and 3) a prescription of paracetamol and ibuprofen to be filled by parents the same day. In the blended learning GPs will be trained to a) address pain management during consultation by using effective communication skills; b) adhere to the 2014 guideline "AOM in children" and the 2007 "Pain Relief' guideline issued by the Dutch College of GPs which recommend a high dose paracetamol at fixed time intervals for the first three days, and a non-steroidal anti-inflammatory drug (NSAID) as add-on if needed; c) use an interactive leaflet during consultation; and d) prescribe paracetamol and ibuprofen (as add-on if needed)

Comparator group: 'care as usual'
\end{abstract}

Outcomes

Primary outcome: mean ear pain score during the first 3 days after the initial visit to the GP as measured by the Wong-Baker FACES ${ }^{\circledR}$ Pain Rating Scale (WBS). 
Secondary outcomes: number of days with ear pain and ear pain severity; number of days with fever; proportion of children with ear pain at various time points ( 24 hours, 2 to 3 days, 4 to 7 days); GP re-consultations because of AOM; (delayed) antibiotic prescriptions because of AOM; health-related quality of life (HRQoL) of the child and its parents; parental days off work, days lost from nursery or school for children; complications of AOM, including acute mastoiditis, meningitis and intracranial abscess; adverse effects of analgesics; costs (cost-effectiveness)

\begin{tabular}{ll}
\hline Starting date & January 2015 \\
\hline Contact information & Prof.dr. Roger AMJ Damoiseaux \\
\hline Notes & $\begin{array}{l}\text { Alies Sjoukes, Roderick P Venekamp, Alma C van de Pol, Anne GM Schilder, Roger AMJ Damoiseaux } \\
\text { are researchers of the PIM-POM study; This trial is funded by a research grant from The Netherlands } \\
\text { Organisation for Health Research and Development/SBOH no. 80-83910-98-13006 }\end{array}$ \\
\hline
\end{tabular}

DATA AND ANALYSES

\section{Comparison 1. Paracetamol versus placebo}

\begin{tabular}{lllll}
\hline $\begin{array}{l}\text { Outcome or subgroup } \\
\text { title }\end{array}$ & No. of studies & $\begin{array}{l}\text { No. of partici- } \\
\text { pants }\end{array}$ & Statistical method & Effect size \\
\hline 1 Pain at 48 hours & 1 & 148 & Risk Ratio (M-H, Fixed, 95\% Cl) & $0.38[0.17,0.85]$ \\
\hline 2 Adverse events & 1 & 148 & Risk Ratio (M-H, Fixed, 95\% Cl) & $1.03[0.21,4.93]$ \\
\hline 3 Fever at 48 hours & 1 & 148 & Risk Ratio (M-H, Fixed, 95\% Cl) & $1.03[0.07,16.12]$ \\
\hline
\end{tabular}

Analysis 1.1. Comparison 1 Paracetamol versus placebo, Outcome 1 Pain at 48 hours.

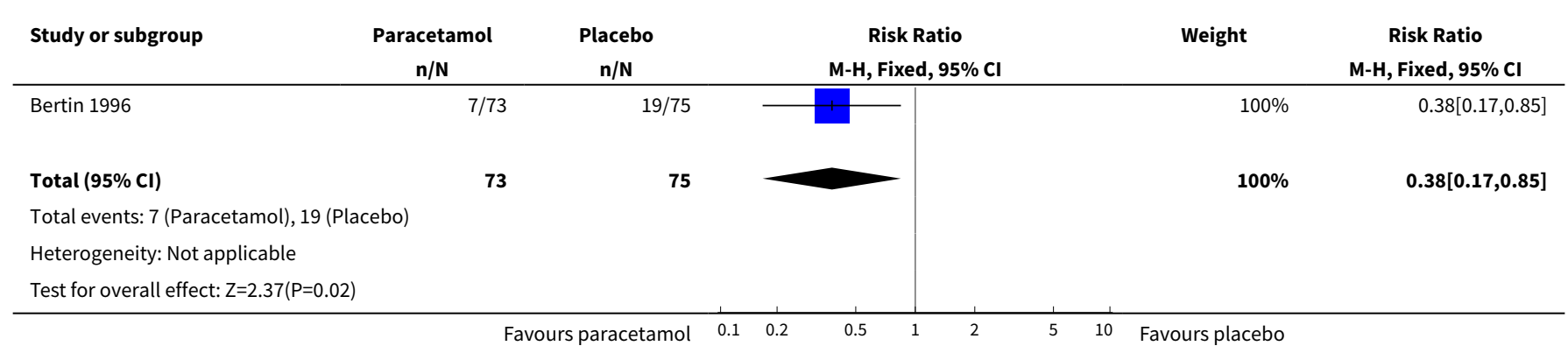

Analysis 1.2. Comparison 1 Paracetamol versus placebo, Outcome 2 Adverse events.

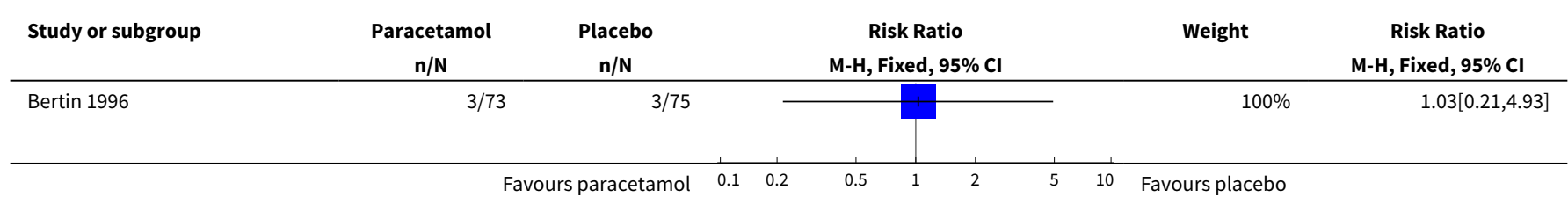




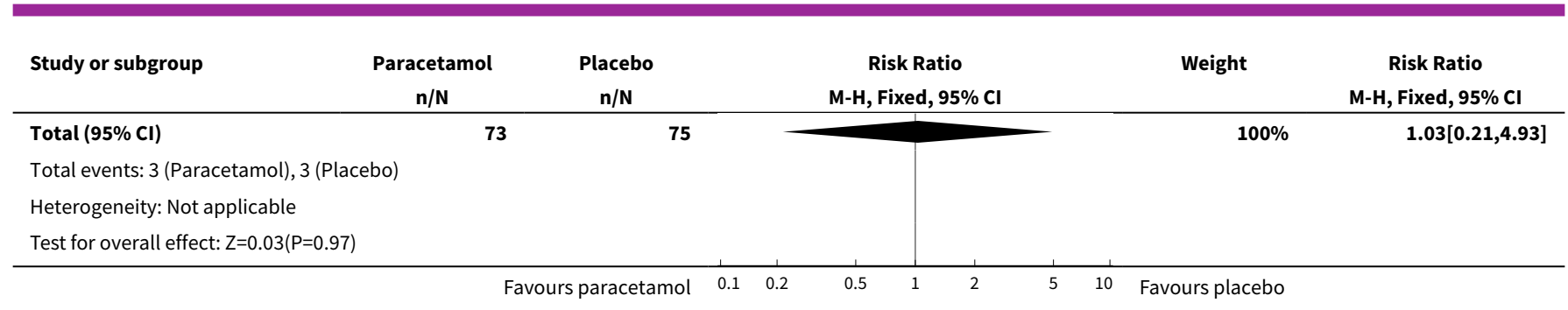

Analysis 1.3. Comparison 1 Paracetamol versus placebo, Outcome 3 Fever at 48 hours.

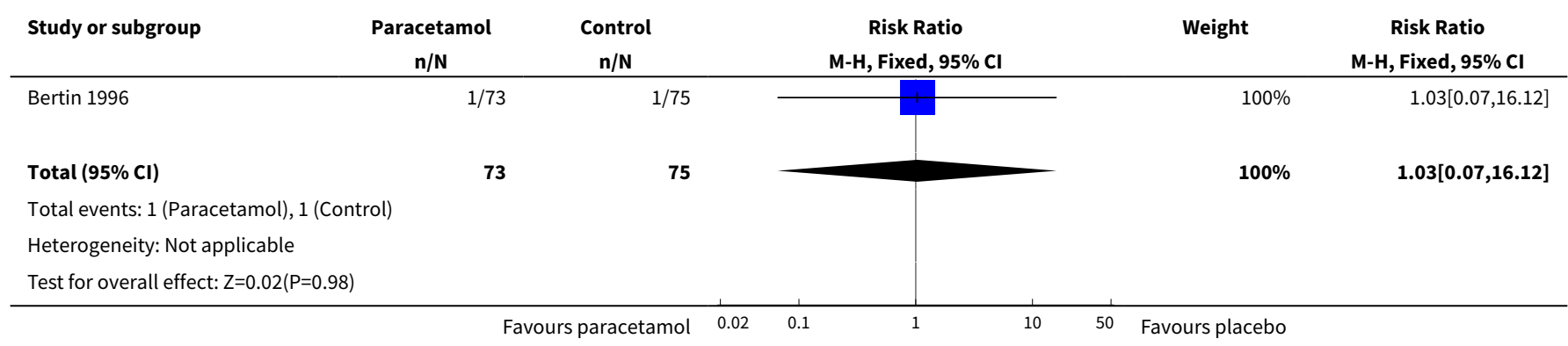

\section{Comparison 2. NSAIDs versus placebo}

\begin{tabular}{lllll}
\hline $\begin{array}{l}\text { Outcome or subgroup } \\
\text { title }\end{array}$ & No. of studies & $\begin{array}{l}\text { No. of partici- } \\
\text { pants }\end{array}$ & Statistical method & Effect size \\
\hline 1 Pain at 48 hours & 1 & 146 & Risk Ratio (M-H, Fixed, 95\% Cl) & $0.28[0.11,0.70]$ \\
\hline 2 Adverse events & 1 & 146 & Risk Ratio (M-H, Fixed, 95\% Cl) & $1.76[0.44,7.10]$ \\
\hline 3 Fever at 48 hours & 1 & 146 & Risk Ratio (M-H, Fixed, 95\% Cl) & $1.06[0.07,16.57]$ \\
\hline
\end{tabular}

Analysis 2.1. Comparison 2 NSAIDs versus placebo, Outcome 1 Pain at 48 hours.

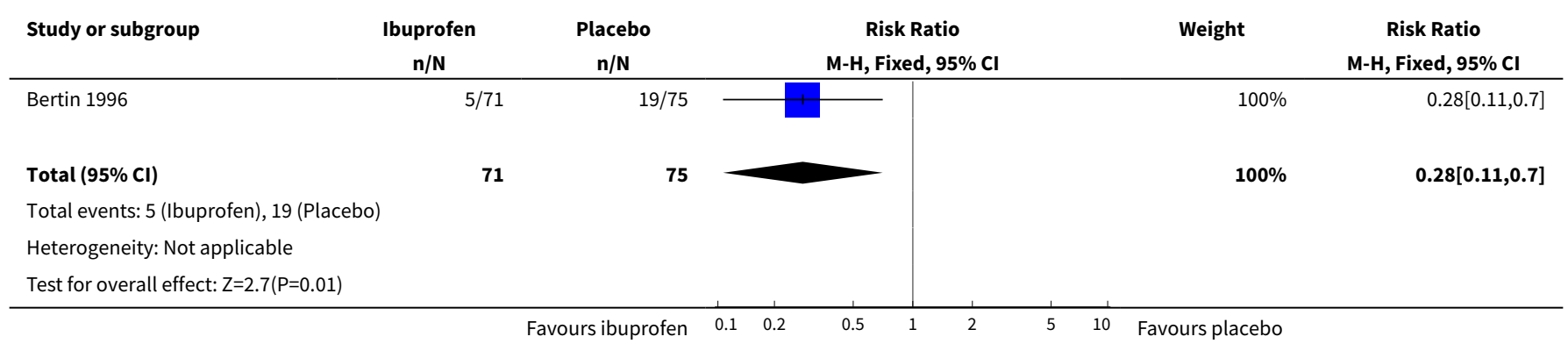


Analysis 2.2. Comparison 2 NSAIDs versus placebo, Outcome 2 Adverse events.

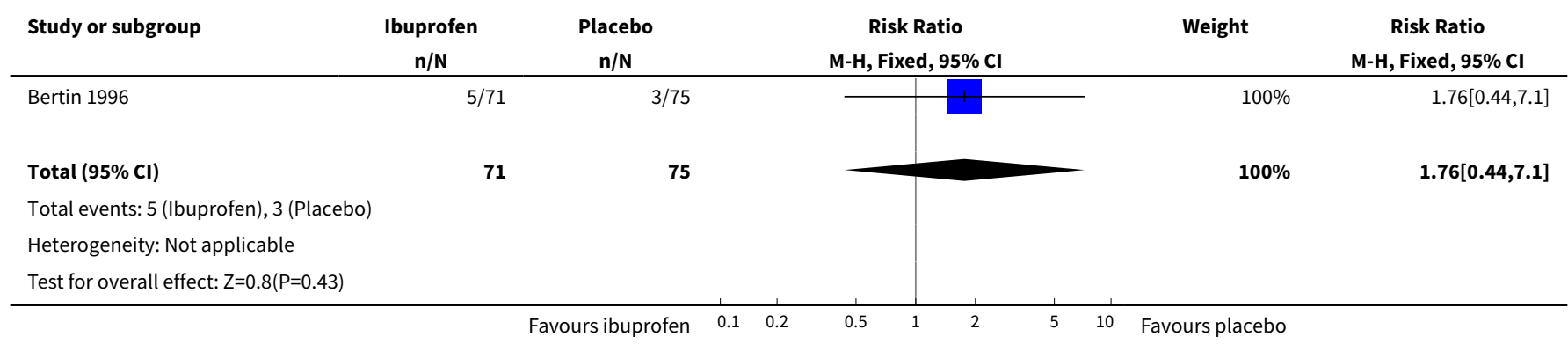

Analysis 2.3. Comparison 2 NSAIDs versus placebo, Outcome 3 Fever at 48 hours.

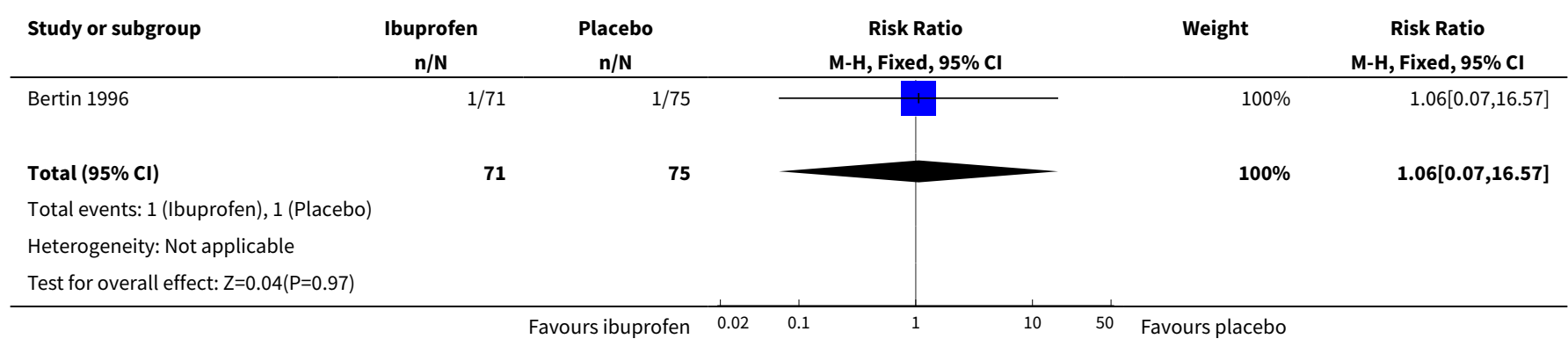

\section{Comparison 3. NSAIDs versus paracetamol}

\begin{tabular}{|c|c|c|c|c|}
\hline Outcome or subgroup title & No. of studies & $\begin{array}{l}\text { No. of partici- } \\
\text { pants }\end{array}$ & Statistical method & Effect size \\
\hline 1 Pain at 24 hours & 2 & 39 & Risk Ratio (M-H, Fixed, 95\% Cl) & $0.83[0.59,1.18]$ \\
\hline 2 Pain at 48 to 72 hours & 3 & 183 & Risk Ratio (M-H, Fixed, 95\% Cl) & $0.91[0.54,1.54]$ \\
\hline 3 Pain at 4 to 7 days & 2 & 38 & Risk Ratio (M-H, Fixed, 95\% Cl) & $0.74[0.17,3.23]$ \\
\hline 4 Adverse events & 2 & 197 & Risk Ratio (M-H, Random, 95\% Cl) & $1.71[0.43,6.90]$ \\
\hline 5 Mild pain at 24 hours & 2 & 39 & Risk Ratio (M-H, Fixed, 95\% Cl) & $1.08[0.31,3.73]$ \\
\hline 6 Mild pain at 48 to 72 hours & 2 & 39 & Risk Ratio (M-H, Fixed, 95\% Cl) & $1.35[0.62,2.91]$ \\
\hline 7 Mild pain at 4 to 7 days & 2 & 39 & Risk Ratio (M-H, Fixed, 95\% Cl) & $0.91[0.37,2.23]$ \\
\hline $\begin{array}{l}8 \text { Mean pain score at } 24 \\
\text { hours }\end{array}$ & 2 & 39 & Mean Difference (IV, Fixed, 95\% Cl) & $0.10[-0.47,0.67]$ \\
\hline $\begin{array}{l}9 \text { Mean pain score at } 48 \text { to } \\
72 \text { hours }\end{array}$ & 2 & 39 & Mean Difference (IV, Fixed, 95\% CI) & $0.19[-0.27,0.65]$ \\
\hline $\begin{array}{l}10 \text { Mean pain score at } 4 \text { to } 7 \\
\text { days }\end{array}$ & 2 & 31 & Mean Difference (IV, Fixed, 95\% CI) & $-0.30[-2.38,1.78]$ \\
\hline
\end{tabular}

Paracetamol (acetaminophen) or non-steroidal anti-inflammatory drugs, alone or combined, for pain relief in acute otitis media in 


\begin{tabular}{llllll}
\hline Outcome or subgroup title & No. of studies & $\begin{array}{l}\text { No. of partici- } \\
\text { pants }\end{array}$ & Statistical method & Effect size \\
\hline 11 Fever at 24 hours & 2 & 39 & Risk Ratio (M-H, Fixed, 95\% Cl) & $0.69[0.24,2.00]$ \\
\hline 12 Fever at 48 to 72 hours & 3 & 182 & Risk Ratio (M-H, Fixed, 95\% Cl) & $1.18[0.31,4.44]$ \\
\hline 13 Fever at 4 to 7 days & 2 & 39 & Risk Ratio (M-H, Fixed, 95\% Cl) & $2.75[0.12,60.70]$ \\
\hline 14 Re-consultations & 1 & 53 & Risk Ratio (M-H, Fixed, 95\% Cl) & $1.13[0.92,1.40]$ \\
\hline $\begin{array}{l}15 \text { Delayed antibiotic pre- } \\
\text { scriptions }\end{array}$ & 1 & 53 & Risk Ratio (M-H, Fixed, 95\% Cl) & $1.32[0.74,2.35]$ \\
\hline
\end{tabular}

Analysis 3.1. Comparison 3 NSAIDs versus paracetamol, Outcome 1 Pain at 24 hours.

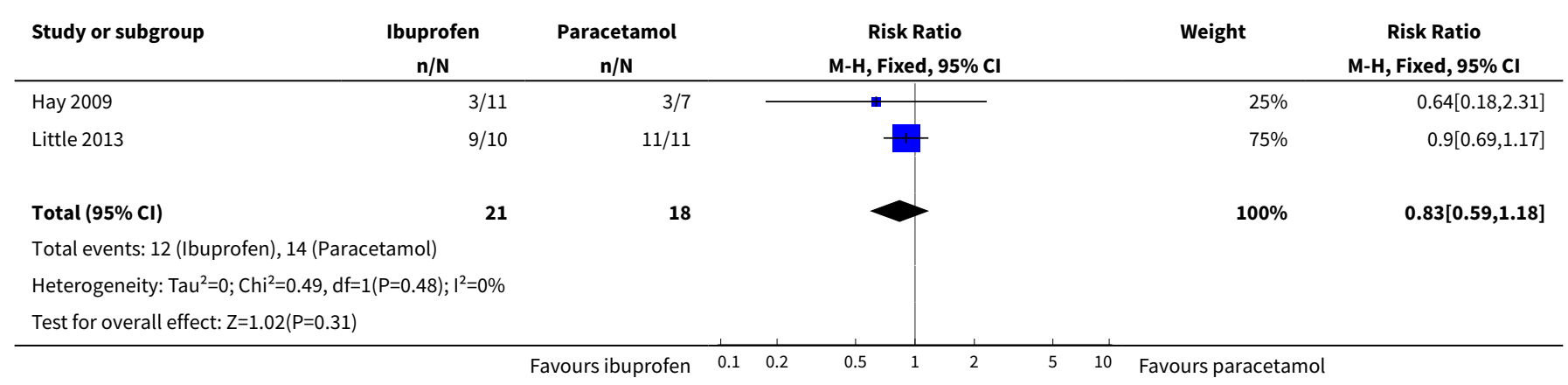

Analysis 3.2. Comparison 3 NSAIDs versus paracetamol, Outcome 2 Pain at 48 to 72 hours.

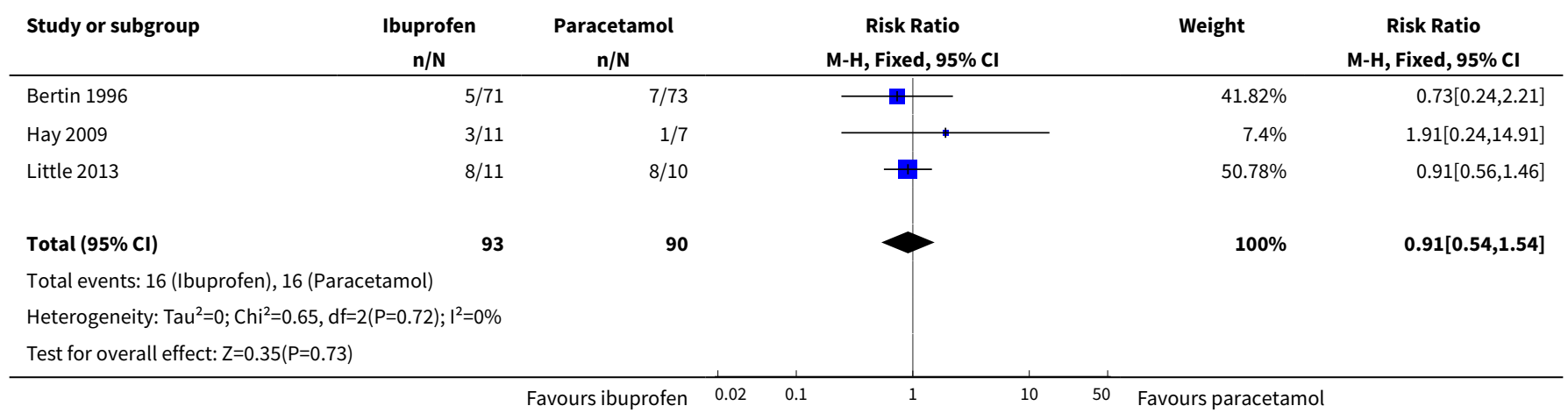

Analysis 3.3. Comparison 3 NSAIDs versus paracetamol, Outcome 3 Pain at 4 to 7 days.

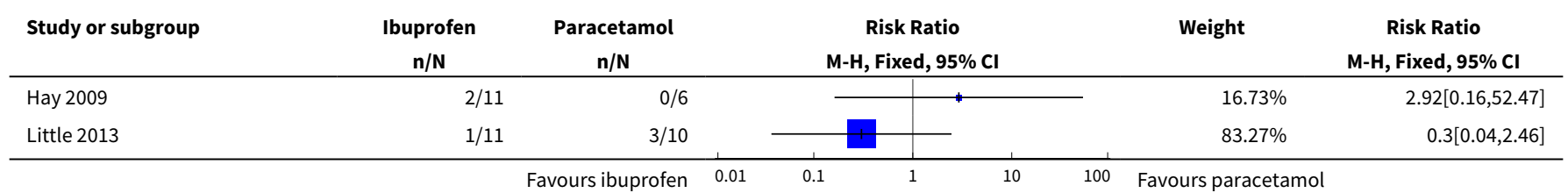




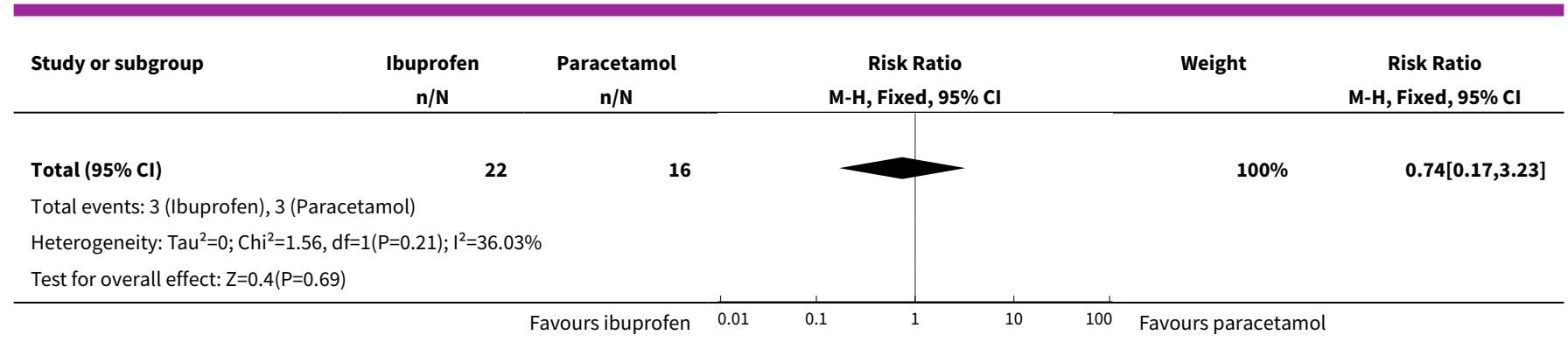

Analysis 3.4. Comparison 3 NSAIDs versus paracetamol, Outcome 4 Adverse events.

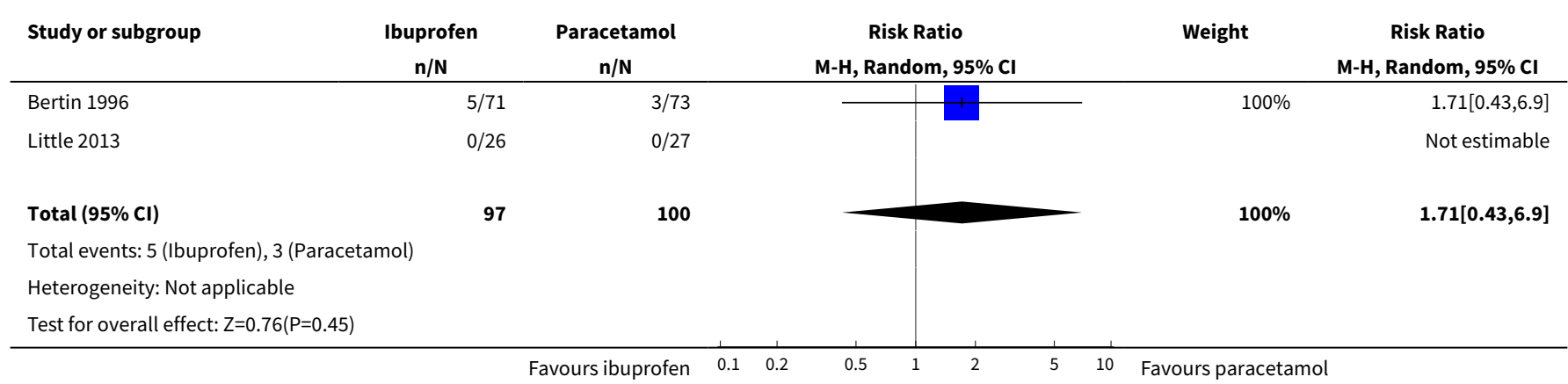

Analysis 3.5. Comparison 3 NSAIDs versus paracetamol, Outcome 5 Mild pain at 24 hours.

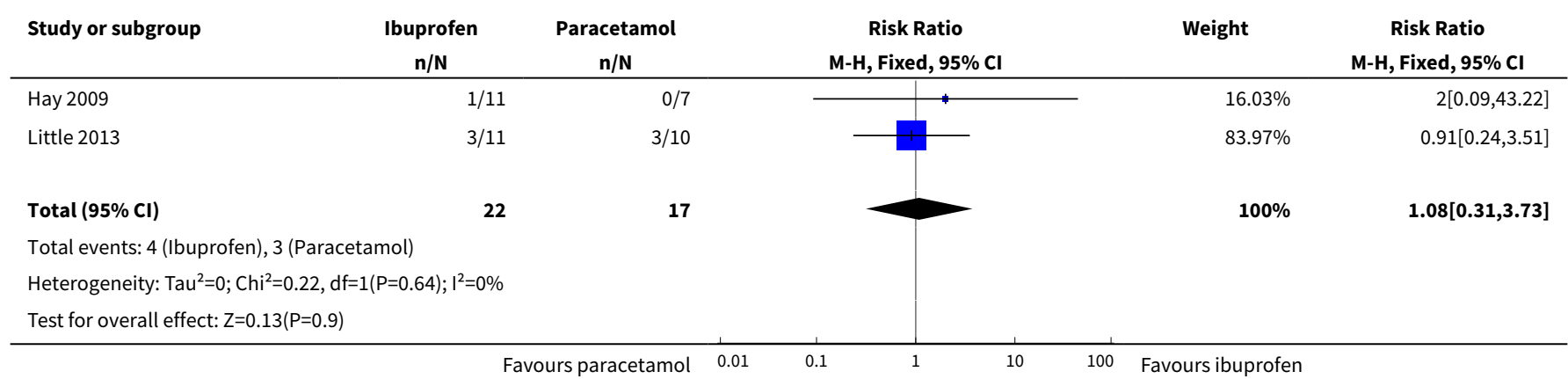

Analysis 3.6. Comparison 3 NSAIDs versus paracetamol, Outcome 6 Mild pain at 48 to 72 hours.

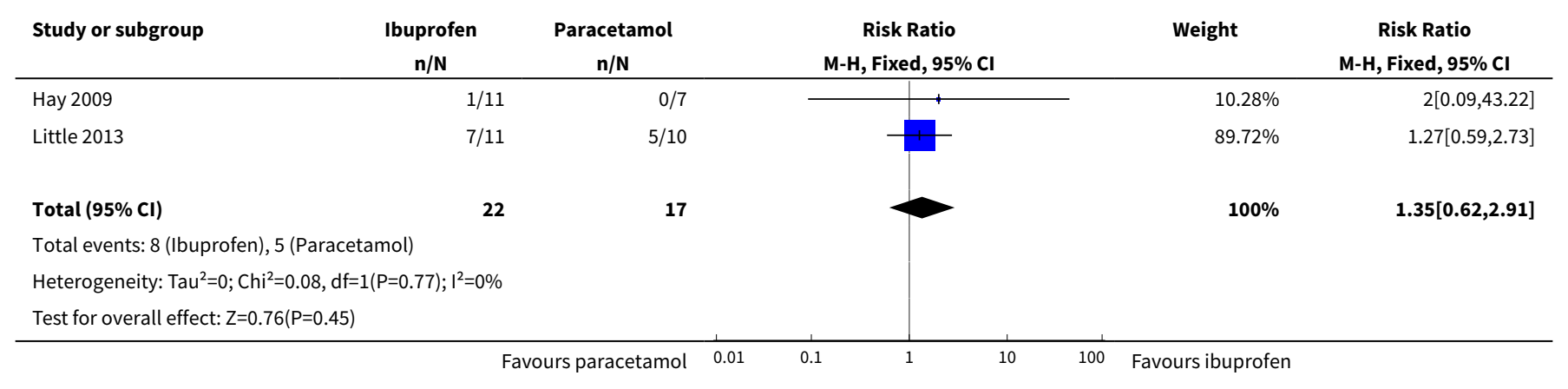

Paracetamol (acetaminophen) or non-steroidal anti-inflammatory drugs, alone or combined, for pain relief in acute otitis media in 40 children (Review)

Copyright (c) 2016 The Cochrane Collaboration. Published by John Wiley \& Sons, Ltd. 
Analysis 3.7. Comparison 3 NSAIDs versus paracetamol, Outcome 7 Mild pain at 4 to 7 days.

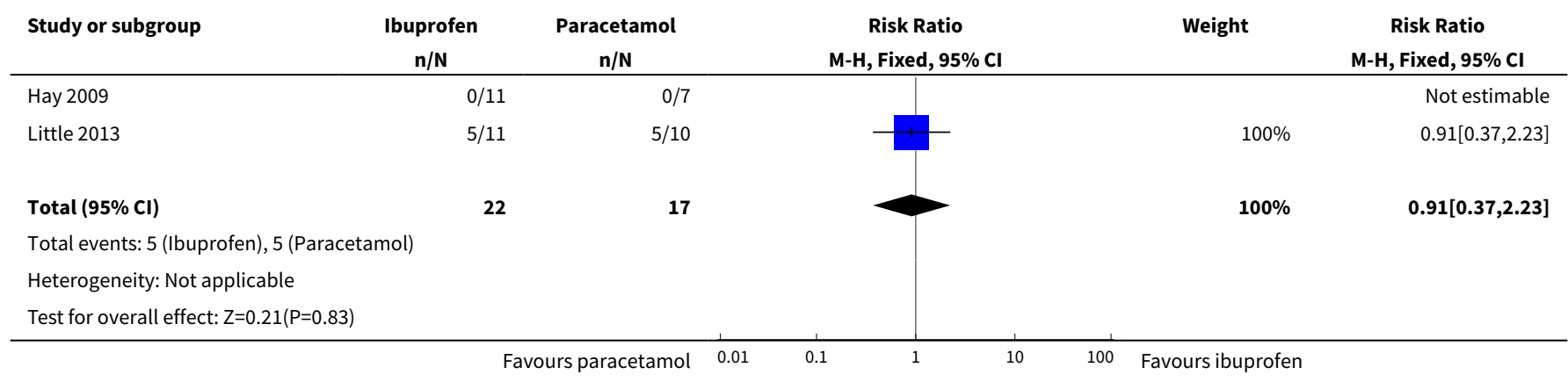

Analysis 3.8. Comparison 3 NSAIDs versus paracetamol, Outcome 8 Mean pain score at 24 hours.

\begin{tabular}{|c|c|c|c|c|c|c|c|}
\hline \multirow[t]{2}{*}{ Study or subgroup } & \multicolumn{2}{|c|}{ Ibuprofen } & \multicolumn{2}{|c|}{ Paracetamol } & \multirow{2}{*}{$\begin{array}{c}\text { Mean Difference } \\
\text { Fixed, } 95 \% \mathrm{Cl}\end{array}$} & \multirow[t]{2}{*}{ Weight } & \multirow{2}{*}{$\begin{array}{c}\text { Mean Difference } \\
\text { Fixed, } 95 \% \mathrm{Cl}\end{array}$} \\
\hline & $\mathbf{N}$ & Mean(SD) & $\mathbf{N}$ & Mean(SD) & & & \\
\hline Hay 2009 & 11 & $2.5(0.9)$ & 7 & $2.4(0.5)$ & & $72.04 \%$ & $0.02[-0.66,0.7]$ \\
\hline Little 2013 & 11 & $3.9(1.1)$ & 10 & $3.6(1.4)$ & 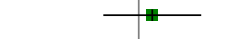 & $27.96 \%$ & $0.3[-0.78,1.38]$ \\
\hline 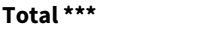 & 22 & & 17 & & & $100 \%$ & $0.1[-0.47,0.67]$ \\
\hline \multicolumn{8}{|c|}{ Heterogeneity: $\mathrm{Tau}^{2}=0 ; \mathrm{Chi}^{2}=0.18, \mathrm{df}=1(\mathrm{P}=0.67) ; \mathrm{I}^{2}=0 \%$} \\
\hline \multicolumn{8}{|c|}{ Test for overall effect: $Z=0.34(P=0.74)$} \\
\hline
\end{tabular}

Analysis 3.9. Comparison 3 NSAIDs versus paracetamol, Outcome 9 Mean pain score at 48 to 72 hours.

\begin{tabular}{|c|c|c|c|c|c|c|c|}
\hline \multirow[t]{2}{*}{ Study or subgroup } & \multicolumn{2}{|c|}{ Ibuprofen } & \multicolumn{2}{|c|}{ Paracetamol } & \multirow{2}{*}{$\begin{array}{c}\text { Mean Difference } \\
\text { Fixed, } 95 \% \mathrm{Cl}\end{array}$} & \multirow[t]{2}{*}{ Weight } & \multirow{2}{*}{$\begin{array}{c}\text { Mean Difference } \\
\text { Fixed, } 95 \% \mathrm{Cl}\end{array}$} \\
\hline & $\mathbf{N}$ & Mean(SD) & $\mathbf{N}$ & Mean(SD) & & & \\
\hline Hay 2009 & 11 & $2.4(0.7)$ & 7 & $2.1(0.4)$ & & $89.43 \%$ & $0.22[-0.27,0.71]$ \\
\hline Little 2013 & 11 & $1.6(1.8)$ & 10 & $1.7(1.5)$ & & $10.57 \%$ & $-0.1[-1.51,1.31]$ \\
\hline Total $\star \star \star$ & 22 & & 17 & & & $100 \%$ & $0.19[-0.27,0.65]$ \\
\hline \multicolumn{8}{|c|}{ Heterogeneity: $\operatorname{Tau}^{2}=0 ; \mathrm{Chi}^{2}=0.18, \mathrm{df}=1(\mathrm{P}=0.67) ;\left.\right|^{2}=0 \%$} \\
\hline
\end{tabular}

Analysis 3.10. Comparison 3 NSAIDs versus paracetamol, Outcome 10 Mean pain score at 4 to 7 days.

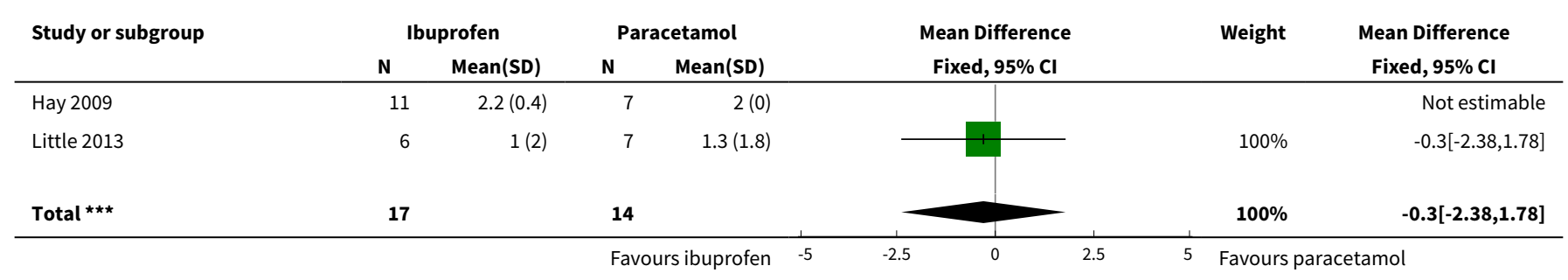

Paracetamol (acetaminophen) or non-steroidal anti-inflammatory drugs, alone or combined, for pain relief in acute otitis media in 


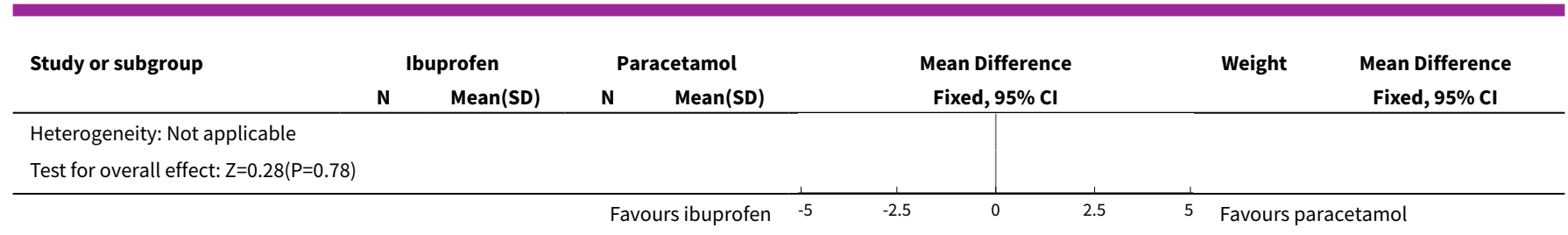

Analysis 3.11. Comparison 3 NSAIDs versus paracetamol, Outcome 11 Fever at 24 hours.

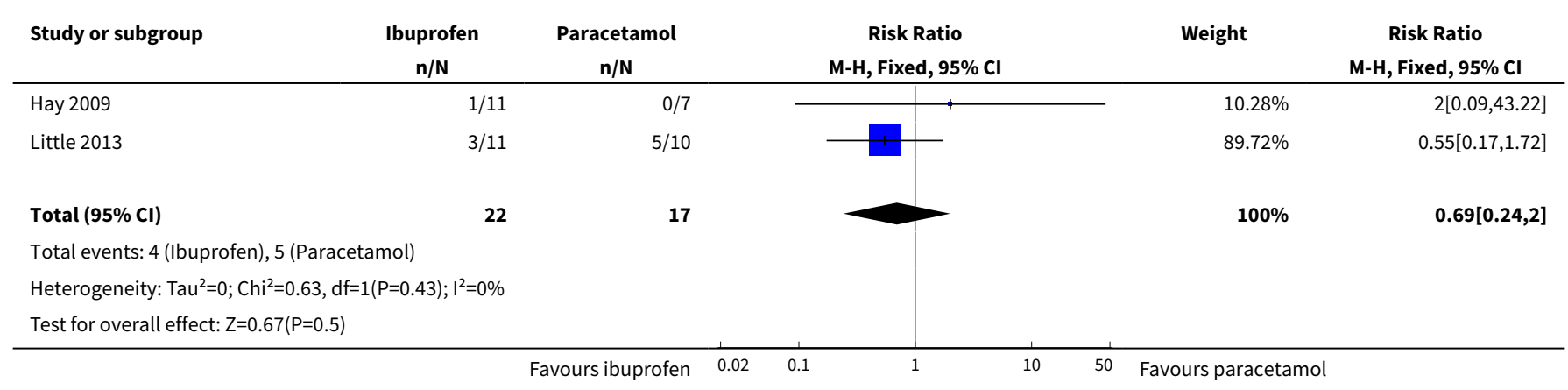

Analysis 3.12. Comparison 3 NSAIDs versus paracetamol, Outcome 12 Fever at 48 to 72 hours.

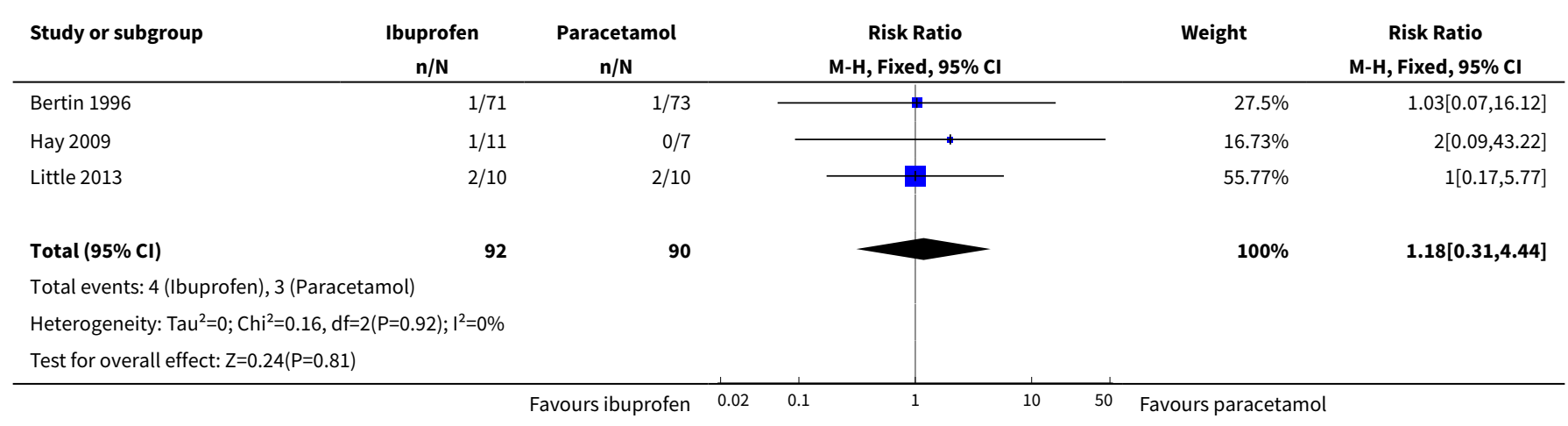

Analysis 3.13. Comparison 3 NSAIDs versus paracetamol, Outcome 13 Fever at 4 to 7 days.

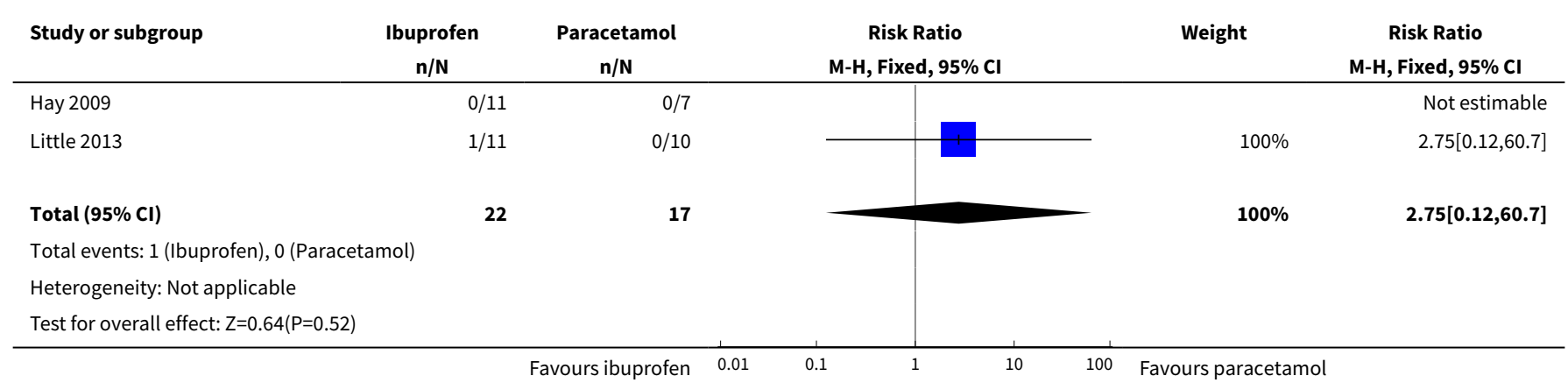


Analysis 3.14. Comparison 3 NSAIDs versus paracetamol, Outcome 14 Re-consultations.

\begin{tabular}{|c|c|c|c|c|c|}
\hline Study or subgroup & $\begin{array}{c}\text { Ibuprofen } \\
n / N\end{array}$ & $\begin{array}{c}\text { Paracetamol } \\
\mathbf{n} / \mathbf{N} \\
\end{array}$ & $\begin{array}{c}\text { Risk Ratio } \\
\text { M-H, Fixed, 95\% Cl }\end{array}$ & Weight & $\begin{array}{c}\text { Risk Ratio } \\
\text { M-H, Fixed, 95\% Cl }\end{array}$ \\
\hline Little 2013 & $24 / 26$ & $22 / 27$ & - & $100 \%$ & $1.13[0.92,1.4]$ \\
\hline Total $(95 \% \mathrm{Cl})$ & 26 & 27 & & $100 \%$ & $1.13[0.92,1.4]$ \\
\hline \multicolumn{6}{|c|}{ Total events: 24 (Ibuprofen), 22 (Paracetamol) } \\
\hline \multicolumn{6}{|c|}{ Heterogeneity: Not applicable } \\
\hline Test for overall effect & & & & & \\
\hline
\end{tabular}

\section{Analysis 3.15. Comparison 3 NSAIDs versus paracetamol, Outcome 15 Delayed antibiotic prescriptions.}

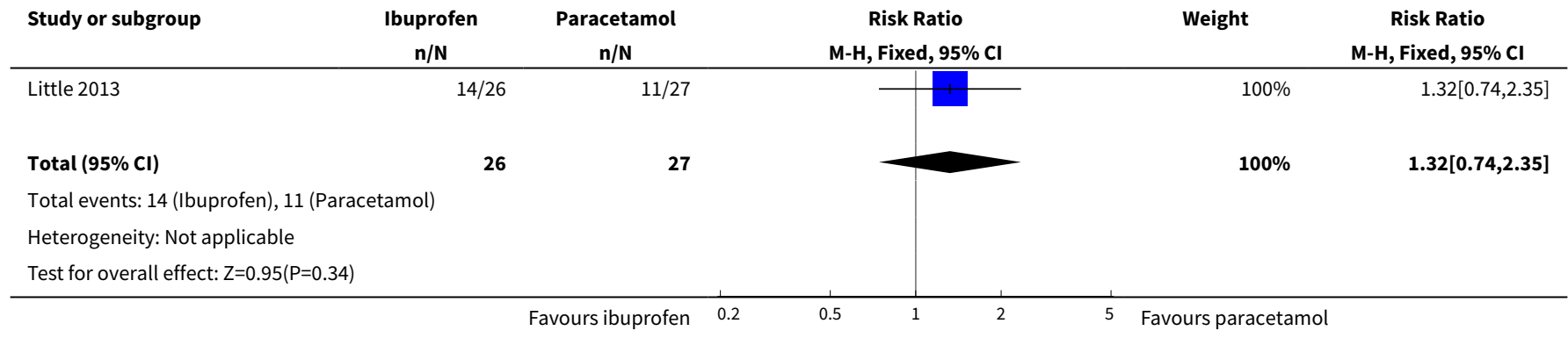

\section{Comparison 4. NSAIDs + paracetamol versus paracetamol}

\begin{tabular}{llllll}
\hline Outcome or subgroup title & No. of studies & $\begin{array}{l}\text { No. of partici- } \\
\text { pants }\end{array}$ & Statistical method & Effect size \\
\hline 1 Pain at 24 hours & 2 & 41 & Risk Ratio (M-H, Fixed, 95\% Cl) & $1.07[0.78,1.47]$ \\
\hline 2 Pain at 48 to 72 hours & 2 & 41 & Risk Ratio (M-H, Fixed, 95\% Cl) & $0.71[0.42,1.20]$ \\
\hline 3 Pain at 4 to 7 days & 2 & 41 & Risk Ratio (M-H, Fixed, 95\% Cl) & $1.65[0.58,4.72]$ \\
\hline 4 Adverse events & 1 & Risk Ratio (M-H, Fixed, 95\% Cl) & $0.0[0.0,0.0]$ \\
\hline 5 Mild pain at 24 hours & 2 & 56 & Risk Ratio (M-H, Fixed, 95\% Cl) & $0.21[0.02,1.74]$ \\
\hline 6 Mild pain at 48 to 72 hours & 2 & 41 & Risk Ratio (M-H, Fixed, 95\% Cl) & $0.63[0.24,1.62]$ \\
\hline 7 Mild pain at 4 to 7 days & 2 & 41 & Risk Ratio (M-H, Fixed, 95\% Cl) & $0.5[0.17,1.43]$ \\
\hline 8 Mean pain at 24 hours & 2 & 41 & $\begin{array}{l}\text { Mean Difference (IV, Random, 95\% } \\
\text { Cl) }\end{array}$ & $0.32[-0.59,1.23]$ \\
\hline $\begin{array}{l}10 \text { Mean pain at 4 to 7 days } \\
\text { hours }\end{array}$ & 2 & 40 & Mean Difference (IV, Fixed, 95\% Cl) & $0.60[-0.77,1.97]$ \\
\hline
\end{tabular}

Paracetamol (acetaminophen) or non-steroidal anti-inflammatory drugs, alone or combined, for pain relief in acute otitis media in 


\begin{tabular}{lllll}
\hline Outcome or subgroup title & No. of studies & $\begin{array}{l}\text { No. of partici- } \\
\text { pants }\end{array}$ & Statistical method & Effect size \\
\hline 11 Fever at 24 hours & 2 & 41 & Risk Ratio (M-H, Fixed, 95\% Cl) & $1.48[0.73,2.99]$ \\
\hline 12 Fever at 48 to 72 hours & 2 & 41 & Risk Ratio (M-H, Fixed, 95\% Cl) & $2.13[0.60,7.60]$ \\
\hline 13 Fever at 4 to 7 days & 2 & 41 & Risk Ratio (M-H, Fixed, 95\% Cl) & $0.0[0.0,0.0]$ \\
\hline 14 Re-consultations & 1 & 56 & Risk Ratio (M-H, Fixed, 95\% Cl) & $0.80[0.58,1.11]$ \\
\hline $\begin{array}{l}15 \text { Delayed antibiotic pre- } \\
\text { scriptions }\end{array}$ & 1 & 56 & Risk Ratio (M-H, Fixed, 95\% Cl) & $1.27[0.71,2.26]$ \\
\hline 16 Serious complications & 2 & 71 & Risk Ratio (M-H, Fixed, 95\% Cl) & $0.0[0.0,0.0]$ \\
\hline
\end{tabular}

\section{Analysis 4.1. Comparison 4 NSAIDs + paracetamol versus paracetamol, Outcome 1 Pain at 24 hours.}

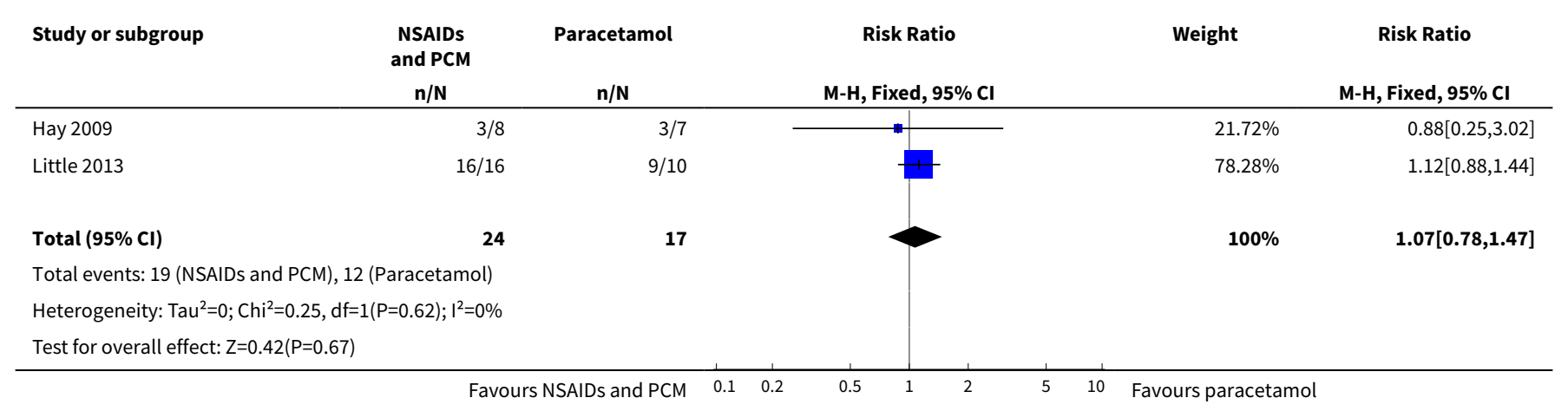

Analysis 4.2. Comparison 4 NSAIDs + paracetamol versus paracetamol, Outcome 2 Pain at 48 to 72 hours.

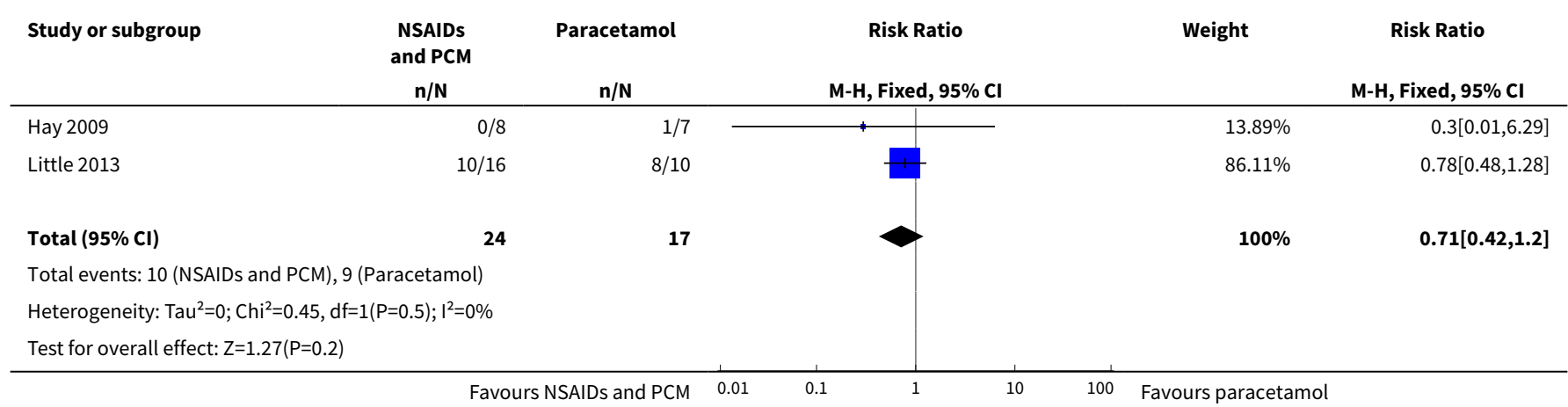


Analysis 4.3. Comparison 4 NSAIDs + paracetamol versus paracetamol, Outcome 3 Pain at 4 to 7 days.

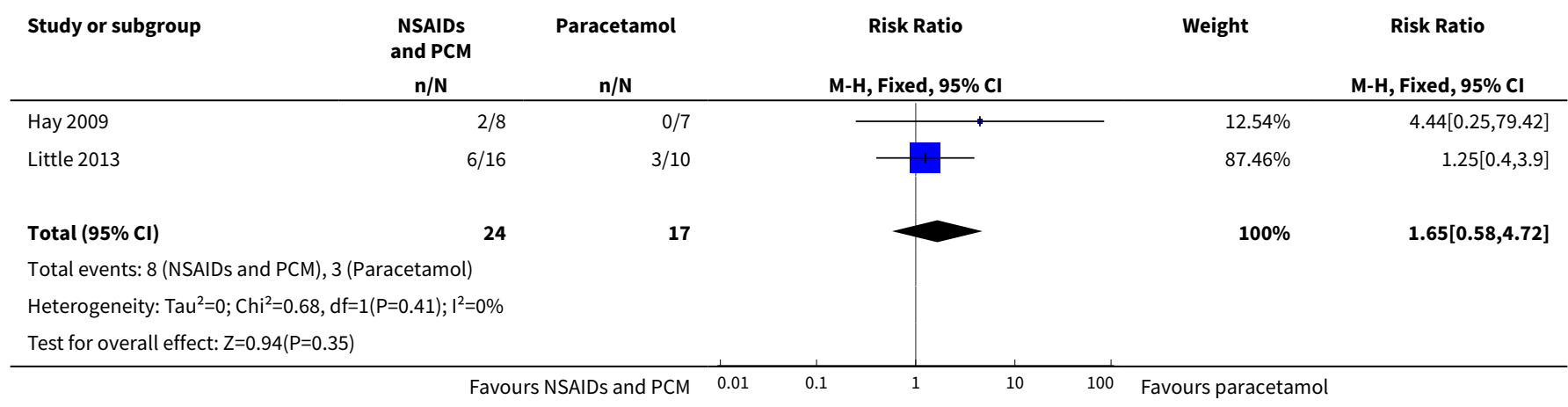

Analysis 4.4. Comparison 4 NSAIDs + paracetamol versus paracetamol, Outcome 4 Adverse events.

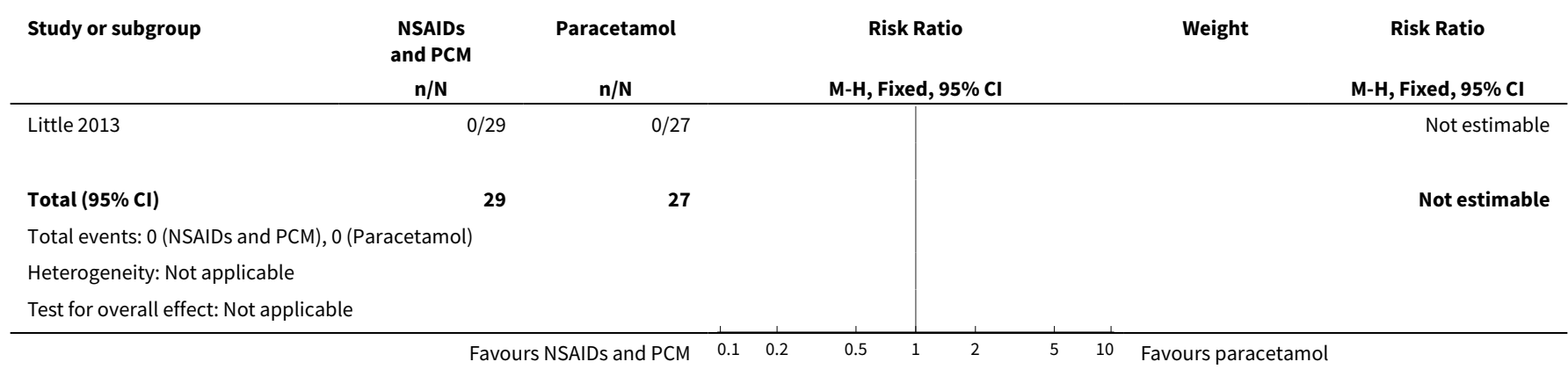

Analysis 4.5. Comparison 4 NSAIDs + paracetamol versus paracetamol, Outcome 5 Mild pain at 24 hours.

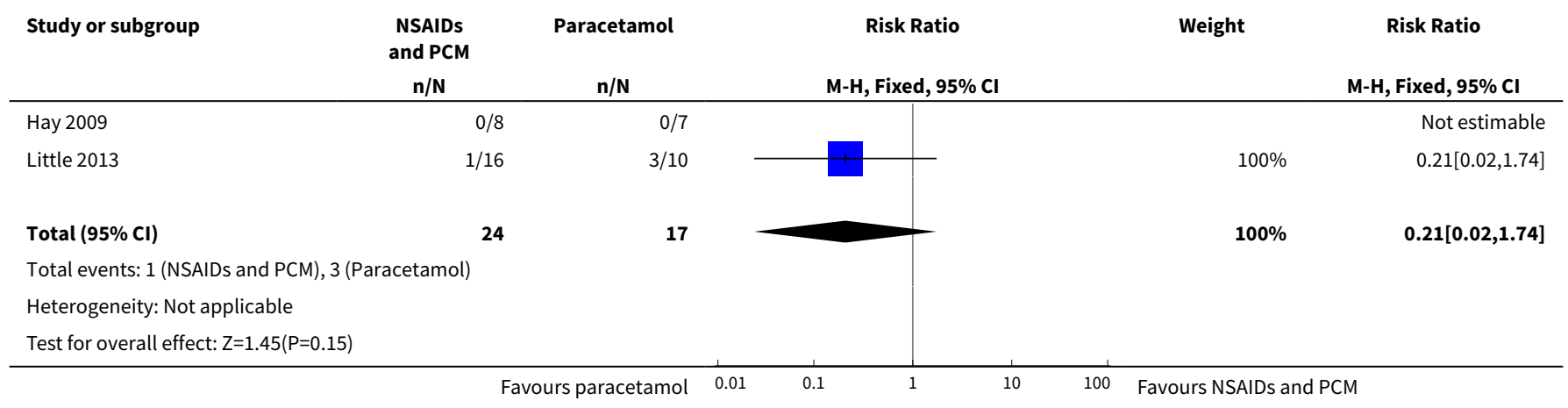

Analysis 4.6. Comparison 4 NSAIDs + paracetamol versus paracetamol, Outcome 6 Mild pain at $\mathbf{4 8}$ to $\mathbf{7 2}$ hours.

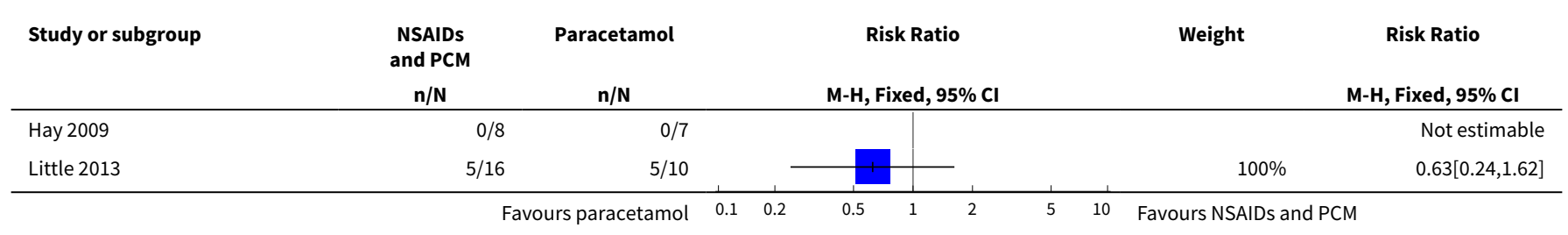

Paracetamol (acetaminophen) or non-steroidal anti-inflammatory drugs, alone or combined, for pain relief in acute otitis media in 45 children (Review)

Copyright (c) 2016 The Cochrane Collaboration. Published by John Wiley \& Sons, Ltd. 


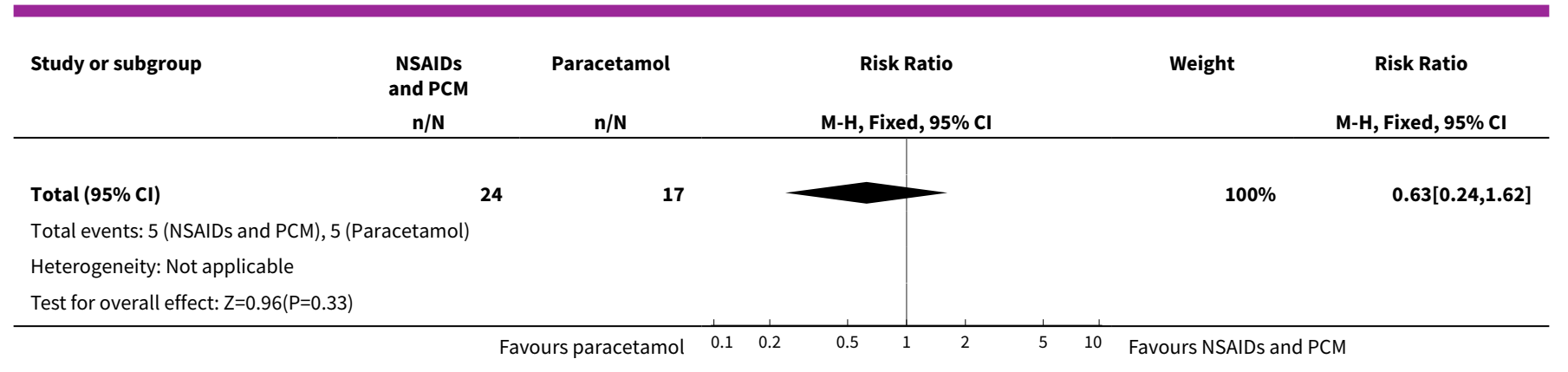

Analysis 4.7. Comparison 4 NSAIDs + paracetamol versus paracetamol, Outcome 7 Mild pain at 4 to 7 days.

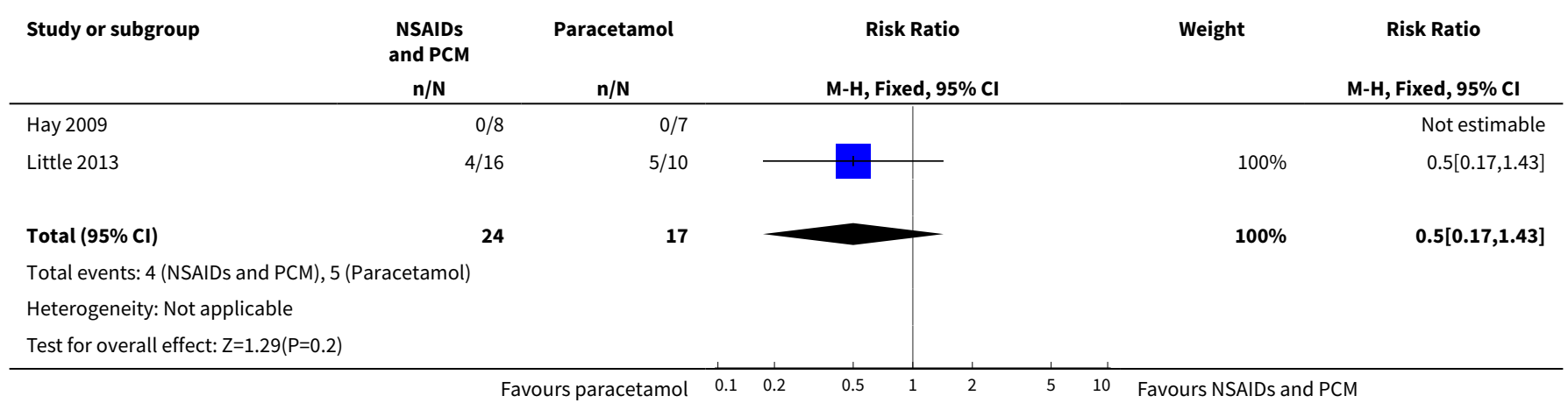

Analysis 4.8. Comparison 4 NSAIDs + paracetamol versus paracetamol, Outcome 8 Mean pain at 24 hours.

\begin{tabular}{|c|c|c|c|c|c|c|c|}
\hline \multirow[t]{2}{*}{ Study or subgroup } & \multicolumn{2}{|c|}{ NSAIDs and PCM } & \multicolumn{2}{|c|}{ Paracetamol } & \multirow{2}{*}{$\begin{array}{l}\text { Mean Difference } \\
\text { Random, } 95 \% \mathrm{Cl}\end{array}$} & \multirow[t]{2}{*}{ Weight } & \multirow{2}{*}{$\begin{array}{l}\text { Mean Difference } \\
\text { Random, } 95 \% \mathrm{Cl}\end{array}$} \\
\hline & $\mathbf{N}$ & Mean(SD) & $\mathbf{N}$ & Mean(SD) & & & \\
\hline Hay 2009 & 8 & $2.4(0.5)$ & 7 & $2.4(0.5)$ & & $61.23 \%$ & $-0.05[-0.58,0.48]$ \\
\hline Little 2013 & 15 & $4.5(1.1)$ & 10 & $3.6(1.4)$ & $\mp$ & $38.77 \%$ & $0.9[-0.13,1.93]$ \\
\hline 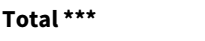 & 23 & & 17 & & & $100 \%$ & $0.32[-0.59,1.23]$ \\
\hline \multicolumn{8}{|c|}{ Heterogeneity: $\mathrm{Tau}^{2}=0.28 ; \mathrm{Chi}^{2}=2.57, \mathrm{df}=1(\mathrm{P}=0.11) ; \mathrm{I}^{2}=61.15 \%$} \\
\hline \multicolumn{8}{|c|}{ Test for overall effect: $Z=0.69(P=0.49)$} \\
\hline
\end{tabular}

Analysis 4.9. Comparison 4 NSAIDs + paracetamol versus paracetamol, Outcome 9 Mean pain at 48 to 72 hours.

\begin{tabular}{|c|c|c|c|c|c|c|c|}
\hline \multirow{3}{*}{$\begin{array}{l}\text { Study or subgroup } \\
\text { Hay } 2009\end{array}$} & \multicolumn{2}{|c|}{ NSAIDs and PCM } & \multicolumn{2}{|c|}{ Paracetamol } & \multirow{2}{*}{$\begin{array}{c}\text { Mean Difference } \\
\text { Fixed, } 95 \% \mathrm{Cl}\end{array}$} & \multirow[t]{2}{*}{ Weight } & \multirow{2}{*}{$\begin{array}{c}\text { Mean Difference } \\
\text { Fixed, } 95 \% \mathrm{Cl}\end{array}$} \\
\hline & $\mathbf{N}$ & $\operatorname{Mean}(S D)$ & $\mathbf{N}$ & Mean(SD) & & & \\
\hline & 8 & $2(0)$ & 7 & $2.1(0.4)$ & & & Not estimable \\
\hline Little 2013 & 15 & $2.3(2)$ & 10 & $1.7(1.5)$ & & $100 \%$ & $0.6[-0.77,1.97]$ \\
\hline Total $\star \star \star$ & 23 & & 17 & & & $100 \%$ & $0.6[-0.77,1.97]$ \\
\hline \multicolumn{8}{|c|}{ Heterogeneity: Not applicable } \\
\hline & & & P & $S$ and $\mathrm{PCM}$ & -2.5 & Favours & etamol \\
\hline
\end{tabular}


Analysis 4.10. Comparison 4 NSAIDs + paracetamol versus paracetamol, Outcome 10 Mean pain at 4 to 7 days.

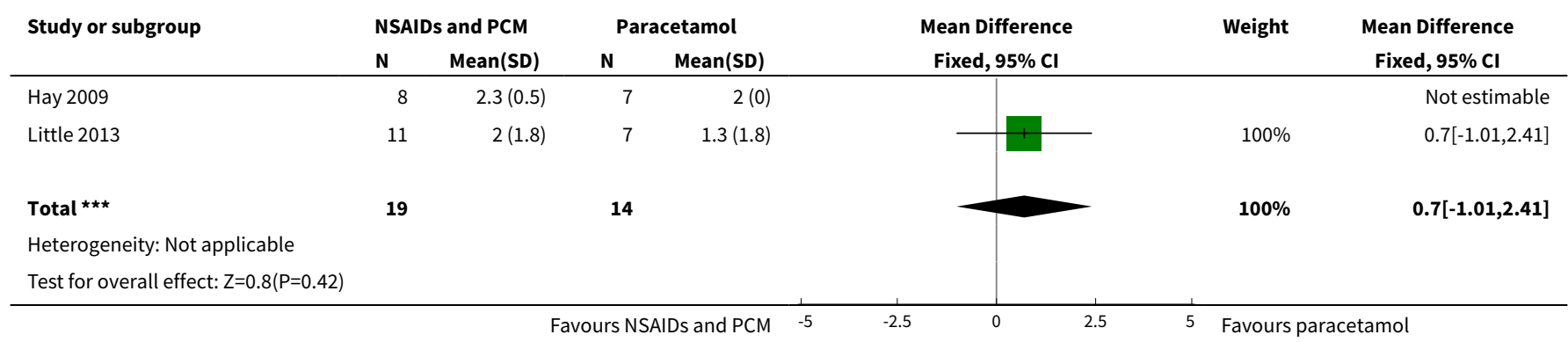

Analysis 4.11. Comparison 4 NSAIDs + paracetamol versus paracetamol, Outcome 11 Fever at 24 hours.

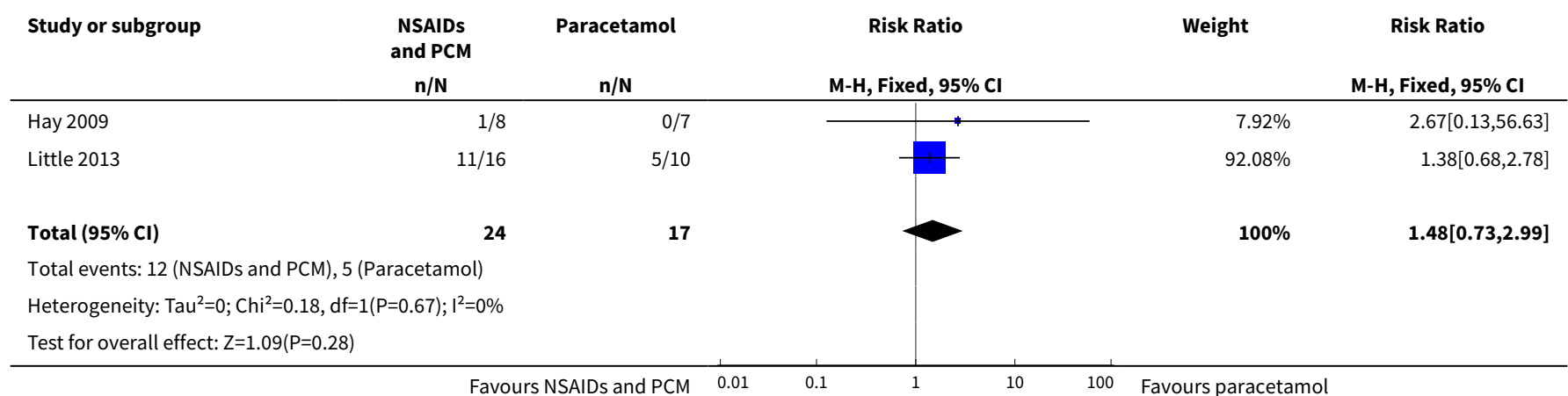

Analysis 4.12. Comparison 4 NSAIDs + paracetamol versus paracetamol, Outcome 12 Fever at 48 to 72 hours.

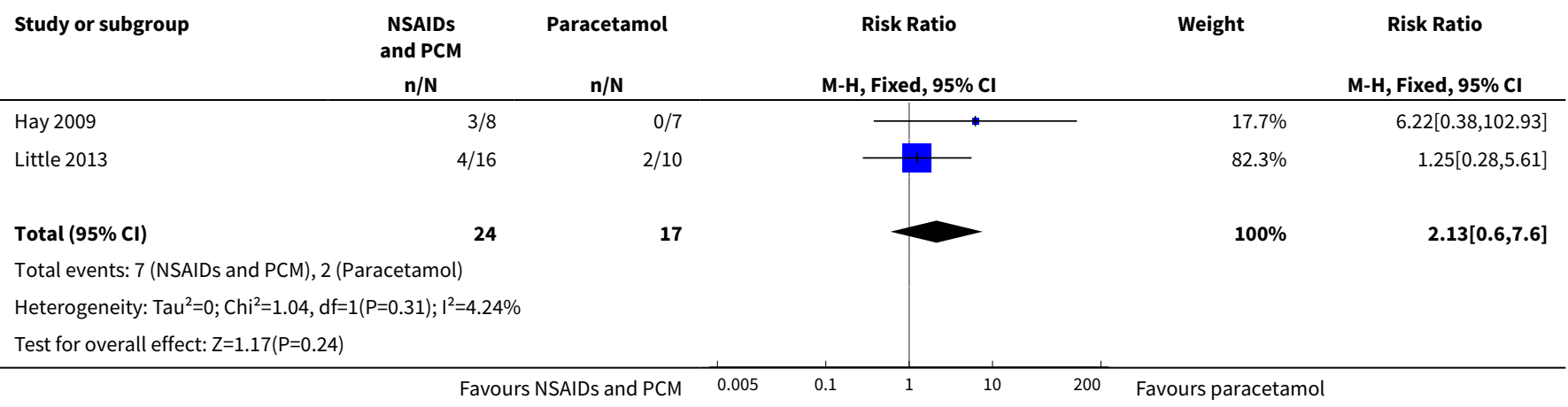

Analysis 4.13. Comparison 4 NSAIDs + paracetamol versus paracetamol, Outcome 13 Fever at 4 to 7 days.

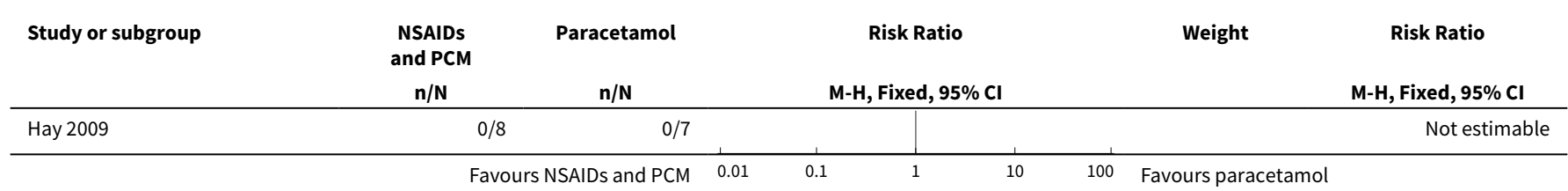

Paracetamol (acetaminophen) or non-steroidal anti-inflammatory drugs, alone or combined, for pain relief in acute otitis media in 


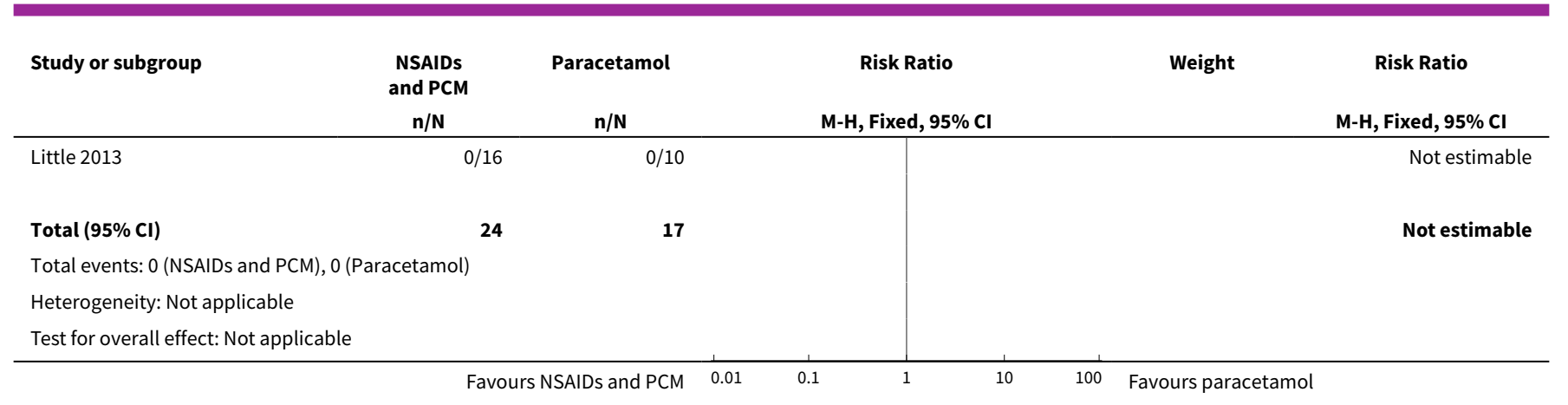

Analysis 4.14. Comparison 4 NSAIDs + paracetamol versus paracetamol, Outcome 14 Re-consultations.

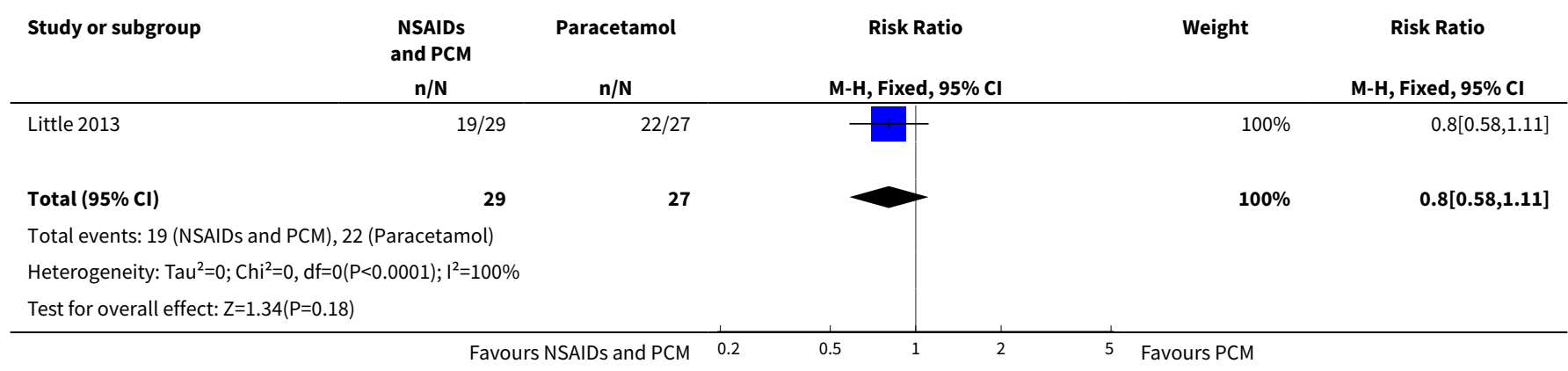

Analysis 4.15. Comparison 4 NSAIDs + paracetamol versus paracetamol, Outcome 15 Delayed antibiotic prescriptions.

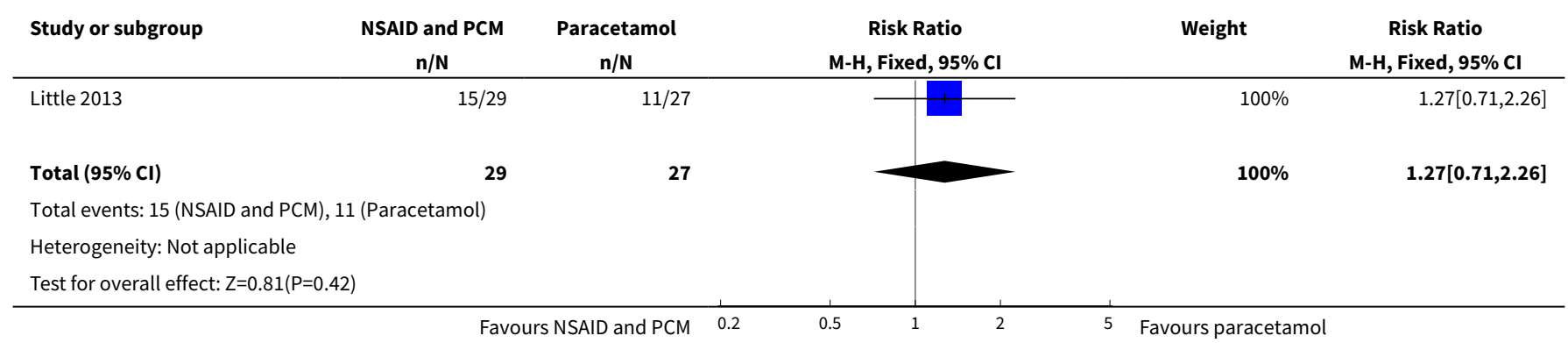

\section{Analysis 4.16. Comparison 4 NSAIDs + paracetamol versus paracetamol, Outcome 16 Serious complications.}

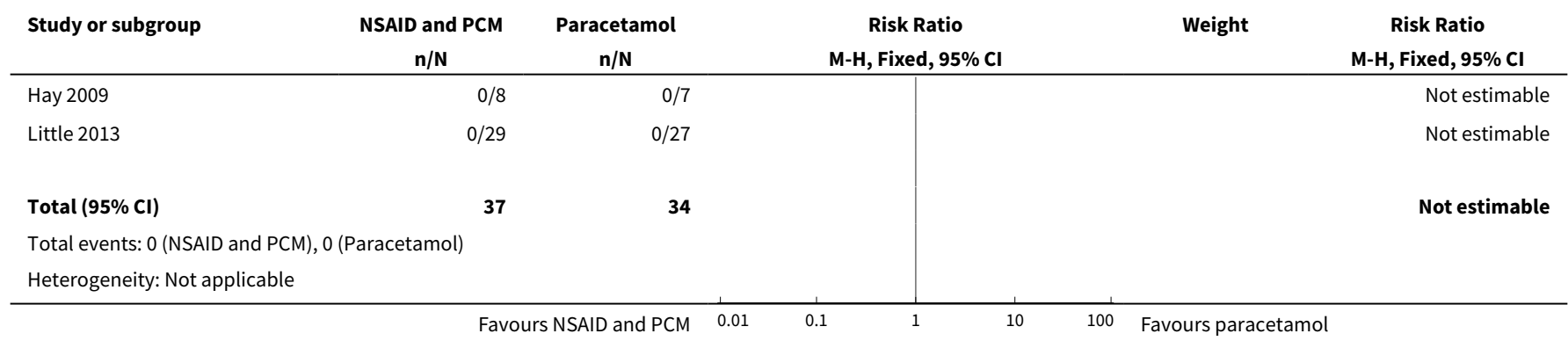

Paracetamol (acetaminophen) or non-steroidal anti-inflammatory drugs, alone or combined, for pain relief in acute otitis media in 48 children (Review)

Copyright (c) 2016 The Cochrane Collaboration. Published by John Wiley \& Sons, Ltd. 


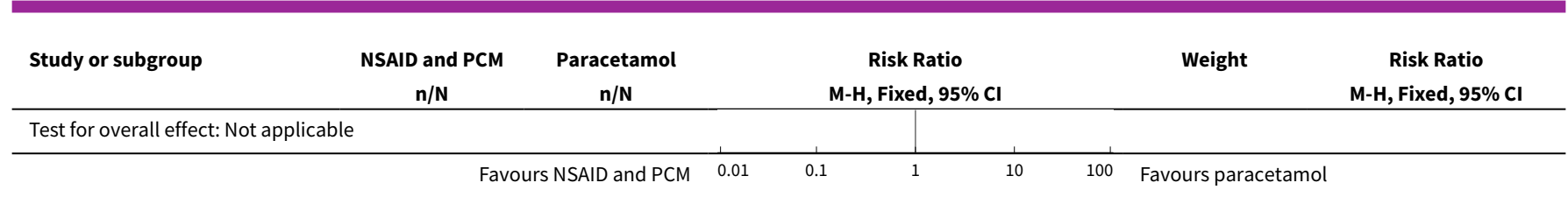

\section{A P PEN DICES}

\section{Appendix 1. CENTRAL search strategy}

\#1 [mh "otitis media"] OR otitis media OR aom OR ome OR (middle AND ear AND (effusion OR inflammation* OR infection`)) OR glue ear \#2 [mh “respiratory tract infection”] OR respiratory infection* OR (acute OR upper) respiratory AND (symptom* OR illness* OR infection* OR inflammation*)

\#3 \#1 OR \#2

\#4 [mh acetaminophen] OR paracetamol OR acetaminophen OR acetaminophen OR tylenol OR [mh "Anti-Inflammatory Agents, NonSteroidal"] OR (nonsteroidal OR 'non steroidal' AND (antiinflammatory OR 'anti inflammatory')) OR nsaid OR nsaids

\#5 [mh pain] OR [mh "Pain Management"] OR Pain OR Pains OR Ache OR Aches OR analgesia

\#6 \#3 AND \#4 AND \#5

\section{Appendix 2. MEDLINE (Ovid) search strategy}

1 exp Otitis Media/ OR otitis media OR aom OR ome OR (middle ear adj2 (effusion OR inflam* OR infection OR infections)) OR glue ear 2 exp Respiratory Tract Infections/ OR (respiratory adj2 infection*) OR ((acute or upper) adj2 respiratory adj2 (symptom or illness* or infect* or inflam $\left.^{\star}\right)$ )

31 OR 2

4 exp Acetaminophen/ OR paracetamol OR acetaminophen OR acetaminophen OR tylenol OR exp Anti-Inflammatory Agents, NonSteroidal/ OR ((nonsteroid* or non-steroid*) adj1 (antiinflam* or anti-inflam*)) OR nsaid or nsaids

5 exp Pain/ OR exp Pain Management/ OR Pain OR Pains OR Ache OR Aches OR Analgesia

6 ((randomized controlled trial or controlled clinical trial).pt. or randomized.ab. or randomised.ab. or placebo.ab. or drug therapy.fs. or randomly.ab. or trial.ab. or groups.ab.) not (exp animals/ not humans.sh.)

\section{AND 4 AND 5 AND 6}

\section{Appendix 3. Embase search strategy}

\#1 'otitis media'/exp OR otitis media OR aom OR ome OR (middle AND ear AND (effusion OR inflammation* OR infection*)) OR glue ear \#2 'respiratory tract infection'/exp OR respiratory infection* OR (acute OR upper) respiratory AND (symptom* OR illness* OR infection* OR inflammation*)

\section{\#3 \#1 OR \#2}

\#4 'paracetamol'/exp OR paracetamol OR acetaminophen OR acetaminophen OR tylenol OR 'nonsteroid antiinflammatory agent'/exp OR (nonsteroidal OR 'non steroidal' AND (antiinflammatory OR 'anti inflammatory')) OR nsaid OR nsaids

\#5 'pain'/exp OR 'analgesia'/exp OR Pain OR Pains OR Ache OR Aches OR analgesia

\#6 random* OR factorial OR crossover OR placebo OR blind OR blinded OR assign OR assigned OR allocate OR allocated OR 'crossover procedure'/exp OR 'double-blind procedure'/exp OR 'randomized controlled trial'/exp OR 'single-blind procedure'/exp

\#7 \#3 AND \#4 AND \#5 AND \#6

Paracetamol (acetaminophen) or non-steroidal anti-inflammatory drugs, alone or combined, for pain relief in acute otitis media in 


\section{Appendix 4. CINAHL search strategy}

S1 (MH "Otitis Media+") OR otitis media OR aom OR ome OR (middle ear (effusion OR inflammation* OR infection*)) OR glue ear

S2 (MH "Respiratory Tract Infections+") OR respiratory infection* OR (acute OR upper) respiratory (symptom* OR illness* OR infection* OR inflammation*)

\section{S3 S1 OR S2}

S4 (MH "Acetaminophen") OR paracetamol OR acetaminophen OR acetaminophen OR tylenol OR (MH "Antiinflammatory Agents, NonSteroidal+") OR (nonsteroid* OR non-steroid*) (antiinflam* or anti-inflam*) OR nsaid OR nsaids

S5 (MH "Pain+") OR (MH "Analgesia+") OR Pain OR Pains OR Ache OR Aches OR Analgesia

S6 (MH "Clinical Trials+") OR random* OR factorial OR crossover OR placebo OR blind OR blinded OR assign OR assigned OR allocate OR allocated OR trial OR trials OR groups

\section{S7 S3 AND S4 AND S5 AND S6}

\section{Appendix 5. LILACS search strategy}

(tw:(Otitis media OR aom OR ome OR (middle ear (effusion OR inflammation* OR infection*)) OR glue ear OR Respiratory infection* OR (acute OR upper) respiratory (symptom* OR illness* OR infection* OR inflammation*)))

AND

(tw:(Paracetamol OR acetaminophen OR acetaminophen OR tylenol OR (nonsteroid* OR non-steroid*) (antiinflam or anti-inflam) OR nsaid OR nsaids))

AND

(tw:(Pain OR Pains OR Ache OR Aches OR Analgesia))

AND

(tw:(random* OR factorial OR crossover OR placebo OR blind OR blinded OR assign OR assigned OR allocate OR allocated OR trial OR trials OR groups))

\section{Appendix 6. Web of Science search strategy}

\#1 TOPIC: (Otitis media OR aom OR ome OR (middle ear (effusion OR inflammation* OR infection*)) OR glue ear) OR TOPIC: (Respiratory infection ${ }^{\star}$ OR (acute OR upper) respiratory (symptom* OR illness ${ }^{\star}$ OR infection* OR inflammation $\left.{ }^{\star}\right)$ )

\#2 TOPIC: (Paracetamol OR acetaminophen OR acetaminophen OR tylenol OR (nonsteroid* OR non-steroid*) (antiinflam or anti-inflam) OR nsaid OR nsaids) AND TOPIC: (Pain OR Pains OR Ache OR Aches OR Analgesia) AND TOPIC: (random* OR factorial OR crossover OR placebo OR blind OR blinded OR assign OR assigned OR allocate OR allocated OR trial OR trials OR groups)

\#3 \#2 AND \#1

\section{CONTRIBUTIONSOF AUTHORS}

Protocol drafted by: AS, RPV, ACvdP, AGMS, RAMJD

Screening search results: AS, RPV

Extracting data: AS, RPV

Assessing risk of bias: AS, RPV

Entering data into RevMan: AS, RPV

Carrying out analysis: AS, RPV

Interpreting the analysis: all authors

Writing the review: all authors

General advice on the review: all authors

\section{DECLARATIONS OF INTEREST}

Roger AMJ Damoiseaux (RAMJ) is an Editor of the Cochrane Acute Respiratory Infections Group. Roger is an investigator of the PIM-POM study, an ongoing cluster randomised clinical trial to optimise pain management in children with acute otitis media which is funded by a research grant from The Netherlands Organisation for Health Research and Development/SBOH no. 80-83910-98-13006 (PIM-POM study 2014).

Paracetamol (acetaminophen) or non-steroidal anti-inflammatory drugs, alone or combined, for pain relief in acute otitis media in 
Alastair D Hay (ADH) is funded by NIHR Research Professorship (NIHR-RP-02-12-012) and principal investigator of the ongoing UK primary care based RCT comparing the clinical- and cost-effectiveness of anaesthetic (benzocaine-phenazone) eardrops versus placebo drops and no drops in children aged 12 months to 10 years with AOM (CEDAR)

Paul Little (PL) is an Editor of the Cochrane Acute Respiratory Infections Group and investigator of the ongoing UK primary care based RCT comparing the clinical- and cost-effectiveness of anaesthetic (benzocaine-phenazone) eardrops versus placebo drops and no drops in children aged 12 months to 10 years with AOM (CEDAR).

Anne GM Schilder (AGMS) is Joint Co-ordinating Editor of Cochrane ENT. Her team, evidENT, at the Ear Institute, University College London, is supported by an NIHR Research Professorship award. Anne is an investigator of the PIM-POM study, an ongoing cluster randomised clinical trial to optimise pain management in children with acute otitis media which is funded by a research grant from The Netherlands Organisation for Health Research and Development/SBOH no. 80-83910-98-13006 (PIM-POM study 2014).

Alies Sjoukes (AS) is an investigator of the PIM-POM study, an ongoing cluster randomised clinical trial to optimise pain management in children with acute otitis media which is funded by a research grant from The Netherlands Organisation for Health Research and Development/SBOH no. 80-83910-98-13006 (PIM-POM study 2014).

Roderick P Venekamp (RPV) is an Editor of the Cochrane Acute Respiratory Infections and ENT Groups. Roderick is an investigator of the PIM-POM study, an ongoing cluster randomised clinical trial to optimise pain management in children with acute otitis media which is funded by a research grant from The Netherlands Organisation for Health Research and Development/SBOH no. 80-83910-98-13006 (PIMPOM study 2014).

Alma C van de Pol (ACvdP) is an investigator of the PIM-POM study, an ongoing cluster randomised clinical trial to optimise pain management in children with acute otitis media which is funded by a research grant from The Netherlands Organisation for Health Research and Development/SBOH no. 80-83910-98-13006 (PIM-POM study 2014).

\section{SOURCES OFSUPPORT}

\section{Internal sources}

- No sources of support supplied

\section{External sources}

- The Netherlands Organisation for Health Research and Development (ZonMw), Netherlands.

The authors of this review received a grant from the The Netherlands Organisation for Health Research and Development (ZonMw) to conduct a pragmatic, cluster-randomised clinical trial on pain management for children with AOM in primary care. This trial is currently ongoing.

- NIHR Research Professorship Award, UK.

Professor Anne Schilder has received an NIHR Research Professorship Award in 2012

\section{DIFFERENCES BETWEEN PROTOCOL AND REVIEW}

We excluded studies that focused on hospitalised children because we aimed to summarise evidence on analgesics for children with AOM applicable to every day clinical practice. Hospitalisation secondary to AOM is now rare in high-income countries and any evidence on this study population is not easily transferable to every day clinical practice. This was not specifically mentioned in our published protocol (Sjoukes 2015).

\section{N DEX TERMS}

\section{Medical Subject Headings (MeSH)}

Acetaminophen [*therapeutic use]; Acute Disease; Analgesics, Non-Narcotic [*therapeutic use]; Anti-Bacterial Agents [therapeutic use]; Anti-Inflammatory Agents, Non-Steroidal [therapeutic use]; Drug Therapy, Combination; Fever [drug therapy]; Ibuprofen [therapeutic use]; Otitis Media [ ${ }^{*}$ complications]; Pain [ ${ }^{*}$ drug therapy] [etiology]; Randomized Controlled Trials as Topic

\section{MeSH check words}

Child; Child, Preschool; Humans

Paracetamol (acetaminophen) or non-steroidal anti-inflammatory drugs, alone or combined, for pain relief in acute otitis media in 